University of Louisville

ThinkIR: The University of Louisville's Institutional Repository

Electronic Theses and Dissertations

8-2008

\title{
The role of protein kinase A in hypoxia-induced PC-12 cell death.
}

Cynthia Jayne Miller

University of Louisville

Follow this and additional works at: https://ir.library.louisville.edu/etd

\section{Recommended Citation}

Miller, Cynthia Jayne, "The role of protein kinase A in hypoxia-induced PC-12 cell death." (2008). Electronic Theses and Dissertations. Paper 976.

https://doi.org/10.18297/etd/976

This Doctoral Dissertation is brought to you for free and open access by ThinkIR: The University of Louisville's Institutional Repository. It has been accepted for inclusion in Electronic Theses and Dissertations by an authorized administrator of ThinkIR: The University of Louisville's Institutional Repository. This title appears here courtesy of the author, who has retained all other copyrights. For more information, please contact thinkir@louisville.edu. 


\title{
THE ROLE OF PROTEIN KINASE A IN HYPOXIA-INDUCED PC-12 CELL DEATH
}

\author{
By \\ Cynthia Jayne Miller \\ B.A., Lindsey Wilson College, 2004 \\ M.S., University of Louisville, 2006
}

\begin{abstract}
A Dissertation
Submitted to the Faculty of the

Graduate School of the University of Louisville in Partial Fulfillment of the Requirements for the Degree of
\end{abstract}

Doctor of Philosophy

Department of Physiology and Biophysics

University of Louisville

Louisville, Kentucky

August 2008 
THE ROLE OF PROTEIN KINASE A IN HYPOXIA-INDUCED PC-12 CELL DEATH

By

Cynthia Jayne Miller

B.A., Lindsey Wilson College, 2004

M.S., University of Louisville, 2006

A Dissertation Approved on

July 1,2008

By the following Dissertation Committee:

Dissertałion Directnr-Evelyne Gołal

Irviøá G. J̋́shua

Andrew M. Roberts

$-\overline{\text { Suresh C. Tyagi }}$
$-\quad$ Madhavi Rane 


\section{ACKNOWLEDGEMENTS}

I would like to thank my mentor, Dr. Evelyne Gozal, for her guidance and patience in the planning and execution of this research project. I would also like to thank the following individuals: Dr. Irving G Joshua, Dr. Madhavi Rane, Dr. Andrew M. Roberts, Dr. Suresh Tyagi, and Dr. Avital Schurr for their careful critiques and advice throughout my graduate career. Lastly, I would like to extend thanks to my family and friends for their constant support and encouragement over the past four years. 


\section{ABSTRACT \\ THE ROLE OF PROTEIN KINASE A IN HYPOXIA-INDUCED \\ PC-12 CELL DEATH \\ Cynthia Jayne Miller}

July 1,2008

Hypoxia is characterized by an inadequate oxygen supply to the tissues in proportion to their metabolic needs, and is a primary factor in traumatic CNS injury, strokes, cardiopulmonary diseases, and obstructive sleep apnea. The cAMP-dependent protein kinase (PKA) has been attributed a role as an antiapoptotic kinase as well as a pro-apoptotic signal. Thus the role of PKA in hypoxia-induced cell survival is currently unclear.

We show here that hypoxia induces cell death in WT PC-12 cells, pheochromocytoma cells used as a model of the oxygen-sensitive carotid body glomus cells. The onset of cell death following 24 hours of severe, sustained hypoxia also correlated with an increase in oxidative stress and a drop in ATP levels. Inactivation of PKA in the 123.7 PC-12 cell line prevented the hypoxiainduced ROS surge, energy depletion, and cell death. PKA activity thus contributes to hypoxia-induced cell death in WT cells via enhanced ROS production and energy depletion, but was not shown to play a role in the regulation of cellular antioxidant mechanisms. 
123.7 cells had lower levels of hypoxia-induced glucose utilization and lactate release than WT cells, thus PKA appears to stimulate increases in glycolytic flux during hypoxia. Mitochondrial potentials were higher in 123.7 cells than in WT cells, indicating that PKA inhibits mitochondrial metabolism. Furthermore, the expression of COX IV was decreased by hypoxic exposure in both cell types, but was significantly greater in 123.7 cells. The greater expression of COX IV may allow 123.7 cells to maintain mitochondrial electron flow and energy production under drastically reduced oxygen conditions.

Antioxidant treatment blocked hypoxia-induced cell death, but was not sufficient to prevent depletion of ATP or to modulate the metabolic pathways. Thus, this finding indicates that hypoxia-induced metabolic regulation and energy depletion occur independently of oxidative stress.

Consequently, the PKA signaling pathway appears to contribute to hypoxia-induced cell death through its regulatory effects on oxidative stress and metabolic pathways. Modulation of the PKA signaling pathway could provide novel therapeutic strategies to improve cellular adaptation and recovery in the many pathologies characterized by periods of hypoxia. 


\section{TABLE OF CONTENTS}

PAGE

ACKNOWLEDGMENTS ............................................................

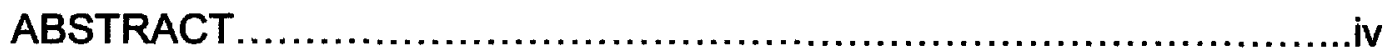

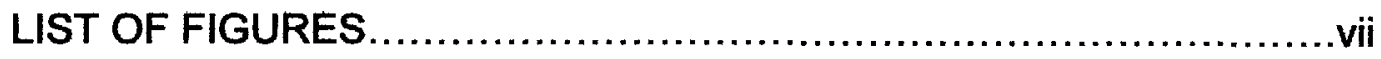

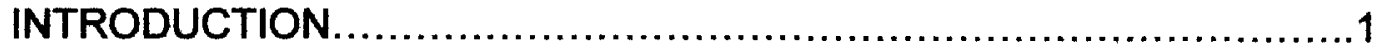

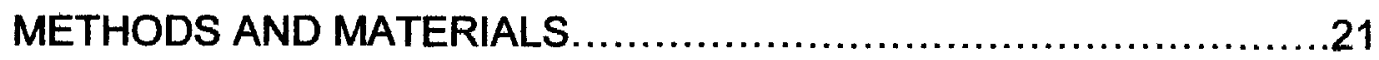

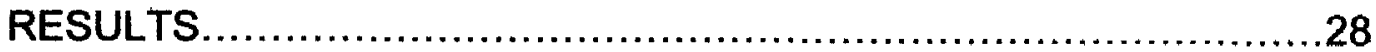

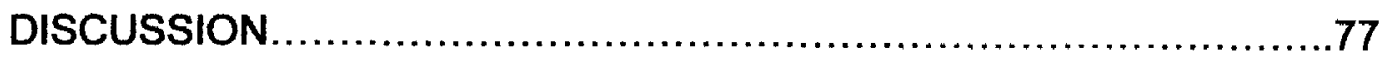

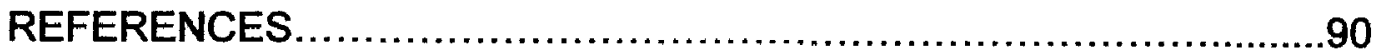

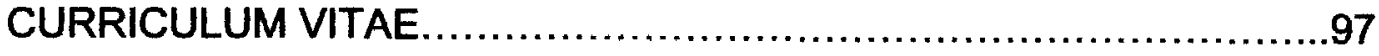




\section{LIST OF FIGURES}

FIGURE

PAGE

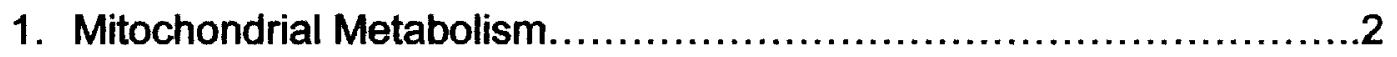

2. Glutathione Redox cycle...........................................5

3. Effect of Hypoxia on Reactive Oxygen Species Generation in the Electron Transport Chain..................................................6

4. Protein Kinase A Activation...............................................

5. Regulation of the Hypoxia Inducible Factor-1 (HIF-1) under normoxic and hypoxia conditions

6. Specific Aim 1: To determine whether PKA activity affects cellular tolerance to hypoxia and production of oxidant species

7. Specific Aim 2: To determine whether PKA regulates hypoxia-induced cell death via oxidative stress and/or energy depletion .18

8. Specific Aim 3: To determine whether PKA affects cellular energetic status through regulation of metabolic pathways .19

9. Specific Aim 4: To determine whether restoration of PKA activity in 123.7 cells will abrogate differences in hypoxic susceptibility and energy homeostasis between the two cell types. .20

10. Cellular Tolerance of WT cells to Sustained Hypoxia: MTT Asssay...29

11. Cellular Tolerance of 123.7 cells to Sustained Hypoxia: MTT Assay..30 
12. Trypan Blue Exclusion Assay

13. Reactive Oxygen Species Production: DCF Fluorescence..............33

14. Cellular Redox Status: GSH/GSSG ratio............................35

15. Cellular Redox Status: Total Glutathione...........................36

16. Cellular Antioxidant Capacity: SOD-1 Expression.....................37

17. Cellular Energetic Status: ATP levels................................39

18. Cellular Energetic Status: cAMP levels..........................40

19. Effect of Antioxidant treatment on DCF Fluorescence.................42

20. Effect of Antioxidant treatment on Trypan Blue Exclusion Assay......43

21. Effect of Antioxidant treatment on GSH/GSSG ratio...................44

22. Effect of Antioxidant treatment on Total Glutathione Levels...........45

23. Effect of Antioxidant treatment on ATP levels........................46

24. Effect of Antioxidant treatment on cAMP levels.......................47

25. Mitochondrial Potential: JC-1 Assay ................................49

26. Effect of Antioxidant Treatment on COX IV expression.................50

27. Glyolytic Flux: Extracellular Glucose ................................52

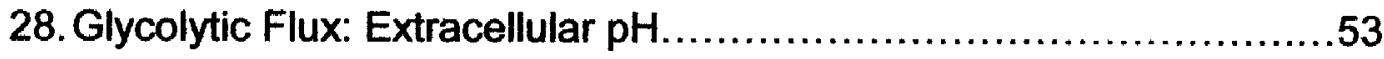

29. Glycolytic Flux: Extracellular Lactate ................................54

30. Glycolytic Flux: Extracellular Pyruvate ...............................55

31. Effect of Antioxidant treatment on Extracellular Glucose................57

32. Effect of Antioxidant treatment on Extracellular $\mathrm{pH} \ldots \ldots \ldots \ldots \ldots \ldots \ldots . \ldots . \ldots \ldots$

33. Effect of Antioxidant treatment on Extracellular Lactate.................59

34. Effect of Antioxidant treatment on Extracellular Pyruvate...............60 


\section{INTRODUCTION}

Hypoxia is characterized by an inadequate oxygen supply to the tissues in proportion to their metabolic need and can result from a number of conditions that cause defective oxygen uptake at the lungs, or insufficient transport of oxygen-rich blood to the tissues. Hypoxia is a primary factor in traumatic CNS injury, strokes, cardiopulmonary diseases, and obstructive sleep apnea (OSA). Strokes, resulting from severe hypoxic events, are among the most prevalent causes of death nationwide, (1) while OSA affects $2-5 \%$ of the population in the United States (2).

It has been previously reported that hypoxia induces apoptosis and that the extent of the apoptotic response is critically dependent on the severity and the duration of the hypoxic injury (3). Hypoxia induces gene transcription by cooperative activation of several transcription factors, notably NF-kB, AP-1 and the hypoxia-inducible HIF-1 $\alpha(4,5,6,7)$. Thus, an understanding of the mechanisms underlying cellular survival to hypoxia may provide novel therapies to improve cellular outcome of hypoxia/ischemia and some neurodegenerative pathologies.

When cells are exposed to hypoxia, there is a shift in cellular metabolism (Figure 1) from aerobic, mitochondrial energy production to anaerobic glycolytic 
processes. In the process of glycolysis, cells harness the energy of the carbohydrate glucose in a series of cytoplasmic enzymatic reactions, resulting in a net production of two pyruvate, two ATP, and two NADH molecules. In the presence of oxygen, pyruvate is converted in a transition reaction to acetyl CoA, producing two additional molecules of $\mathrm{NADH}$. Acetyl CoA then enters a series of enzymatic reactions in the mitochondria known as the Krebs Cycle, resulting in the production of $6 \mathrm{NADH}$ and $2 \mathrm{FADH}_{2}$.

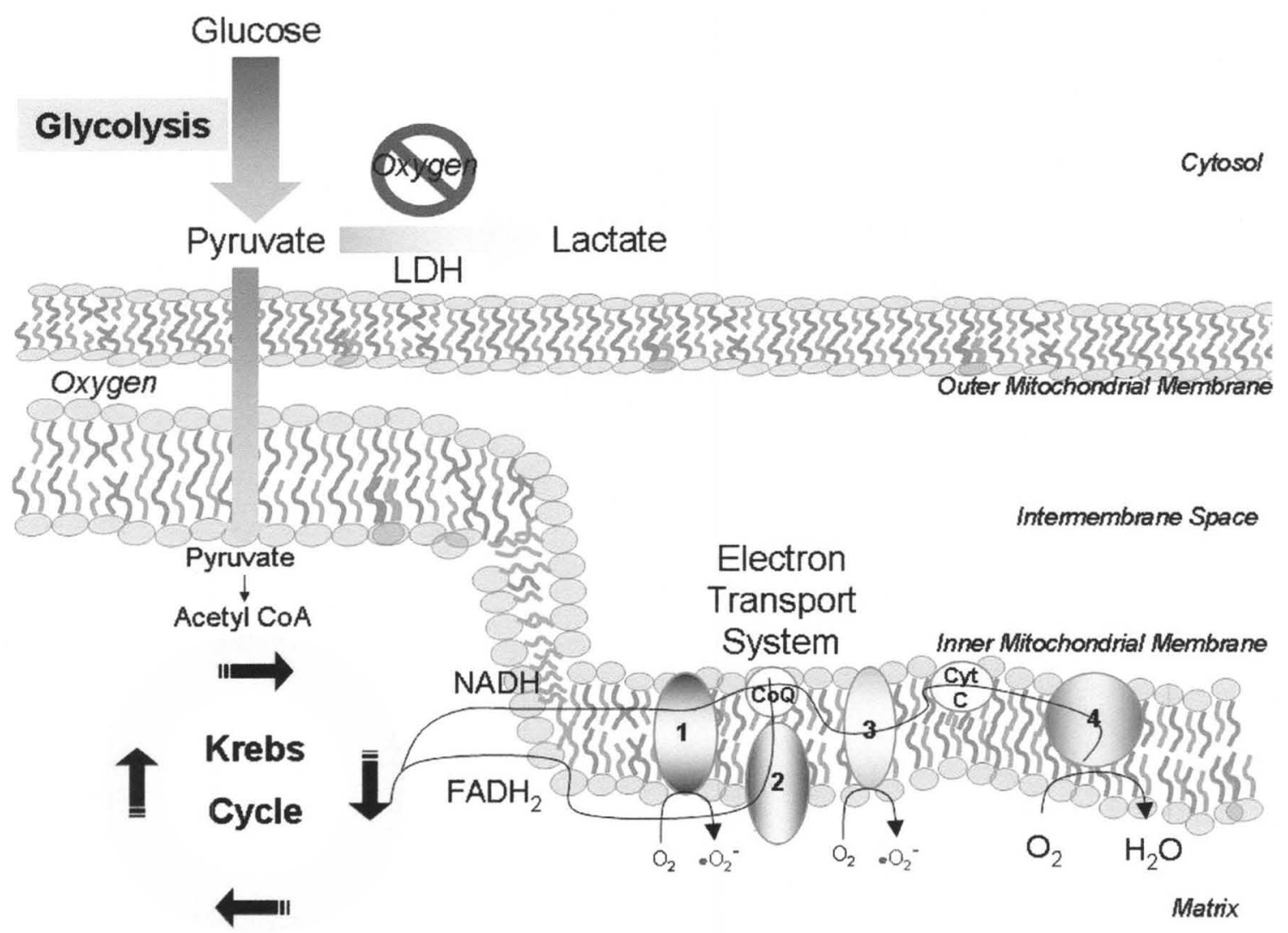

Figure 1: Mitochondrial Metabolism. Under normoxic conditions, energy is produced via both glycolysis and aerobic, mitochondrial pathways. However, under hypoxic states, aerobic metabolism is decreased and cells must rely on glycolysis for energy production. 
Cytoplasmic NADH from glycolysis can be transported in the mitochondria using either the glycerophosphate shuttle or the malate-aspartate shuttle, producing $\mathrm{FADH}_{2}$ or $\mathrm{NADH}$, respectively, on the matrix side of the inner mitochondrial membrane. The reduced compounds derived from glycolysis and the Krebs Cycle then donate electrons to a series of redox carriers in the mitochondria known as the electron transport chain. At complex IV, cytochrome oxidase, the electrons are used to reduce $\mathrm{O}_{2}$ to $\mathrm{H}_{2} \mathrm{O}$.

The movement of electrons through the chain to more positive redox potentials results in the formation of energy, harnessed in the form of a proton gradient. The movement of protons back down their electrochemical gradient across the inner mitochondrial membrane is used to produce ATP via the enzyme ATP synthase. Under aerobic conditions, one molecule of glucose can produce 36-38 ATP, depending on the NADH shuttle system utilized.

However, during hypoxia, oxygen-dependent oxidative phosphorylation processes decline and cells must progressively rely on anaerobic metabolism. Hypoxia has been shown in PC-12 cells to decrease the activity of enzymes involved in oxidative phosphorylation, including Complexes I, II, and IV of the electron transport chain (8). Furthermore, hypoxic upregulation of glycolytic enzymes, such as hexokinase and phosphofructokinase, has been shown in PC12 cells $(8)$. This decreased oxidative phosphorylation can present a significant problem in energy homeostasis, since glycolysis produces a net gain of only 2 ATP relative to the approximately 38 ATP that can be produced by oxidative phosphorylation and glycolytic processes combined. 
Mitochondria contain a large number of redox carriers, such as those of the mitochondrial electron transport chain, that are capable of leaking electrons. Under physiological cellular conditions, some of these electrons slip away from their oxidative pathways to oxygen and produce superoxide anion, a progenitor reactive oxygen species (ROS). In resting cells, approximately $1-2 \%$ of the electrons passing through the electron transport chain undergo this process, resulting in a significant basal production of ROS (9). It is believed that Complexes I and III of the electron transport chain are the primary sites of superoxide production (10). Mitochondria are thus particularly susceptible to oxidative injury due to their constant generation and close proximity to the shortlived ROS. Furthermore, mitochondrial DNA is prone to oxidative injury because it lacks the protection of histone proteins, and mitochondrial DNA polymerases are highly susceptible to ROS damage (11).

While a certain basal level of ROS appear to be required for proper cell function (12), dysregulation may result in overproduction of superoxide anion and increased formation of toxic ROS. Consequently, cells have elaborate defense systems in place to counteract the production of ROS. It is only once these defense systems become overwhelmed that oxidative stress ensues.

Many primary defense mechanisms exist to neutralize reactive oxygen species before they inflict damage on cellular structures. These include enzymes such as superoxide dismutase, catalase, and glutathione peroxidase. Superoxide dismutase (SOD) catalyzes the conversion of the superoxide free radical into another ROS, hydrogen peroxide. Hydrogen peroxide can then be 
converted to water and oxygen by the enzymes catalase or glutathione peroxidase. Catalase, which is present only in peroxisomes, is a highly efficient, unsaturable enzyme under physiological conditions. The tripeptide glutathione ( $\gamma$-Glu-Cys-Gly), which is present in both the cytosol and mitochondria, makes up one of the main cellular antioxidant defenses and detoxification pathways (Figure 2).

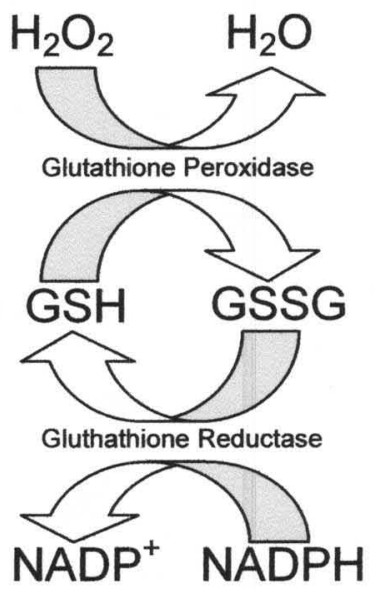

In an unstressed cell, glutathione redox balance is achieved by the maintenance of the GSH (reduced)/GSSG (oxidized) glutathione ratio. This balance is

Figure 2: Glutathione Redox Cycle. The reduced form of glutathione (GSH) detoxifies hydrogen peroxide. NADPH is used to regenerate GSH from its oxidized form.

tightly regulated by the availability of $\mathrm{NADPH}$, which is required to regenerate GSH from its oxidized GSSG form in the glutathione redox cycle. Upon oxidant stress, GSH will react with ROS and GSSG will increase, decreasing the GSH/GSSG ratio. Therefore, measurements of cellular GSH/GSSG and NADPH can be used as indicators of cellular redox status.

Low oxygen availability may perturb the mitochondrial electron transfer chain, resulting in increased ROS and disruption of cellular energy balance (13). In cardiomyocytes and hepatocytes, hypoxia decreases $V_{\max }$ of the rate limiting, oxygen-dependent enzyme of the mitochondrial respiratory chain, cytochrome oxidase (COX IV) $(14,15)$. COX IV is the terminal electron acceptor in the mitochondrial electron transport chain which converts molecular oxygen $\left(\mathrm{O}_{2}\right)$ to 
water. COX IV consists of 13 subunits, 3 of which (subunits I, II, and II) are encoded by mitochondrial DNA and synthesized directly in the mitochondria (8). The other 10 subunits of cytochrome oxidase (IV, Vb, Vla, VIb, Vic, VIIA, VIlb, and VIII) are synthesized in the cytosol by the nuclear genome, and then transported into the mitochondria (8).

Hypoxia has been shown to decrease the activity of COX IV in rat macrophages and PC-12 cells (8). This drop in activity of the terminal electron complex could produce

Sustained Hypoxia

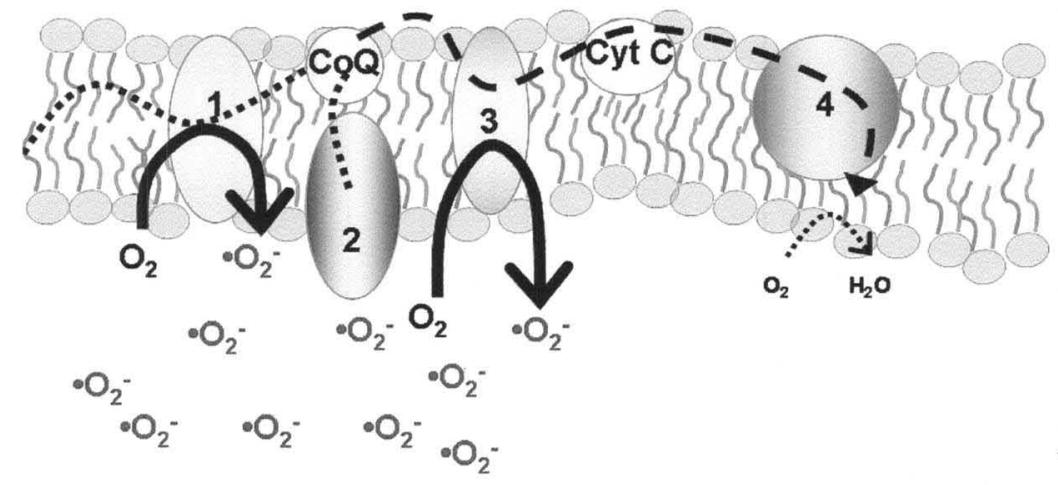

Figure 3: Effect of Hypoxia on Reactive Oxygen Species Generation in the Electron Transport Chain. Hypoxia decreases the activity of Complex 4 of the mitochondrial electron transport chain, leading to an increased production of superoxide anion, a progenitor reactive oxygen species. a "trafficking" problem

through the electron

transport chain,

resulting in an

increased slippage of

electrons away from

their normal movement

through the chain, and increased production of ROS (Figure 3). This process could potentially overwhelm the antioxidant

capabilities of the cell, leading to oxidative stress, and cellular death.

Protein Kinase A (PKA) signaling may affect multiple mitochondrial chain enzymes. PKA has been shown in mouse fibroblasts to directly phosphorylate 
an 18kDA subunit of complex I of the mitochondrial electron transport chain, resulting in an increase in its activity (16). Furthermore, PKA has been shown to phosphorylate subunits I, IV, and Vb of complex IV of the mitochondrial electron transport chain. In vitro phosphorylation of COX IV by PKA in bovine heart and rat macrophages decreases its activity by $40-70 \%$ (17). Furthermore, the Rl $\alpha$ regulatory subunit of PKA directly binds to the Vb subunit of COX IV and inhibits its activity (18). All of these PKA-mediated effects could potentially increase the leakage of electrons away from the mitochondrial electron transport chain, and shift the redox balance of the cell towards a state of oxidative stress. Indeed, it has been shown in rat macrophages that PKA phosphorylation of COX IV under

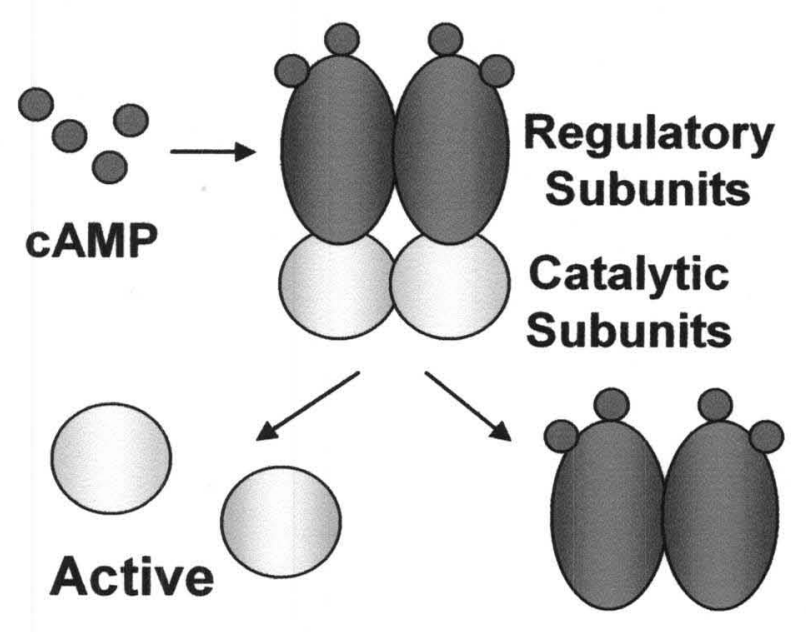

Figure 4: Protein Kinase A Activation. CAMP binds to the regulatory subunits of PKA, inducing a conformation change that allows the catalytic subunits to dissociate and phosphorylate PKA substrates. hypoxic conditions leads to a decrease in COX IV activity and generation of excess ROS (17). Furthermore, in the rabbit heart, inhibitors of PKA were shown to have protective effects against ischemia-reperfusion injury (17).

The ubiquitously expressed cAMP-dependent protein kinase (PKA) is a tetramer consisting of two regulatory subunits and two catalytic subunits (Figure 4) (19). Upon stimulation, CAMP is increased and binds to the regulatory subunits, inducing the release of 
the catalytic subunits to phosphorylate PKA substrates. Intracellular cAMP levels are maintained through a G-protein signaling cascade regulating the enzyme adenylate cyclase. The binding of an extracellular ligand to a G-protein coupled receptor facilitates the dissociation of the heterotrimeric G-protein. Upon stimulation, the $\alpha$-subunit binds GTP and dissociates from the $\beta$ - $\gamma$ subunit. The activated $\alpha$-subunit is then able to modulate the activity of adenylate cyclase.

Activation of the stimulatory $G$ protein cascade $\left(G_{s}\right)$ increases adenylate cyclase activity and cAMP production, while stimulation of the inhibitory $G$ protein $\left(G_{i}\right)$ inhibits adenylate cyclase and decreases cAMP levels. Under basal conditions, CAMP concentrations are kept at a low level of around $10^{-7} \mathrm{M}(19)$. However, upon stimulation cAMP levels can rise over twenty fold (19). CAMP levels are thus carefully regulated in cells through an intricate process of formation by adenylate cyclase and degradation via cAMP phosphodiesterase. Activity of cAMP phosphodiesterase is essential for the maintenance of localized cAMP gradients and compartmentalization of PKA signaling $(20,21)$.

CAMP binds to PKA in a positive cooperative manner, allowing the dissociation of the catalytic subunits to phosphorylate intracellular substrates. One of the most studied PKA cellular targets is the ubiquitously expressed transcription factor, cAMP response element binding protein (CREB). PKA phosphorylates CREB at a single serine residue (22), resulting in its activation. CREB then recruits a transcriptional activator, the CREB binding protein (CBP), and binds to the CAMP response element (CRE) producing alteration in gene 
expression. Therefore, PKA is essential to the transcriptional control of a wide variety of CREB-driven genes.

Although several isoforms of PKA have been identified, two main types of PKA (PKA I and II) have been described, differing in their regulatory subunit (RI and RII), and their relative sensitivity to CAMP levels. RI contains a high affinity binding site for Mg-ATP, while RII contains an auto-phosphorylation site $(23,24)$. PKA I responds to small, transient alterations in CAMP levels, while PKA II is activated by sustained, high CAMP levels (25). It was originally thought that PKA I was a cytosolic protein, while PKA II was tethered to specific intracellular locations via the A Kinase Anchoring Proteins (AKAPs). However, recent evidence identified AKAPs that bind to both isoforms, as well as AKAPs that are specific for PKA I (26). AKAPs bind PKA to specific intracellular membranes, organelles, or cytoskeletal components, allowing for localization of PKA close to its upstream activators and downstream phosphorylation targets.

PKA activity is also controlled by endogenous protein kinase inhibitor peptides (PKIs). These heat stable peptides bind to the free catalytic subunit of PKA and inhibit its activity (27). PKIs also transports the free catalytic subunit from the nucleus into the cytoplasm, thus diminishing its effects on gene transcription (27).

PKA regulates a wide variety of cellular processes including cell cycle and growth, ion fluxes, microtubule dynamics, chromatin condensation, and nuclear envelope formation (26). It has been attributed a role as an anti-apoptotic kinase as well as a pro-apoptotic signal, thus the role of PKA in hypoxia-induced cell 
survival is currently unclear $(28,29)$. It is widely accepted that PKA phosphorylates and inhibits the pro-apoptotic protein BAD, and has thus been classically defined as an anti-apoptotic kinase. Furthermore, PKA has also been shown to bind to the pro-apoptotic p73, phosphorylating and inhibiting the activity of this p53 tumor suppressor homolog (30). Activation of PKA has been shown to be neuroprotective in a variety of neuronal models (31). This protection may be due to PKA phosphorylation and activation of CREB pathways, suppression of neuronal Nitric Oxide Synthase (nNOS), and/or inhibition of the IP3 receptor and the subsequent drop in calcium release from the endoplasmic reticulum $(32,33,34)$.

More recent work suggests that PKA has numerous pro-apoptotic roles in the hypoxic response. Consequently, the role of PKA in hypoxia-induced cell death may be critically dependent on the severity and duration of the insult. In addition to its role in electron transport chain regulation, PKA has been implicated in the control of the glycolytic rate limiting enzyme, phosphofructokinase, implicating PKA in the regulation of glucose metabolism $(35,36)$. PKA-dependent transcription factors are also required for the hypoxiainducible factor, HIF-1 $\alpha$ transcriptional activity, necessary for up-regulation of glycolytic enzymes and glucose transporters $(6,37,38)$. 
HIF-1 is a heterodimeric protein consisting of $\alpha$ and $\beta$ subunits (Figure 5).

While both subunits are constitutively expressed, HIF-1 $\alpha$ undergoes continuous
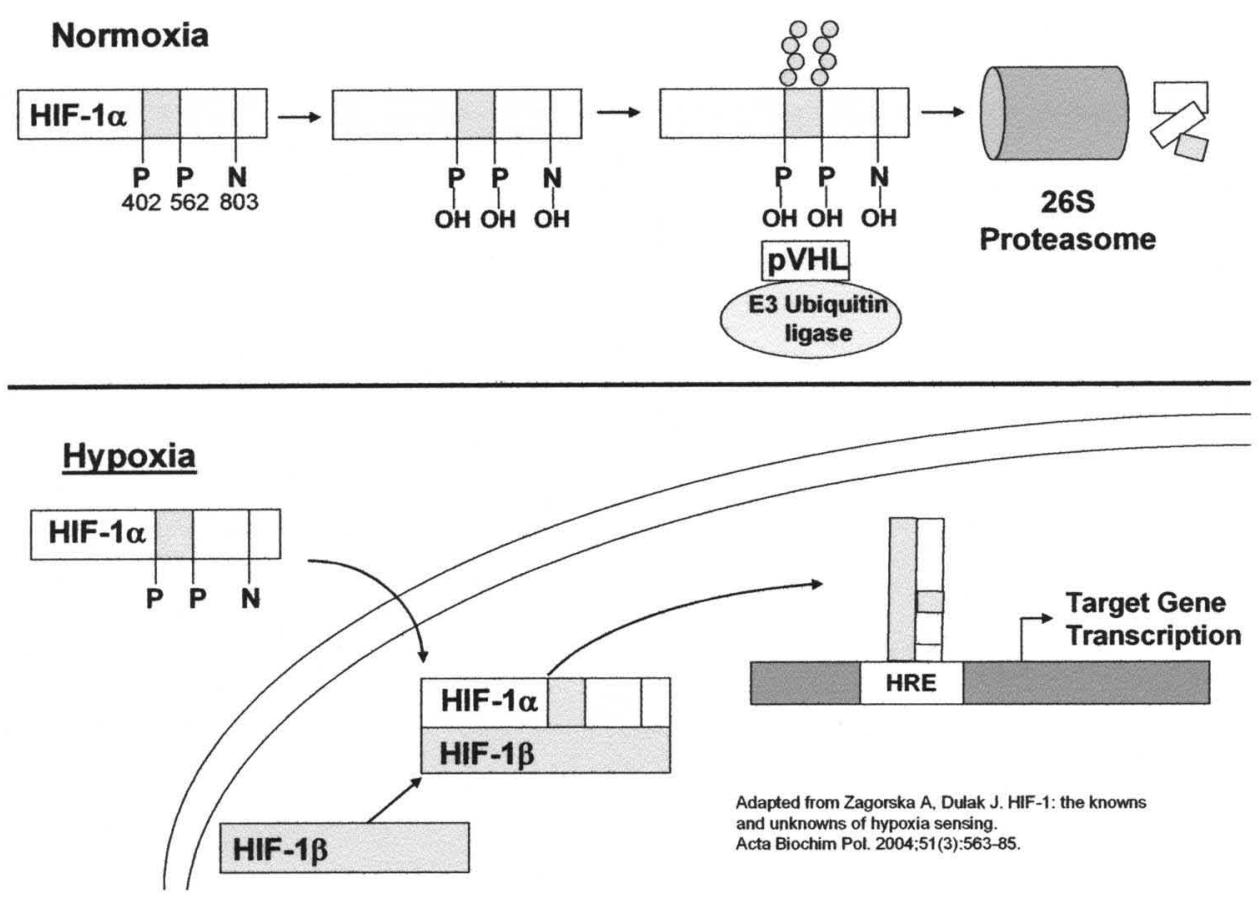

Figure 5: Regulation of the Hypoxia Inducible Factor 1 (HIF-1) under Normoxic and Hypoxic Conditions.

$\mathrm{HIF}-1 \alpha$ is constitutively expressed, but under normoxic conditions is hydroxylated and degraded by the proteosome. Under hypoxic conditions, hydroxylation of $\mathrm{HIF}-1 \alpha$ is inhibited and the protein is able to translocate to the nucleus and associate with HIF-1 $\beta$. The dimer then binds the Hypoxia Response Element (HRE) and initiates gene transcription.

degradation during normoxic conditions. When oxygen is abundant, HIF-1 $\alpha$ is hydroxylated at Pro402 and Pro564 by HIF-1 prolyl-4 hydroxylases, targeting the protein for degradation. von Hippel-Lindau tumor suppressor proteins ( $p$ VHLs) bind to the hydroxylated protein residues, and subsequently attract other members of the E3 ubiquitin ligase complex. HIF-1 $\alpha$ is then ubiquitinated and degraded by the $26 \mathrm{~S}$ proteasome. Under hypoxic conditions, the HIF-1 prolyl 
hydroxylases are inactivated through largely unknown mechanisms, and HIF-1 $\alpha$ is able to escape hydroxylation, ubiquitination, and subsequent degradation.

The activation of HIF-1 $\alpha$ is also regulated by oxygen availability. Under normoxic conditions, an Asn803 residue within the C-terminal transactivation domain is hydroxylated by the factor inhibiting HIF-1 (FIH-1), and the binding of essential coactivators is prevented (39). This hydroxylation is inhibited under hypoxic conditions, thus allowing transcriptional activation to proceed. However, in order for transcription to occur, HIF-1 $\alpha$ must first translocate to the nucleus, where it is able to dimerize with the HIF- $1 \beta$ subunit. HIF- 1 then binds to the hypoxia response element (HRE), allowing the regulation of processes integral to oxygen homeostasis.

While HIF-1 $\alpha$ regulates adaptive genes involved in erythropoiesis, angiogenesis, glucose and energy metabolism, recent reports also implicate HIF$1 \alpha$ in hypoxia-induced cell death after prolonged and severe hypoxia via p53 or pro-apoptotic Bcl2-family members-dependent mechanisms $(40,41,42)$. Hypoxia-induced ROS, which is believed to be increased by PKA activity, may also further activate HIF-1 $\alpha$, enhancing the cell's transcriptional response to hypoxia (43). Consequently, the PKA pathway may have an important role in the regulation of metabolic pathways and energy production.

The rat PC-12 cell line has been widely used as a model of oxygen sensitive, neuronal-like cells to study hypoxia-induced signaling $(44,45,46)$. PC12 cells closely resemble carotid body type I cells, or glomus cells, morphologically and phenotypically (44). Both cell types are excitable, oxygen- 
sensitive, and resistant to hypoxia-induced cell death (46). Carotid body glomus cells increase their firing rate in response to hypoxia, hypercapnia, and/or acidosis. This signal is transmitted via the glossopharyngeal nerve to the dorsal respiratory group of the medulla, which stimulates ventilation.

In PC-12 cells, exposure to hypoxia causes inactivation of an oxygensensitive potassium channel (Shaker $\mathrm{KV} 1.2 \mathrm{~K}^{+}$channel) leading to a graded depolarization of the cell membrane (46). This depolarization opens voltage gated calcium channels, producing an influx of calcium into the cell. The increase in intracellular calcium leads to a variety of effects, including the synthesis and release of neurotransmitters such as dopamine, adenosine, and glutamine, and alterations in gene expression (46). Intracellular calcium binds to calmodulin, leading to activation of a variety of enzymes, including calmodulin kinases and $\mathrm{Ca} 2+$ regulated adenylate cyclases. Thus, there is a direct link between hypoxia-induced responses and PKA signaling in PC-12 cells.

In order to examine the effects of PKA activity on hypoxic cell death, I used a genetically altered line of PC-12 cells, called 123.7 cells, which have a mutated PKA I regulatory subunit. This mutation prevents the binding of cAMP, such that the catalytic subunits of PKA can not be released, and only minimal PKA activity exists (47). Upon stimulation with $5 \mu \mathrm{M}$ of CAMP, 123.7 cells displayed only $12 \%$ PKA I activity and $16 \%$ PKA II activity (47). This suggests that RI and RII compete for the same pool of catalytic subunits (47). cAMP is unable to bind to RI, preventing the dissociation of the catalytic subunits from the mutant PKA I tetramer. PKA I sequesters the catalytic subunits, and prevents 
their binding to the non-mutated RII subunits. In this manner, mutation of one isoform drastically reduces the activity levels of both PKA I and II. The use of the 123.7 cell line allows elucidation of the contribution of the PKA pathway to cellular energy homeostasis and hypoxia-induced oxidative stress.

Based on the current literature, I hypothesized that PKA activity regulates PC-12 hypoxic cell death via oxidative stress and cellular energy depletion. To examine this hypothesis, Specific Aim 1 was to determine whether PKA activity affects cellular tolerance to hypoxia and production of oxidant species. WT and 123.7 PC-12 cells were exposed to either normoxic or sustained hypoxic conditions for up to $24 \mathrm{~h}$. Cellular viability was assessed in each cell line to determine (1) whether hypoxia induced cell death in the PC-12 cell line and (2) whether PKA activity, which is present in the WT cell line but minimal in the 123.7 cell line, contributed to this hypoxia-induced cell death. ROS levels were also analyzed in WT and 123.7 cells to examine the role of hypoxia and/or PKA activity in cellular oxidative stress. However, ROS levels are not only dependent on their rate of production, but also on their rate of detoxification by antioxidant systems. Therefore, I analyzed the glutathione redox system and expression of superoxide dismutase-1 (SOD-1) in WT and 123.7 cells to determine any differences in their antioxidant response.

Specific Aim 2 was to determine whether PKA regulates hypoxia-induced cell death via oxidative stress and/or energy depletion. In order to determine the effect of PKA on hypoxia-induced energy failure, WT and 123.7 cells were exposed to either room air or sustained hypoxia, and ATP levels were analyzed. 
Furthermore, cAMP levels were measured in the two cell lines at both room air and hypoxic conditions to determine any differences. In the 123.7 cells, cAMP is unable to bind to the regulatory subunits of PKA. This could potentially affect cAMP synthesis or degradation and alter CAMP levels within the cells.

Oxidative stress may contribute to hypoxia-induced PC-12 cell death through its effects on energy depletion, or directly through damage to intracellular components. WT and 123.7 cells were pre-treated with the antioxidant $\mathrm{N}$-acetyl cysteine one hour prior to their hypoxic exposure. ROS levels were analyzed to assess the effectiveness of the antioxidant in decreasing oxidative stress, and cell survival was analyzed to determine the role of ROS in hypoxia-induced PC12 cell death. ATP and CAMP levels were examined following antioxidant treatment to establish the role of ROS in hypoxia-induced energy failure.

PKA has been shown to regulate energy production through its control of enzymes in the glycolytic pathway and the mitochondrial electron transport chain. Thus for Specific Aim 3, I wanted to determine whether PKA affects cellular energetic status through regulation of metabolic pathways. In particular, it was important to determine (1) whether PKA plays a role in regulation of mitochondrial function and (2) whether PKA activity has an effect on glycolytic flux. An antioxidant was used to determine whether hypoxia-induced oxidative stress directly regulates the metabolic pathways. Mitochondrial function of WT and 123.7 cells was assessed through the expression of cytochrome oxidase, and measurement of the mitochondrial membrane potential. Glycolytic flux was analyzed by measuring the extracellular $\mathrm{pH}$, glucose, lacate and pyruvate levels. 
In order to confirm the role of PKA in these processes, for Specific Aim 4, I determined whether restoration of PKA activity in 123.7 cells abrogated differences in hypoxic susceptibility and energy homeostasis between the two cell lines. The PKA-activity deficient 123.7 cells were transfected with an active catalytic $\alpha$ subunit of Protein Kinase A. Transfection efficiency was verified through PKA activity assays and western blotting of the PKA cat $\alpha$ subunit. Using the transfected cells, hypoxia-induced cell survival, oxidative stress, energy status, glycolytic flux, and mitochondrial function were examined to confirm the role of PKA in these processes.

Through these experiments, I hoped to determine the role of Protein Kinase $A$ in hypoxia-induced cell death. Clarification of the cellular response to low oxygen conditions is essential to the treatment of pathologies characterized by periods of hypoxia. Understanding the role of PKA in the regulation of cellular metabolic responses, oxidative stress, and cell survival to hypoxia may provide novel therapeutic opportunities to improve cellular adaptation and recovery. 
Specific AIm 1: To determine whether PKA activity affects cellular tolerance to hypoxia and production of oxidant species

1 (A) To identify PKA-mediated changes in hypoxic vulnerability

$\begin{array}{lll}\text { WT cells } & \mathrm{RA}, \mathrm{SH} 0.1 \% \mathrm{O}_{2} \\ \text { cells } & \text { MTT / Trypan Blue } & \text { Cell survival }\end{array}$

1 (B) To determine the role of PKA in hypoxia-induced oxidant stress

\begin{tabular}{|c|c|}
\hline WT cells & $\mathrm{RA}, \mathrm{SH} 0.1 \% \mathrm{OZ}$ \\
\hline 123.7 cells & $\begin{array}{c}\text { DCF } \\
7,7 \text {-dichiorofluoresce }\end{array}$ \\
\hline
\end{tabular}

1 (C) To determine whether PKA plays a role in the regulation of cellular antioxidant mechanisms that will affect hypoxia-induced oxidative stress

$\begin{array}{lll}\text { WT cells } & \text { RA, SHO.1\% O2 } \\ 123.7 \text { cells } & \begin{array}{c}\text { GSHI GSSG } \\ \text { Total Glutathione } \\ \text { SOD-1 Western Blotting }\end{array}\end{array}$ Cellular redox status


Specific Alm 2: To determine whether PKA regulates hypoxia-induced cell death vla oxldative stress and/or energy depletion

2 (A) PKA effect on hypoxia-induced energy fallure

$$
\begin{aligned}
& \text { WT cells } \\
& 123.7 \text { cells }
\end{aligned} \stackrel{\text { RA, SH } 0.1 \% \text { O2 }}{\text { ATP, GAMP }} \text { Cellular energy status }
$$

2 (B) To determine whether ROS comtribute to hypoxia-induced energy failure

\begin{tabular}{|c|c|c|c|}
\hline \multirow{3}{*}{$\begin{array}{l}\text { WT cells } \\
123.7 \text { cells }\end{array}$} & & & \\
\hline & & & \\
\hline & $\underset{\mathrm{RA}, \mathrm{SH} 0.1 \% 02}{\mathrm{O}}$ & $\underset{\text { Trypan Blue }}{\text { DCF }}$ & $\begin{array}{l}\text { ROS } \\
\text { Cell survival }\end{array}$ \\
\hline
\end{tabular}


Specific Aim 3: To determine whether PKA affects cellular energetic status through regulation of metabolic pathways

3 (A) To determine whether PKA plays a role in the regulation of mitochondrial function

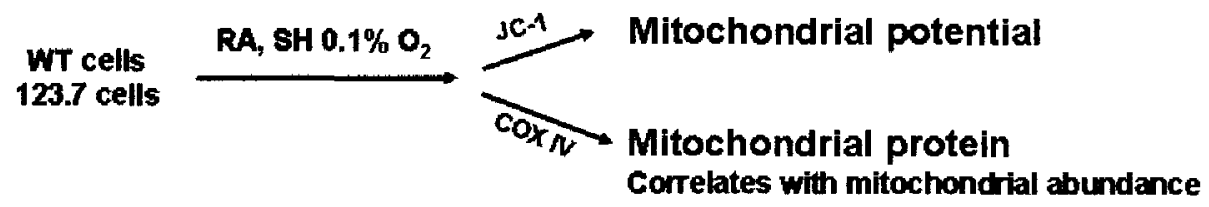

3 (B) To determine the effect of PKA activity on glycolytic flux

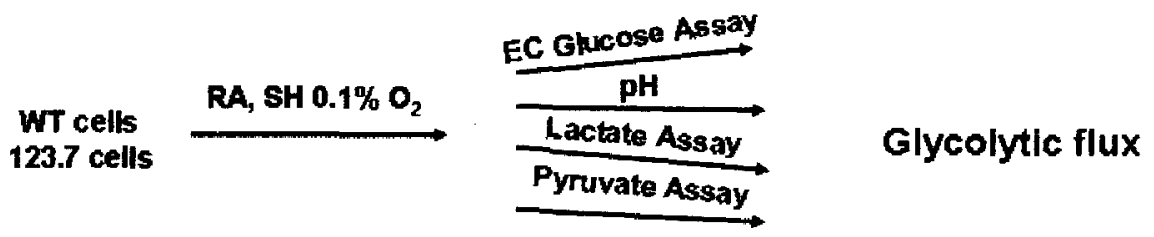

3 (C) To determine whether hypoxia-induced oxidant stress affects glycolytic flux

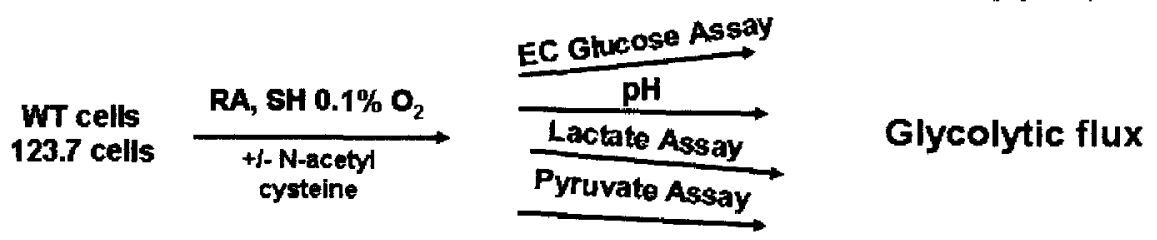


Specific Aim 4: To determine whether restoration of PKA activity in 123.7 cells will abrogate differences in hypoxic susceptibility and energy homeostasis between the two cell types

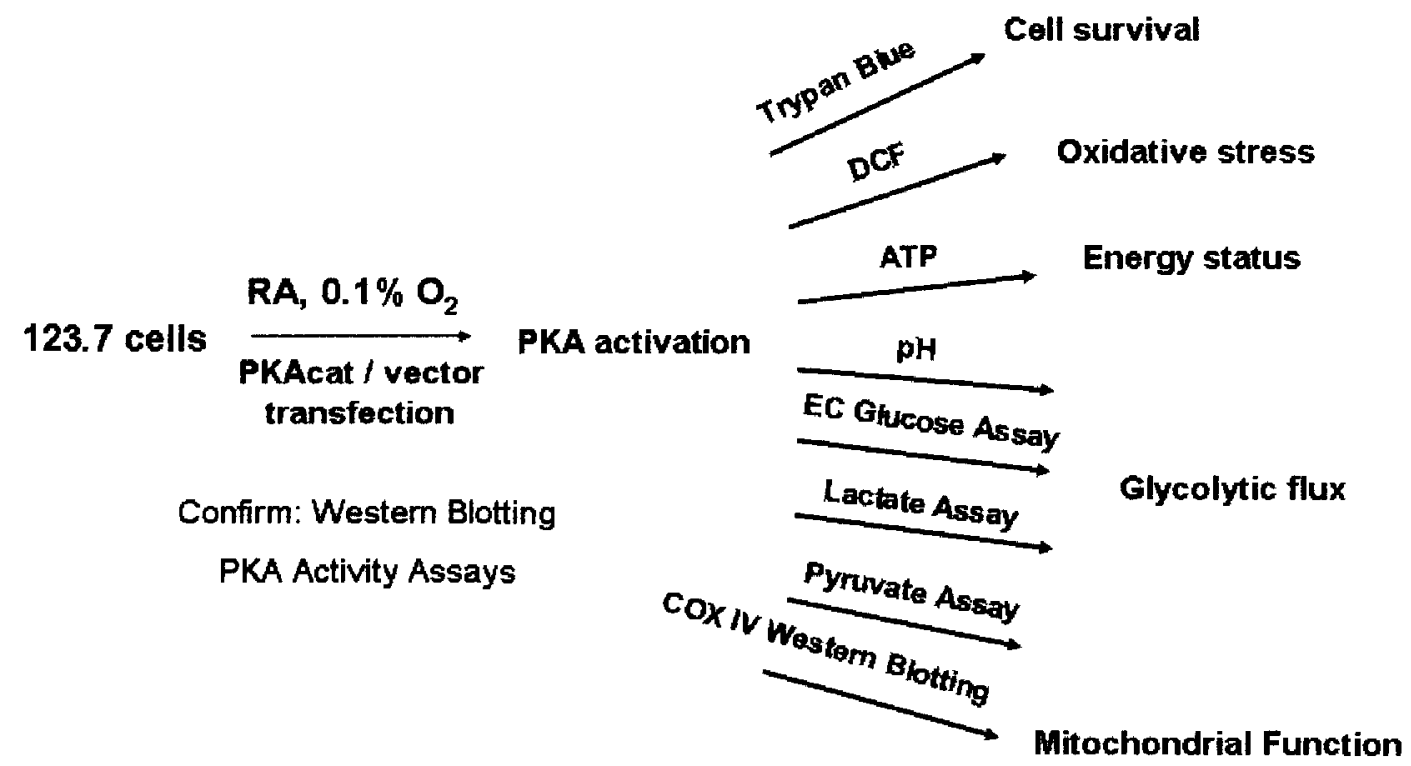




\section{MATERIALS AND METHODS}

Cell Culture and Hypoxic Exposures: WT and PKA-deficient (123.7) PC-12 cells were kindly provided by Dr. JA Wagner from Cornell University and grown on collagen coated plates in RPMl1640 medium (Gibco/Invitrogen, Carlsbad, CA), supplemented with $10 \%$ horse serum and $5 \%$ fetal bovine serum. Cells were exposed to hypoxia $\left(0.1 \%\right.$ or $5 \% \mathrm{O}_{2}, 5 \% \mathrm{CO}_{2}$, balanced $\left.\mathrm{N}_{2}\right)$, using a customdesigned, computer controlled incubator chamber attached to an external $\mathrm{O}_{2} / \mathrm{CO}_{2}$ computer-driven controller (Biospherix, Redfield, NY) as previously described $(48,49)$.

Cell viability: Cell viability was measured as previously described $(45,49,50)$ by assessment of 3-(4,5-dimethyldiazol-2yl)-2,5,-diphenyltetrazolium bromide (MTT) reduction (Sigma Chemical, St. Louis, MO). MTT was added to the cell cultures one hour prior to the end of the hypoxic exposure and incubated at $37^{\circ} \mathrm{C}$. Cells were collected by centrifugation and resuspended in DMSO for $24 \mathrm{~h}$. Absorption of reduced MTT was measured at $340 \mathrm{~nm}$ using a Multiskan EX plate reader (Thermo electron corporation, Milford, MA) and values for DMSO blanks were subtracted. Cell survival was also analyzed using Trypan Blue (J.T. Baker, Philipsburg, NJ) exclusion as a marker of live cells with intact membranes. Cells 
were collected, resuspended in PBS/trypan, counted using a hematocytometer, and total cell number was calculated and averaged.

cAMP determination: Intracellular CAMP levels were determined using a chemiluminescent immunoassay kit according to the manufacturer's instructions (Upstate, Temecula, CA). In this kit, a 96-well plate was precoated with a capture antibody. Standards and samples were mixed with an anti-cAMP antibody, as well as an alkaline phosphatase-labeled cAMP conjugate. The conjugate competes with native cAMP in the standards and samples for binding sites on the antibody. Thus, chemiluminescence levels are inversely related to the amount of CAMP in the standards and samples. Luminescence was detected using a SpectraFluor Plus (Tecan, San Jose, CA).

ATP determination: Intracellular ATP levels were determined using a bioluminescence ATP determination kit according to the manufacturer's instructions (Alexis Biochemicals, San Diego, CA). In this kit, the enzyme luciferase uses endogenous cellular ATP to catalyze the formation of light from luciferin. Luminescence was detected using a SpectraFluor Plus (Tecan, San Jose, CA).

Reactive oxygen species: Formation of intracellular oxidant species was detected by fluorescence, using the cell permeable, non-fluorescent 2'-7' dichlorodihydrofluorescin diacetate ( $\mathrm{DCFH}_{2}$-DA; Molecular Probes, Eugene, OR), 
which is de-esterified in cells by endogenous esterases and trapped. 2'-7' dichlorofluorescin is oxidized by intracellular oxidant species to fluorescent 2'-7' dichlorofluorescein. Cells were loaded for $1 \mathrm{~h}$ with $5 \mu \mathrm{M} \mathrm{DCFH} \mathrm{H}_{2}-\mathrm{DA}$, washed, and fluorescence was measured at $485 \mathrm{~nm}$ excitation and $535 \mathrm{~nm}$ emission using a SpectraFluor Plus (Tecan, San Jose, CA) For antioxidant treatments, cells were pretreated with $2.5 \mathrm{mM} \mathrm{N}$-acetyl cysteine (Sigma, St. Louis, MO) for 1 hour prior to hypoxic exposure.

Extracellular Glucose determination: Growth media was analyzed for glucose levels using the Amplex Red Glucose/Glucose Oxidase Assay Kit (Molecular Probes, Eugene, OR). In this assay, D-glucose present in the growth media reacts with glucose oxidase to from D-gluconolactone and hydrogen peroxide $\left(\mathrm{H}_{2} \mathrm{O}_{2}\right)$. The Amplex Red reagent (10-acetyl-3,7-dihydroxyphenoxazine) reacts with $\mathrm{H}_{2} \mathrm{O}_{2}$ in the presence of horseradish peroxidase to generate the fluorescent product, resorufin. Fluorescence was measured in a 96-well plate at $550 \mathrm{~nm}$ excitation and $595 \mathrm{~nm}$ emission using a SpectraFluor Plus (Tecan, San Jose, CA)

Extracellular Lactate determination: Growth media samples without phenol red were collected from cell cultures, deproteinized with perchloric acid, and centrifuged at $8,000 \mathrm{rpm}$ for $5 \mathrm{~min}$ at $4^{\circ} \mathrm{C}$. Samples were neutralized using a $\mathrm{KOH} / \mathrm{Na}_{2} \mathrm{HPO}_{4}$ solution and added in duplicate to a 96-well plate, with lactate standards and controls. The assay reactant $(0.2 \mathrm{M}$ Glycine-semicarbazide, 0.003 
M NAD, and $14 \mathrm{U} / \mathrm{mL} L D H$ ) was added to the samples and incubated for $1 \mathrm{~h}$ at $37^{\circ} \mathrm{C}$. Optical density was read at $340 \mathrm{~nm}$ and subtracted from background using a SpectraFluor Plus (Tecan, San Jose, CA). All chemicals were analytical grade (Sigma Chemical, St. Louis, MO).

Extracellular Pyruvate determination: Growth media samples without phenol red were collected from cell cultures, deproteinized with perchloric acid, and centrifuged at $8,000 \mathrm{rpm}$ for $5 \mathrm{~min}$ at $4^{\circ} \mathrm{C}$. Samples were neutralized using a $\mathrm{KOH} / \mathrm{Na}_{2} \mathrm{HPO}_{4}$ solution and added in duplicate to a 96-well plate, with pyruvate standards and controls. The assay reactant $(0.083 \mathrm{M}$ Tris-HCL, $0.0083 \mathrm{M}$ EDTA, $0.75 \mathrm{mM} \mathrm{NADH}, 15 \mathrm{U} / \mathrm{mL} \mathrm{LDH}$ ) was added to the samples and incubated for 15 min at room temperature. Optical density was read at $340 \mathrm{~nm}$ and subtracted from background using a SpectraFluor Plus (Tecan, San Jose, CA). All chemicals were analytical grade (Sigma Chemical, St. Louis, MO).

Preparation of Cell Lysates and Westem Blotting: Cells were collected by centrifugation and pellets were resuspended in RIPA buffer (PBS, $1 \%$ NP-40, $0.5 \%$ Deoxycholate, $1 \%$ SDS, $1 \mathrm{mM}$ Sodium orthovanadate, $0.5 \mathrm{mM}$ PMSF, 10 $\mathrm{mg} / \mathrm{ml}$ Aprotinin, $20 \mathrm{mg} / \mathrm{ml}$ Leupeptin), incubated on ice for $30 \mathrm{~min}$., briefly sonicated, and centrifuged at $4^{\circ} \mathrm{C}$ at $15,000 \mathrm{rpm}$ for $10 \mathrm{~min}$. Total protein concentration in the supernatant was determined using a DC-Bio-Rad protein assay (Bio-Rad, Hercules, CA). Immunoblotting was done as described previously $(5,47,49,51,52)$. Samples were diluted in buffer $(125 \mathrm{mM}$ Tris, $5 \%$ 
Glycerol, 4\% Sodium dodecyl sulfate, 0.1 M Dithiothreitol, 0.0025\% Pyronin Ypink, $\mathrm{ddH}_{2} \mathrm{O}$ ) and loaded onto $4-12 \%$ Tris-Glycine gels (Invitrogen, Carlsbad, CA). Gels were run in buffer (25 mM Tris, $193 \mathrm{mM}$ Glycine, $0.1 \%$ Sodium dodecyl sulfate, $d_{d H_{2}} \mathrm{O}$ ) for $2 \mathrm{~h}$ at $120 \mathrm{~V}$, and transferred onto nitrocellulose filter membranes for $1 \mathrm{~h}$ at $30 \mathrm{~V}$ in transfer buffer (12 mM Tris, $96 \mathrm{mM}$ Glycine, $20 \%$ Methanol). Membranes were stained with Ponceau-S to ensure proper transfer, and blocked ( $5 \%$ non-fat dry milk in Tris buffered saline and $0.05 \%$ Tween-20) for 1 hour. Membranes were incubated with primary antibodies overnight at $4^{\circ} \mathrm{C}$, washed, and incubated with secondary antibodies for $1 \mathrm{~h}$ at room temperature. Membranes were then washed, and chemiluminescence was detected using an ECL plus western blotting detection kit (GE Healthcare, Buckinghamshire, UK). Membranes were immunoblotted for $\beta$-actin to ensure loading efficiency.

Mitochondrial Membrane Potential Assay (MMP): MMP was determined with the fluorescent probe $5,5^{`}, 6,6^{`}$-tetrachloro-1,1`3,3`'-tetraethylbenzimidazolyl carbocyanine iodide (JC-1). JC-1 undergoes a reversible change in fluorescence emission from green to red upon an increase in mitochondrial potential. Thus, in live cells, JC- 1 acccumulates as red aggregates in the mitochondria, while in apoptotic or necrotic cells it remains in the green monomeric form. The fluorescence ratio was detected in a 96-well plate according to the manufacturer's instructions (Cell Technology, Mountain View, CA). Red fluorescence was measured at $550 \mathrm{~nm}$ excitation and $595 \mathrm{~nm}$ emission, and 
green fluorescence was measured at $485 \mathrm{~nm}$ excitation and $535 \mathrm{~nm}$ emission using a SpectraFluor Plus (Tecan, San Jose, CA).

Glutathione (GSH/GSSG) ratio and Total Glutathione: The glutathione ratio and total glutathione levels were determined using a fluorescent kit according to the manufacturer's instructions (Biovision, Mountain View, CA). In this kit ophthalaldehyde reacts with the reduced form of glutathione (GSH), but not the oxidized form (GSSG), to form a fluorescent product. GSH, GSSG, and total glutathione levels were detected in separate wells in a 96-well plate. In order to detect GSSG, a GSH quencher was added to rid the samples of endogenous GSH. GSSG in the samples was then converted to GSH using a reducing agent, and fluorescence was detected. To detect total glutathione, the reducing agent was added to convert endogenous GSSG to GSH, and fluorescence was measured using a SpectraFluor Plus (Tecan, San Jose, CA).

Cell Transfection: Tranfections were done using the FuGENE HD transfection reagent (Roche Applied Science, Indianapolis, IN). Plasmids encoding active PKA-cat $\alpha$ were kindly provided by Dr. G. Stanley McKnight, and used as previously described (53). pcDNA 3.0 (Invitrogen, Carlsbad, CA) was used as a vector control with FuGene reagent.

PKA Activity Assay. PKA activity was analyzed as previously described (54). Cells were collected and lysed as described above, and total protein 
concentration in the supernatant was determined using a DC-Bio-Rad protein assay (Bio-Rad, Hercules, CA). Duplicate samples (50 $\mu \mathrm{g}$ protein) were diluted in Kinase Buffer (25 mM Hepes, pH 7.4; $20 \mathrm{mM} \mathrm{MgCl} ; 20 \mathrm{mM} \beta$ glycerophosphate; $0.1 \mathrm{mM}$ Sodium orthovanadate; $2 \mathrm{mM} \mathrm{DTT,} 1 \mathrm{~mL}$ dd $\mathrm{H}_{2} \mathrm{O}$ ), in the presence or absence of a PKA inhibitory peptide, PKI 6-22 amide $(26.7 \mu \mathrm{M}$, Calbiochem, La Jolla, CA) to account for PKA-independent phosphorylation. Reaction Buffer (200 $\mu \mathrm{M}$ Kemptide; $55.6 \mathrm{nM}$ 32P-ATP; Kinase Buffer) was added and samples were incubated for $30 \mathrm{~min}$ at $30^{\circ} \mathrm{C}$ in a water bath. Aliquots of each sample were removed from the tube and spotted on Whatman filter paper p81 (Whatman International Ltd, Maidstone, England). Filter papers were washed for 5 minutes with $1 \%$ phosphoric acid and the waste was drained. Washes were repeated for 15 min with $1 \%$ phosphoric acid, and 15 minutes with $\mathrm{ddH}_{2} \mathrm{O}$ to remove non-specifically bound radioactivity. Radioactivity, representative of $32 \mathrm{P}$ incorporation into the substrate, was counted using a Packard Tri-carb Liquid Scintillation Analyzer 2100TR (Perkin Elmer Life \& Analytical Sciences, Shelton, CT).

Statistical Analyses: Statistical analyses were performed using SigmaStat software version 3.5.1 (Systat Software, Inc., San Jose, CA). Data represented as the means of individual experiments, with the error bars indicating standard deviations. Statistical tests were performed as indicated in the results, with significance defined as $p<.05$. 


\section{RESULTS:}

Specific Aim 1: To determine whether PKA activity affects cellular tolerance to hypoxia and production of oxidant species

1 (A) Effect of PKA activity on cell survival to hypoxia: MTT assays indicated that severe hypoxia induced cell death by $24 \mathrm{~h}$ in WT cells, while a milder hypoxic challenge did not significantly affect cell survival (Figure 10). In contrast, 123.7 cells did not exhibit cell death following $24 \mathrm{~h}$ of severe hypoxic exposure (Figure 11). In addition, basal MTT values were also lower in 123.7 cells, compared to WT cells at a similar confluence, as verified by Trypan Blue exclusion assays (Figure 12). This indicates that PKA activity contributes to PC-12 hypoxic cell death. The consistent difference in cellular reductive capacity, as indicated by the MTT assays, implicates PKA signaling in the regulation of cellular metabolism and suggests that the metabolic function of the two cell lines may differ. 


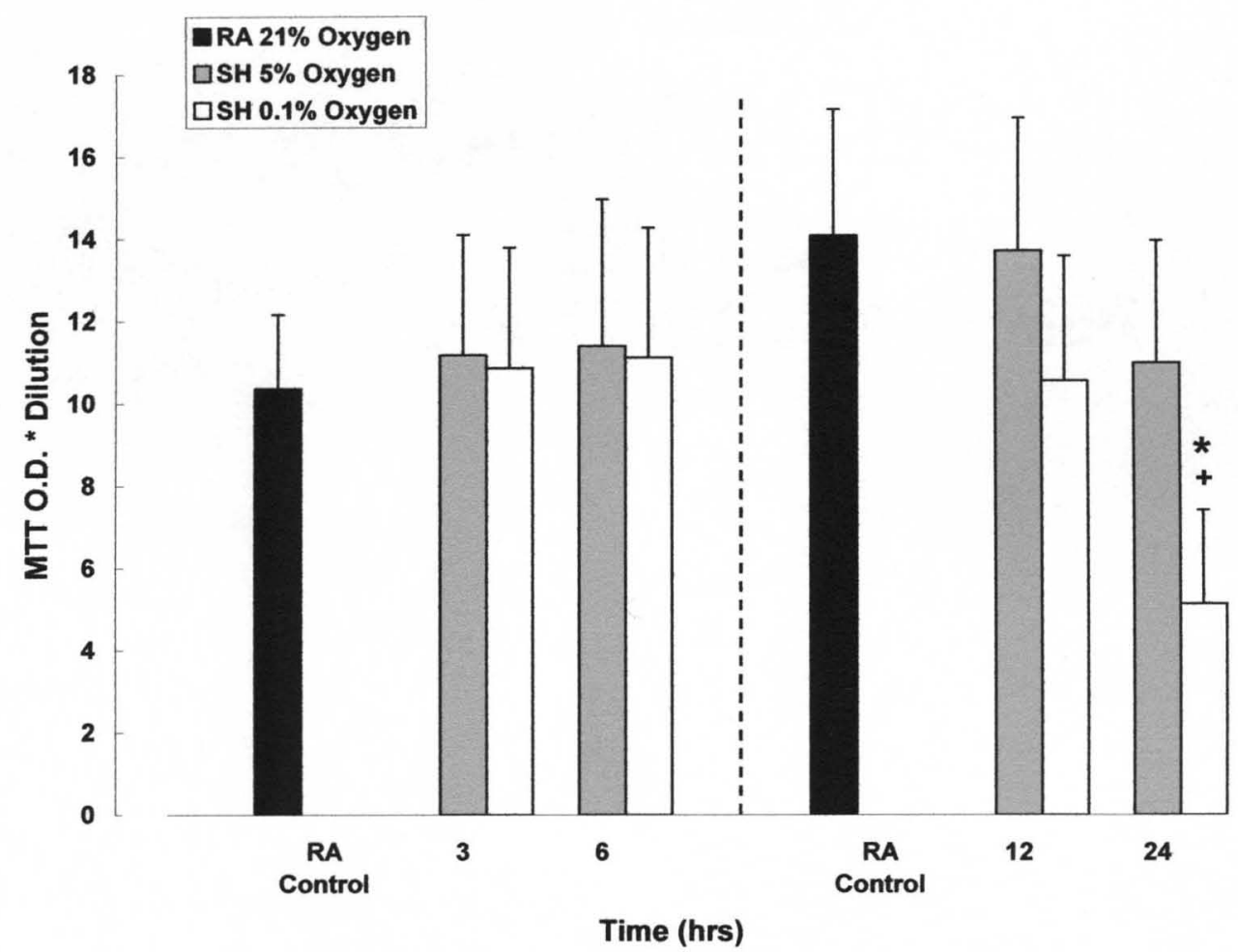

Figure 10. Cellular Tolerance of WT cells to Sustained Hypoxia: MTT Assay WT cells were exposed to room air (RA), severe hypoxia (SH $0.1 \%$ oxygen), or a milder hypoxia (SH 5\% oxygen). Cell viability was analyzed using the reduction of MTT (3-(4,5-dimethyldiazol-2yl)-2,5,-diphenyltetrazolium bromide). WT cell death occurred following $24 \mathrm{~h}$ of severe $\left(0.1 \% \mathrm{O}_{2}\right)$ hypoxia, but was not seen at any other time point of severe hypoxia, or with milder hypoxic exposure. Data expressed as the means of 5 individual experiments $(n=5)$, with error bars indicating standard deviations. One-way ANOVA, Mann Whitney Rank Sum test. ${ }^{*} p<.01 \mathrm{SH}$ vs. RA control at one time point, $+p<.01 \mathrm{SH} 0.1 \%$ vs. SH $5 \%$ at one time point. 


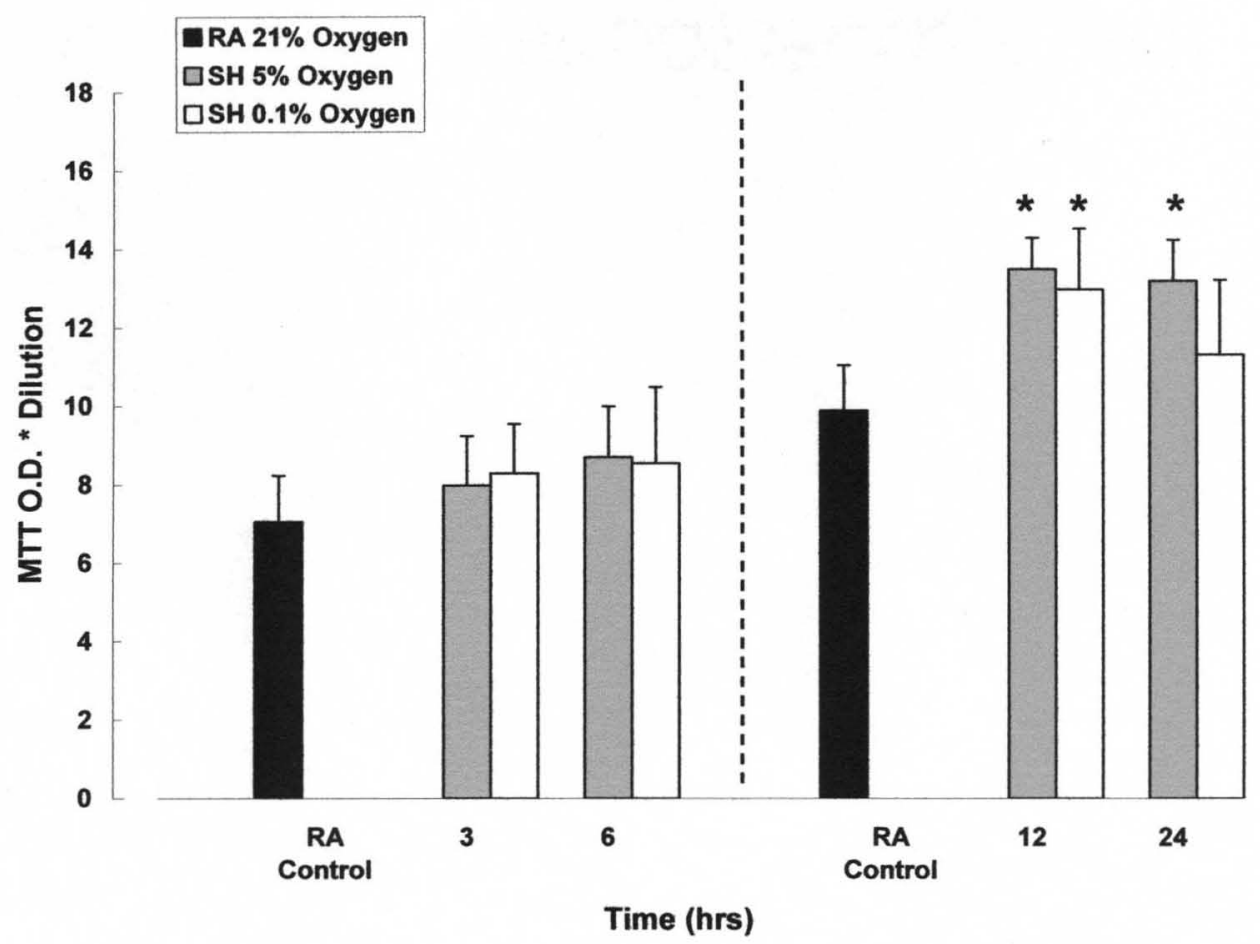

Figure 11. Cellular Tolerance of $\mathbf{1 2 3 . 7}$ cells to Sustained Hypoxia: MTT Assay PKA-activity deficient 123.7 cells were exposed to room air (RA), severe hypoxia (SH $0.1 \%$ oxygen), or a milder hypoxia (SH $5 \%$ oxygen). Cell viability was analyzed using the reduction of MTT (3-(4,5-dimethyldiazol-2yl)-2,5,diphenyltetrazolium bromide). MTT reduction in 123.7 cells was significantly increased from RA controls at later time points of hypoxic exposure, indicating that 123.7 cells are not experiencing cell death over this time course. Data expressed as the means of 5 individual experiments $(n=5)$, with error bars indicating standard deviations. One-way ANOVA, Tukey post-hoc test, ${ }^{*} p<.01$ RA control vs. SH at one time point. 


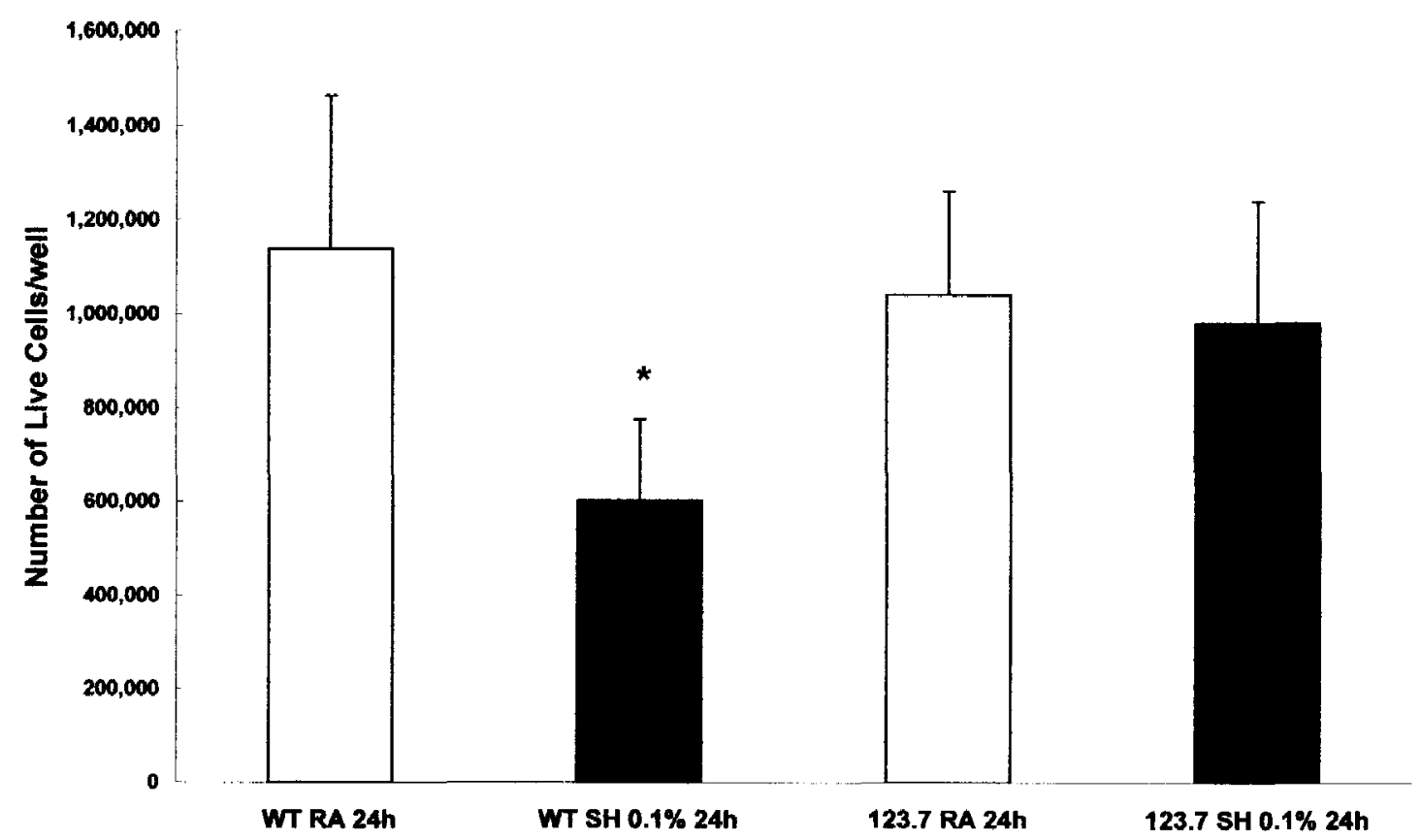

Figure 12. Trypan Blue Exclusion Assay WT and 123.7 cells were exposed to either room air (RA) or sustained $0.1 \% \mathrm{O}_{2}$ hypoxia ( $\mathrm{SH} 0.1 \%$ ) for $24 \mathrm{~h}$. Cell viability was assessed using the Trypan Blue exclusion assay. The number of live cells per well was significantly decreased in WT cells following $24 \mathrm{~h}$ of severe hypoxia, while 123.7 cells had no change in the number of live cells. Data expressed as means of 10 individual experiments $(n=10)$, with error bars indicating standard deviations. Two-way ANOVA, Tukey post-hoc test, " $p<.001$ $\mathrm{RA}$ vs. $\mathrm{SH} 0.1 \% \mathrm{O}_{2}$ for one cell line. 
1 (B) Effect of PKA activity on Oxidative Stress: DCF fluorescence, indicating reactive oxygen species production, significantly increased in WT cells exposed to $24 \mathrm{~h}$ severe hypoxia $\left(0.1 \% \mathrm{O}_{2}\right)$ (Figure 13). In contrast to WT cells, the PKAactivity deficient 123.7 cells had no significant alterations in DCF fluorescence following exposure to $0.1 \% \mathrm{O}_{2}$ for $24 \mathrm{~h}$, (Figure 13), suggesting that PKA activity contributes to ROS formation. 


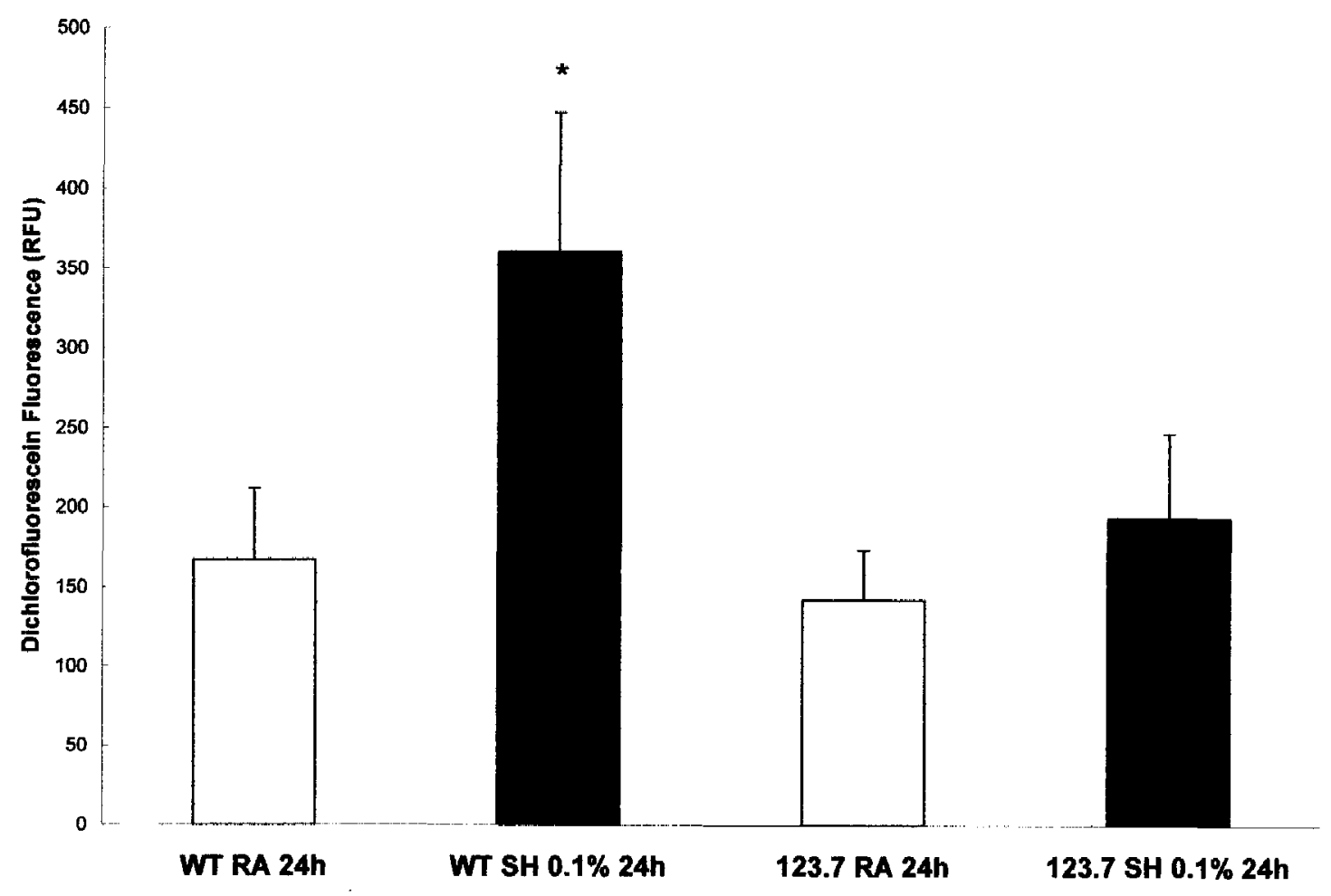

Figure 13. Reactive Oxygen Species Production: DCF Fluorescence WT and 123.7 cells were exposed to either room air (RA) or sustained $0.1 \% \mathrm{O}_{2}$ hypoxia (SH $0.1 \%$ ) for $24 \mathrm{~h}$. ROS levels, as detected by dichlorofluorescein (DCF) fluorescence, were significantly increased in WT cells following $24 \mathrm{~h}$ of severe hypoxia, while 123.7 cells experienced no significant alterations in DCF fluorescence. Data expressed as the means of the relative fluorescence units (RFU) from 14-16 individual experiments ( $n=14-16)$, with error bars indicating standard deviations. Two-way ANOVA, Tukey Post-hoc test, " $p<.001$ RA vs. SH $0.1 \% \mathrm{O}_{2}$ for one cell line. 
1 (C) Effect of PKA on cellular antioxidant response: Following 24h of severe hypoxia, there was surprisingly no detectable difference in the GSH/GSSG ratio (Figure 14) or total glutathione levels in either WT or 123.7 cells (Figure 15). However, it is important to note that most of the detected glutathione was in the oxidized (GGSG) state during both normoxic and hypoxic states. This indicates that, in our PC-12 cell lines, the reductive capacity of the glutathione system may already be compromised, even during normoxic conditions. Furthermore, superoxide dismutase 1 (SOD-1) expression was not altered in either cell line with $24 \mathrm{~h}$ of sustained hypoxia or with antioxidant treatment (Figure 16), indicating that the antioxidant response of PC-12 cells may be compromised by this time. 


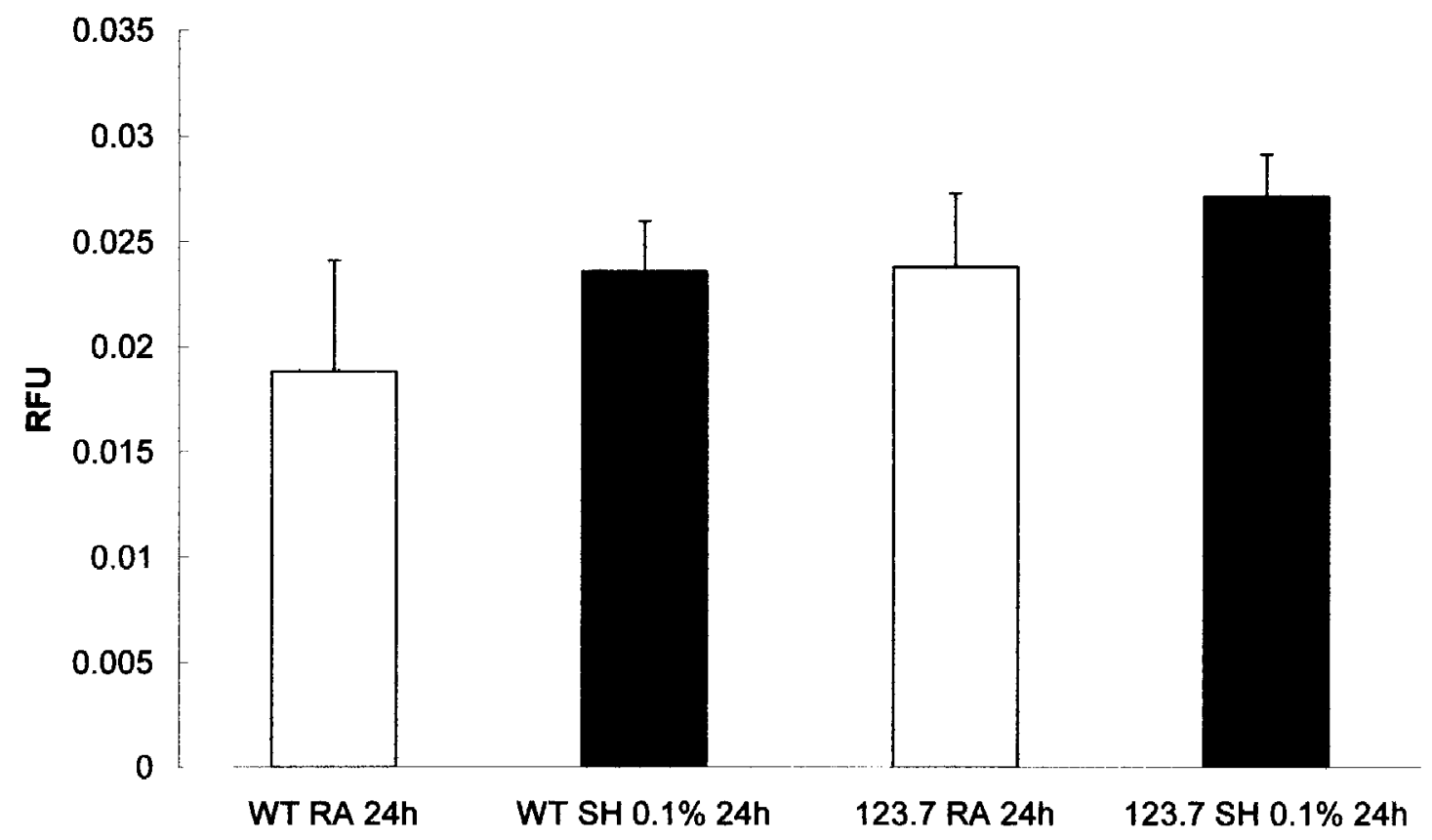

Figure 14. Cellular Redox Status: GSH/GSSG ratio WT and 123.7 cells were exposed to either room air (RA) or sustained $0.1 \% \mathrm{O}_{2}$ hypoxia ( $\mathrm{SH} 0.1 \%$ ) for $24 \mathrm{~h}$. The ratios of reduced to oxidized forms of glutathione were analyzed as an indicator of cellular antioxidant response. Data expressed as the means of the relative fluorescence units (RFU) from 5 individual experiments $(n=5)$, with error bars indicating standard deviations. Two-way ANOVA statistics did not detect a significant difference between the GSH/GSSG ratios of the two cell types, or between room air and hypoxia treated groups in each cell line. 


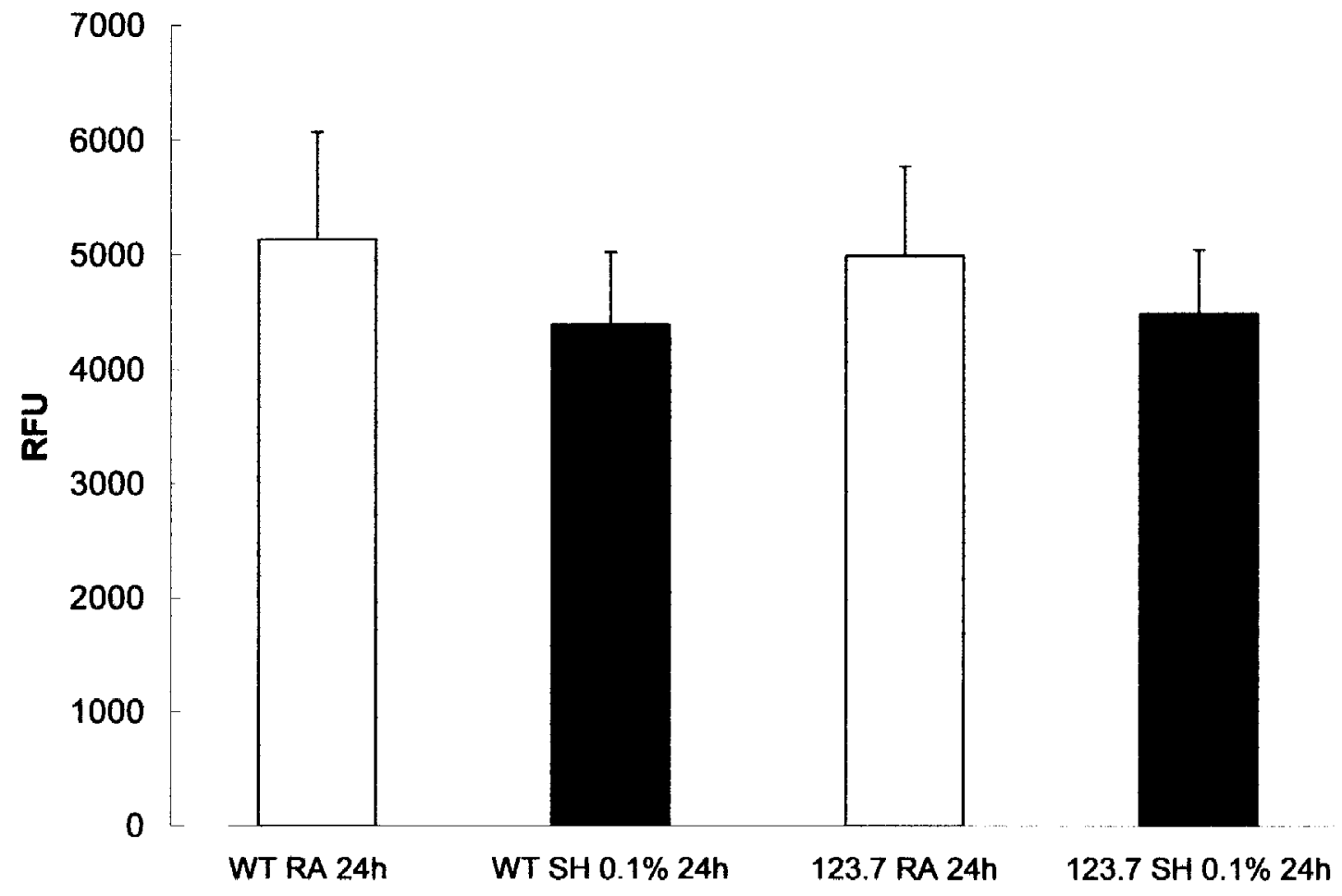

Figure 15. Cellular Redox Status: Total Glutathione The total levels of glutathione were assessed in WT and 123.7 cells exposed to either room air (RA) of sustained $0.1 \% \mathrm{O}_{2}$ hypoxia ( $\mathrm{SH} 0.1 \%$ ) for $24 \mathrm{~h}$. Data expressed as means of the relative fluorescence units (RFU) of 5 individual experiments $(n=5)$, with error bars indicating standard deviations. Two-way ANOVA statistics did not detect a significant difference between the total glutathione levels of the two cell types, or between room air and hypoxia treated groups in each cell line. 


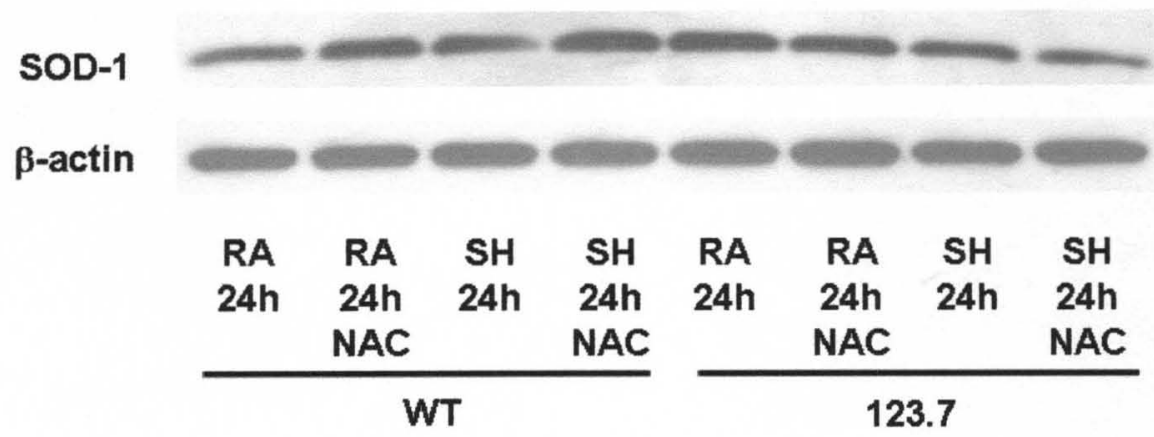

Figure 16. Cellular Antioxidant Capacity: SOD-1 Expression WT and 123.7 cells were exposed to either room air (RA) or sustained $0.1 \% \mathrm{O}_{2}$ hypoxia ( $\mathrm{SH}$ $0.1 \%$ ) for $24 \mathrm{~h}$. Groups were also pre-treated for $1 \mathrm{~h}$ with the antioxidant precursor $\mathrm{N}$-acetyl cysteine (NAC). Western blotting of superoxide dismutase-1 (SOD-1) was performed to analyze the cellular antioxidant responses, and loading efficiency was confirmed through immunoblotting of $\beta$-actin. No alterations in SOD-1 or $\beta$-actin expression were seen between the WT and 123.7 cells, or in either cell line upon hypoxic exposure or with antioxidant pretreatment. Data representative of 3 individual experiments. 
Specific Aim 2: To determine whether PKA regulates hypoxia-induced cell death via oxidative stress and/or energy depletion

2 (A) Effect of PKA Activity on Cellular Energetic Status: Severe hypoxia decreased ATP levels in WT cells by $24 \mathrm{~h}$, while 123.7 cells displayed no change in ATP levels (Figure 17). Furthermore, 123.7 cells had a lower basal level of ATP, indicating that PKA activity may play a role in determining cellular energy requirements. The hypoxia-induced decrease in ATP coincided with the onset of cell death in WT cells, however lower baseline ATP levels did not appear to be detrimental to 123.7 cell survival.

In 123.7 cells, the mutated PKA regulatory subunit prevented the binding of cAMP, and thus, could potentially affect cAMP synthesis or degradation and alter cAMP levels within the cells. However, there was no alteration of CAMP levels between the WT and 123.7 cells, or upon exposure to $24 \mathrm{~h}$ of severe hypoxia (Figure 18), suggesting that cAMP levels are not altered by hypoxia or PKA activity. 


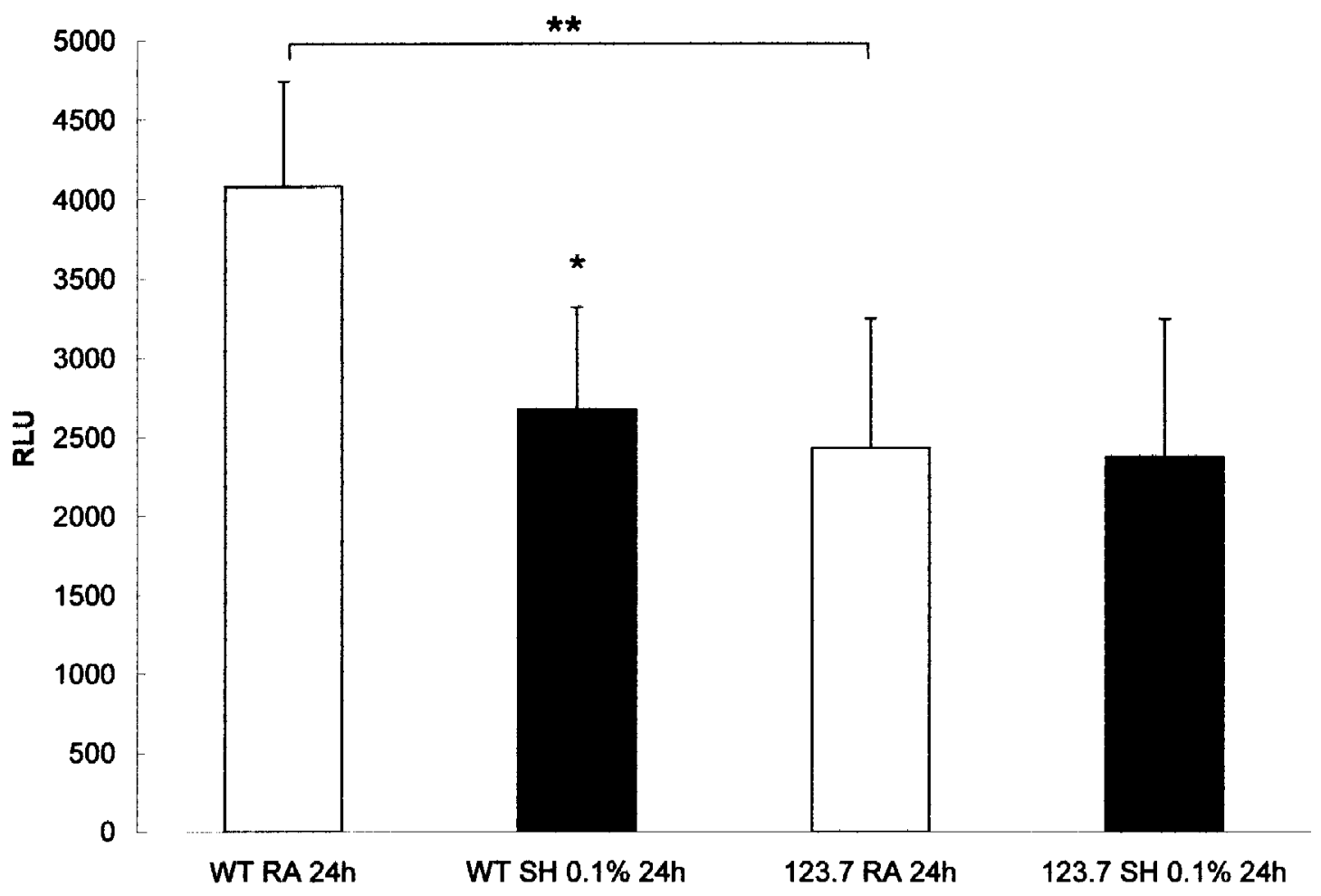

Figure 17. Cellular Energetic Status: ATP levels WT and PKA activitydeficient 123.7 cells were exposed to either room air (RA) or sustained $0.1 \% \mathrm{O}_{2}$ hypoxia ( $\mathrm{SH} 0.1 \%$ ) for $24 \mathrm{~h}$. ATP levels were significantly decreased in WT cells following $24 \mathrm{~h}$ of hypoxic exposure, while 123.7 cells displayed no change in ATP levels. The 123.7 cells also had a lower basal level of ATP than WT cells. Data expressed as the means of relative luminescence units (RLU) from 7 individual experiments $(n=7)$, with error bars indicating standard deviations. Two-way ANOVA, Tukey Post-hoc test, ${ }^{\star \star}{ }^{*} p<.005$ as indicated, ${ }^{*} p<.01$ RA vs. SH $0.1 \%$ $24 \mathrm{~h}$ in each cell line. 


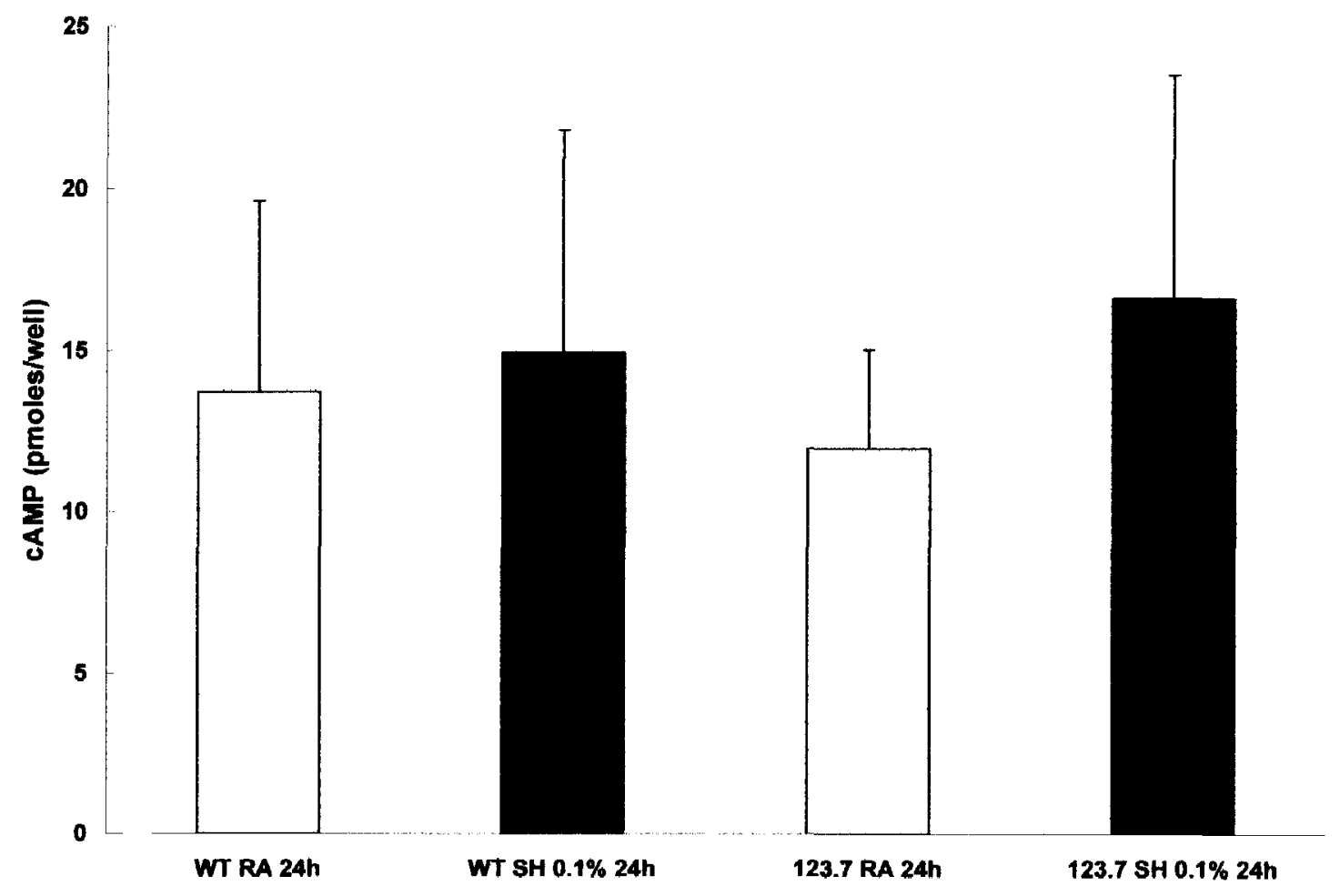

Figure 18. Cellular Energetic Status: cAMP levels WT and 123.7 cells were exposed to either room air (RA) or sustained $0.1 \% \mathrm{O}_{2}$ hypoxia ( $\mathrm{SH} 0.1 \%$ ) for $24 \mathrm{~h}$, and their CAMP levels were analyzed. Two-way ANOVA statistics did not detect a significant difference between the cAMP levels of the two cell types, or between room air and hypoxia treated groups in each cell type. Data expressed as the means of 5-6 individual experiments ( $n=5-6)$, with error bars indicating standard deviations. 
2 (B) Effect of ROS on Hypoxia-induced Energy Failure Pre-treatment of WT cells with the antioxidant $\mathrm{N}$-acetyl cysteine, 1 h prior to $24 \mathrm{~h} \mathrm{SH} 0.1 \% \mathrm{O}_{2}$, reduced ROS levels as detected by DCF fluorescence (Figure 19). Antioxidant treatment also improved cell survival assessed by Trypan blue exclusion (Figure 20), indicating that oxidative stress contributes to hypoxia-induced PC-12 cell death.

$\mathrm{N}$-acetyl cysteine treatment led to a drastic shift in the reduction state of the cell, as shown by the large increase in the GSH/GSSG ratio in both normoxic and hypoxic conditions (Figure 21). However, $\mathrm{N}$-acetyl cysteine treatment did not affect the total glutathione levels in the cell (Figure 22), indicating that the antioxidant may be directly acting as a reducing agent for the existing pool of oxidized GSSG rather than increasing generation of new glutathione.

Furthermore, pretreatment with the antioxidant $\mathrm{N}$-acetyl cysteine, while rescuing WT cells from cell death, had no effect on ATP levels (Figure 23), suggesting that oxidative stress may not be sufficient to induce cellular energy depletion during hypoxia. This data suggests that while hypoxic stress depletes ATP levels, energy depletion does not appear to be directly causing death. CAMP levels were not significantly affected by treatment with the antioxidant $\mathrm{N}$ acetyl cysteine in either of the cell types (Figure 24), suggesting that cAMP levels are not altered by oxidative stress. 


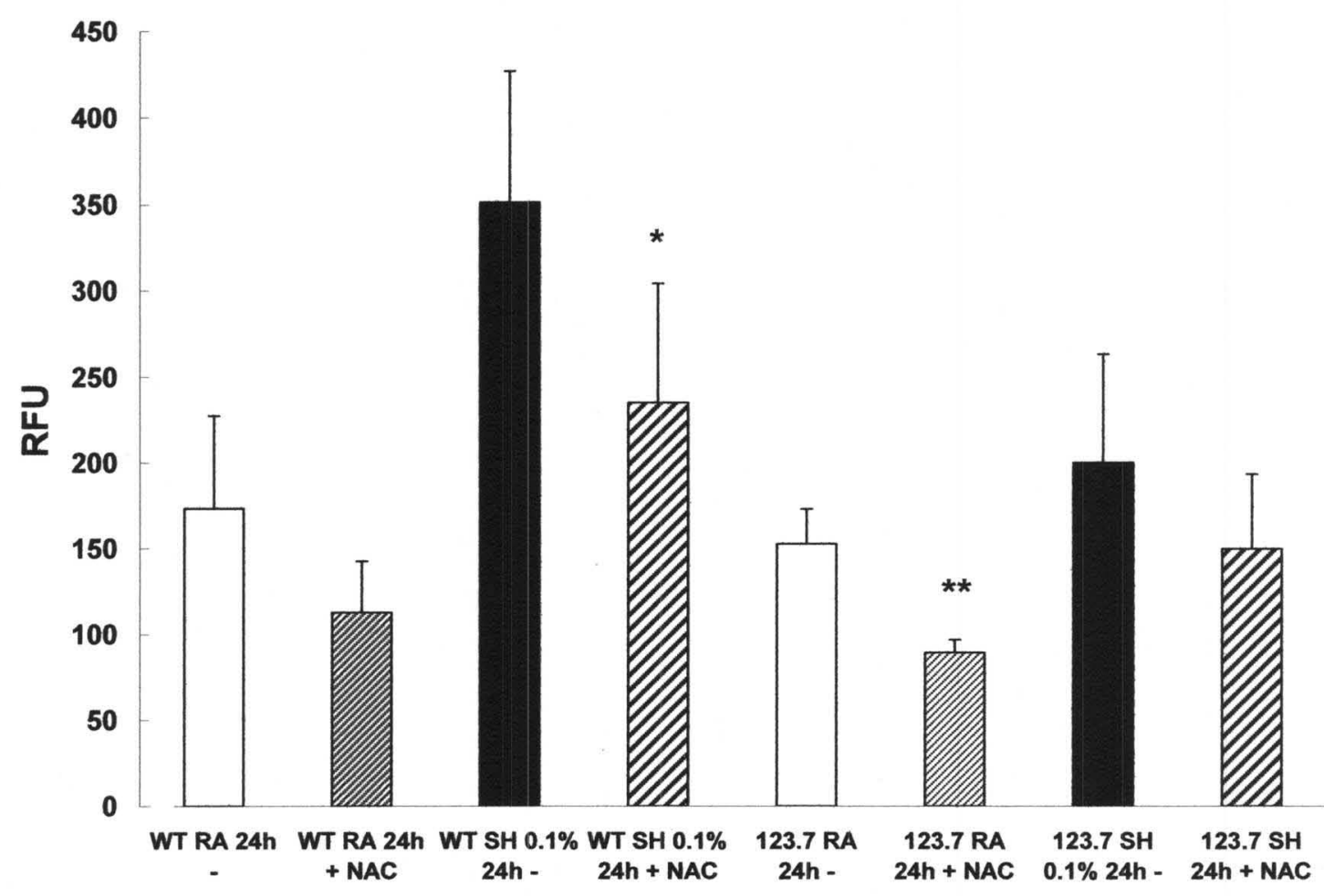

Figure 19. Effect of Antioxidant treatment on DCF Fluorescence WT and 123.7 cells were exposed to either room air (RA) or sustained $0.1 \% \mathrm{O}_{2}$ hypoxia (SH $0.1 \%$ ) for $24 \mathrm{~h}$. Dichlorofluorescein (DCF) fluorescence, indicative of ROS levels, was analyzed in cells pre-treated with the antioxidant $\mathrm{N}$-acetyl cysteine relative to untreated controls. $\mathrm{N}$-acetyl cysteine treated groups had lower values of DCF fluorescence than the untreated controls. Data expressed as the means of relative fluorescence units (RFU) from 5-6 individual experiments ( $n=5-6)$, with error bars indicating standard deviations. Two-way ANOVA, Tukey Post-hoc test, ${ }^{* *} p<.001,{ }^{*} p<.05 \mathrm{~N}$-acetyl cysteine treated cells vs. non-treated cells of the same condition. 


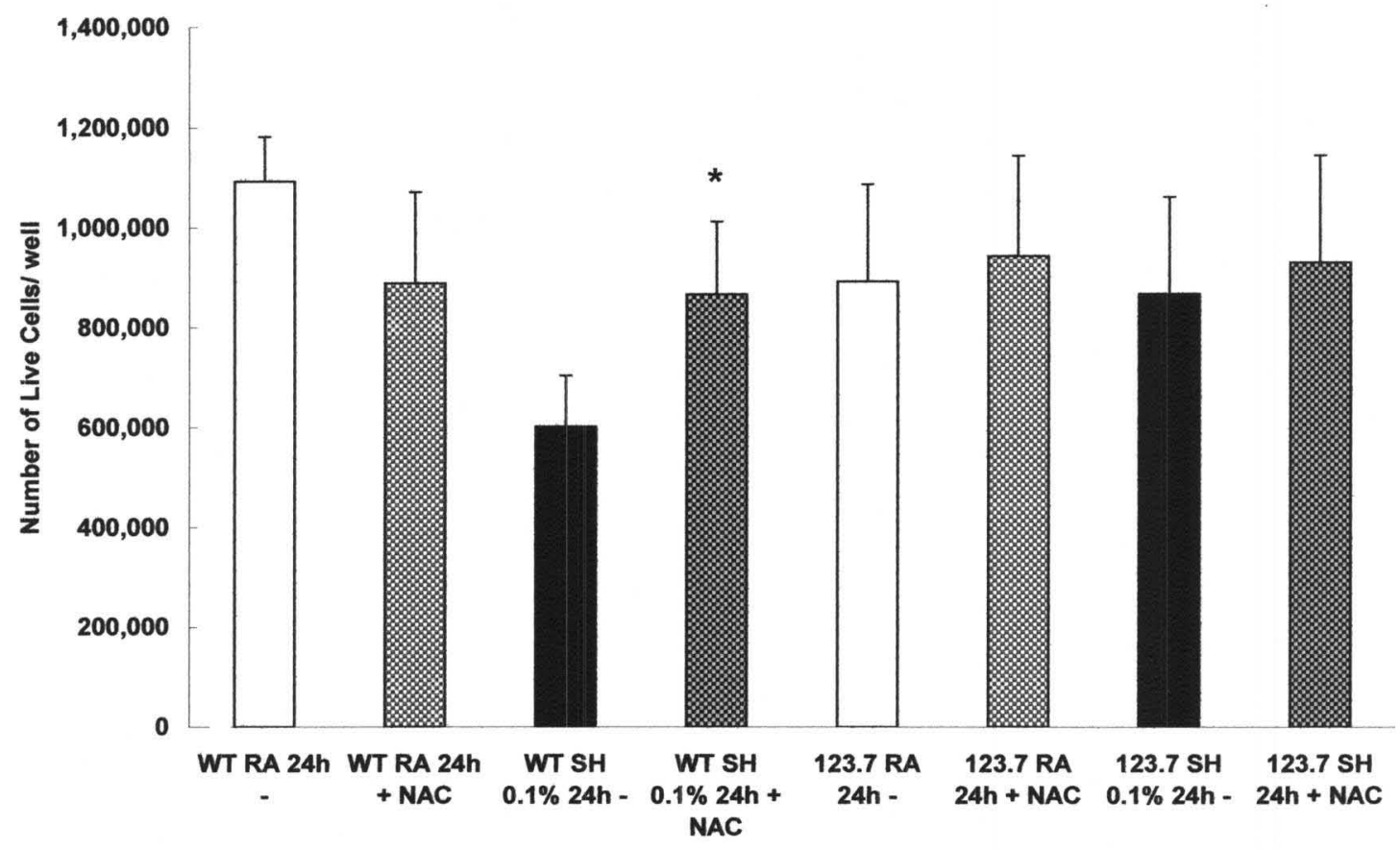

Figure 20. Effect of Antioxidant treatment on Trypan Blue Exclusion Assay WT and 123.7 cells were exposed to either room air (RA) or sustained $0.1 \% \mathrm{O}_{2}$ hypoxia (SH $0.1 \%$ ) for $24 \mathrm{~h}$. Trypan Blue exclusion assays were analyzed in cells pre-treated with the antioxidant $\mathrm{N}$-acetyl cysteine relative to untreated controls to analyze cell viability. WT cells exposed to hypoxia had a significant increase in the number of live cells when pre-treated with $\mathrm{N}$-acetyl cysteine, while the antioxidant treatment did not have a significant effect on the other groups tested. Data expressed as the means of 5 individual experiments $(n=5)$, with error bars indicating standard deviations. Two-way ANOVA, Tukey Post-hoc test, ${ }^{*} p=.01$ $\mathrm{N}$-acetyl cysteine pre-treated cells vs. non-treated cells of the same oxygen condition and cell line. 


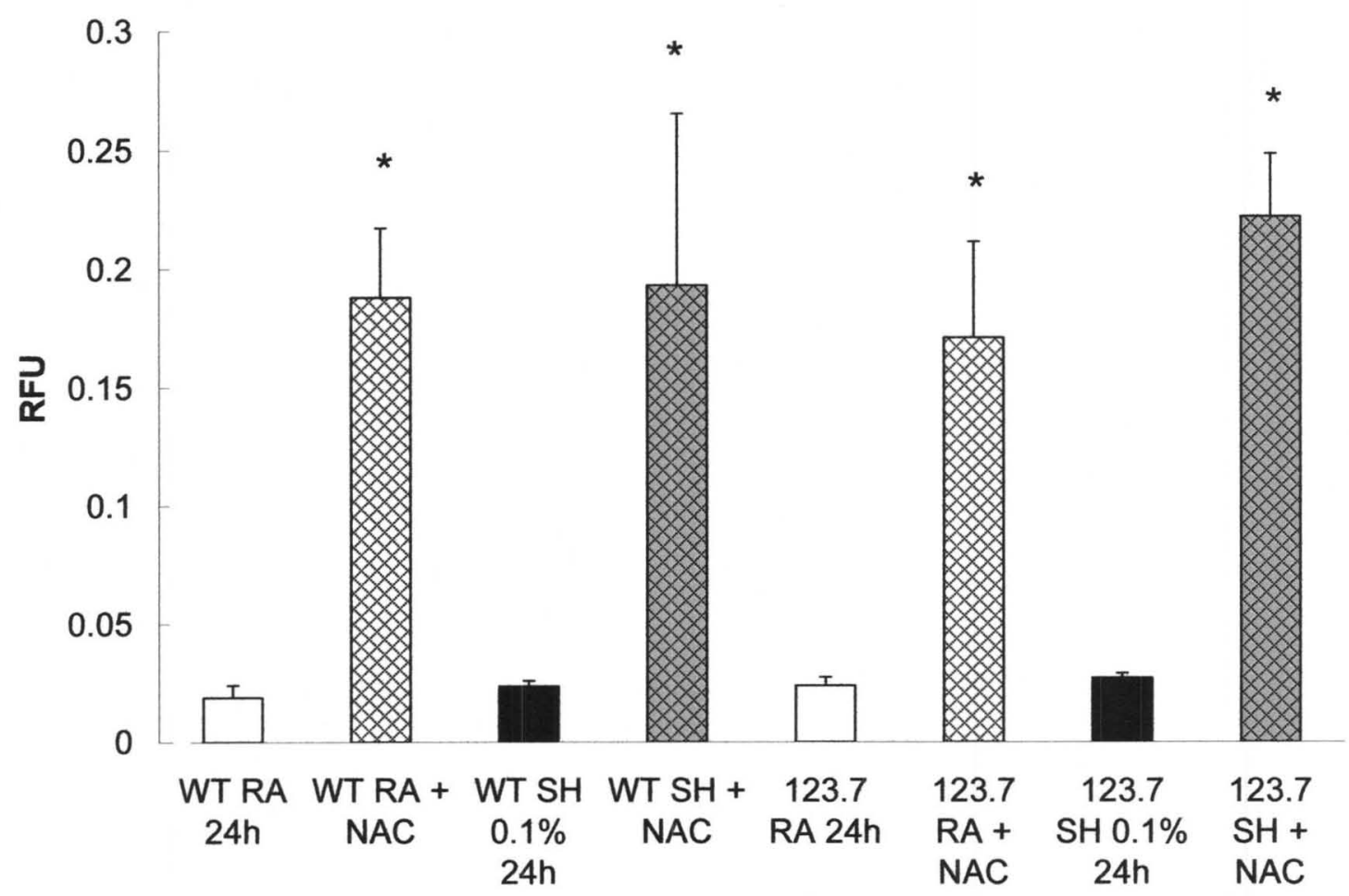

Figure 21. Effect of Antioxidant treatment on GSH/GSSG ratio WT and 123.7 cells were exposed to either room air (RA) or sustained $0.1 \% \mathrm{O}_{2}$ hypoxia (SH $0.1 \%$ ) for $24 \mathrm{~h}$. The ratio of reduced to oxidized glutathione (GSH/GSSG), indicative of cellular antioxidant status, was analyzed in cells pre-treated with the antioxidant $\mathrm{N}$-acetyl cysteine relative to untreated controls. Pre-treatment with the antioxidant significantly increased the ratio of reduced to oxidized glutathione in all of the groups tested. Data expressed as the means of relative fluorescence units (RFU) from 5 individual experiments $(n=5)$, with error bars indicating standard deviations. Two-way ANOVA, Tukey post hoc t-test, $\mathrm{p}<.001 \mathrm{~N}$-acetyl cysteine pre-treated cells vs. non-treated cells of the same oxygen condition and cell line. 


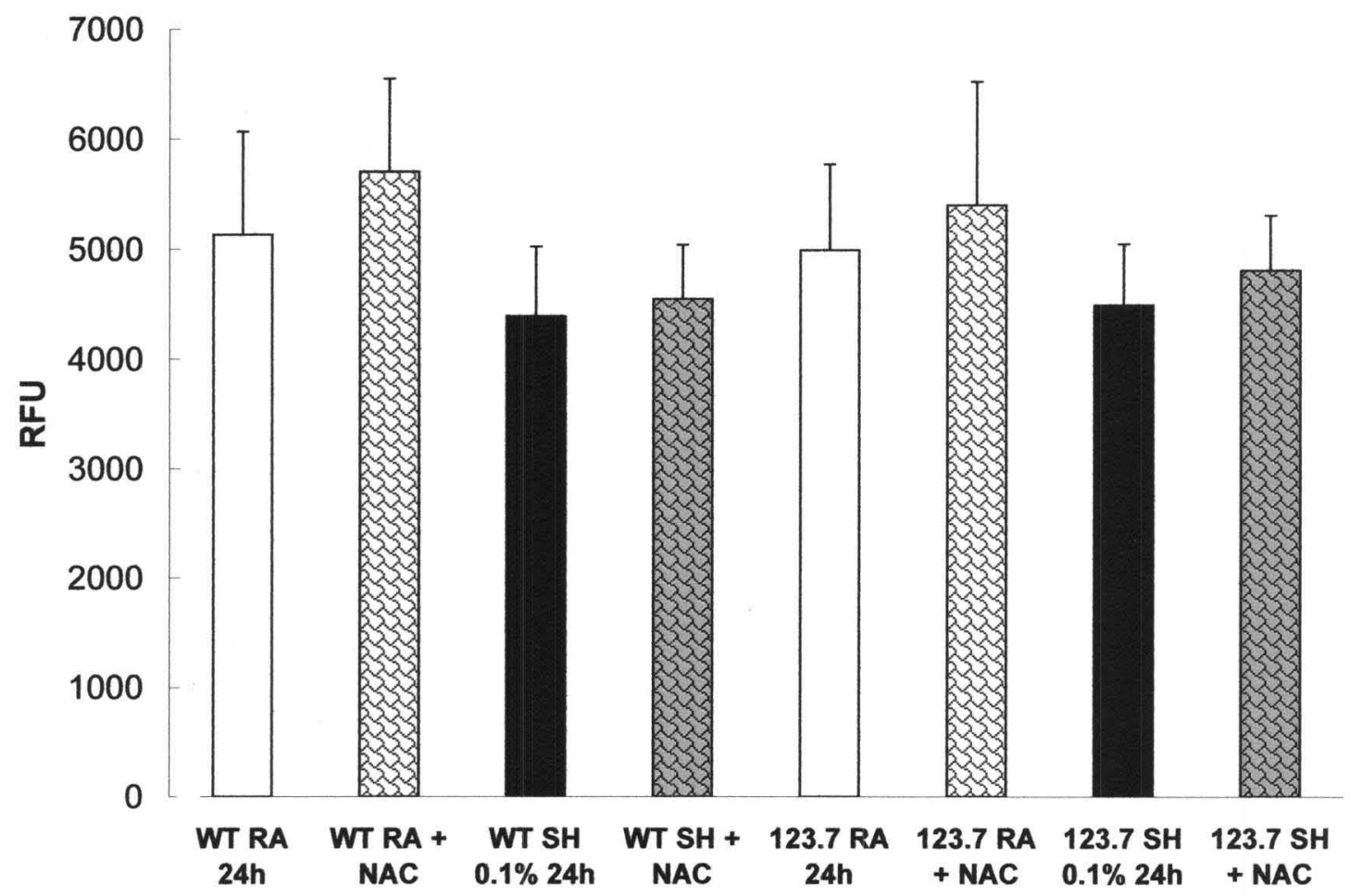

Figure 22. Effect of Antioxidant Treatment on Total Glutathione Levels WT and 123.7 cells were exposed to either room air (RA) or sustained $0.1 \% \mathrm{O}_{2}$ hypoxia (SH $0.1 \%$ ) for $24 \mathrm{~h}$. Total glutathione levels were analyzed in cells pretreated with the antioxidant $\mathrm{N}$-acetyl cysteine relative to untreated controls. Antioxidant treatment did not have an effect on any of the tested groups. Data expressed as the means of relative fluorescence units (RFU) from 5 individual experiments $(n=5)$, with error bars indicating standard deviations. One-way ANOVA statistics did not detect a significant difference between the total glutathione levels of $\mathrm{N}$-acetyl cysteine pre-treated cells vs. non-treated cells in WT or 123.7 cells. 


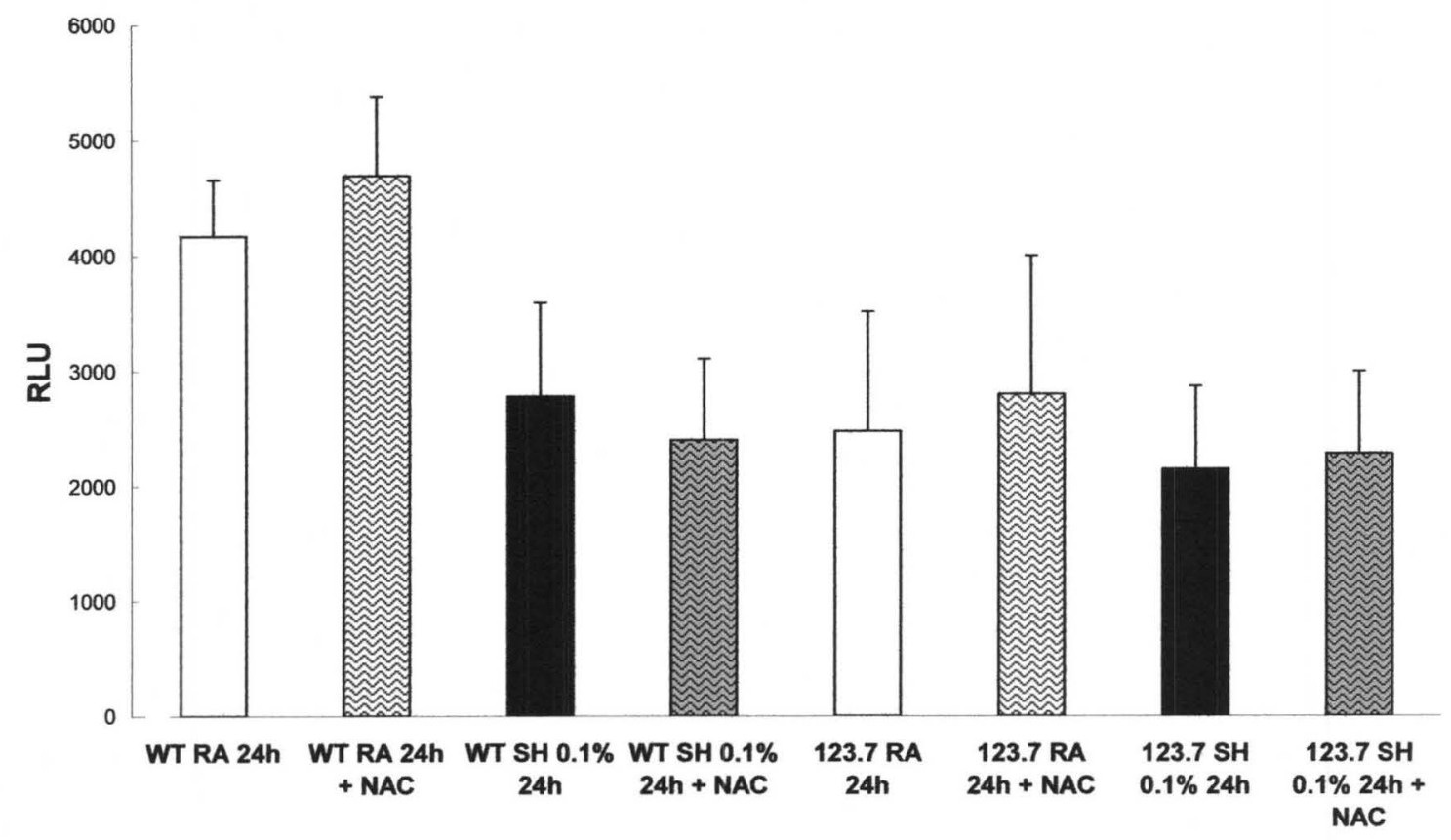

Figure 23. Effect of Antioxidant treatment on ATP levels WT and 123.7 cells were exposed to either room air (RA) or sustained $0.1 \% \mathrm{O}_{2}$ hypoxia $(\mathrm{SH} 0.1 \%$ ) for $24 \mathrm{~h}$. ATP levels were analyzed in cells pre-treated with the antioxidant $\mathrm{N}$ acetyl cysteine relative to untreated controls. Antioxidant treatment had no effect on ATP levels in any of the tested groups. Data expressed as the means of relative luminescence units (RLU) from 4 individual experiments $(n=4)$, with error bars indicating standard deviations. One-way ANOVA statistics did not detect a significant difference between the ATP levels of $\mathrm{N}$-acetyl cysteine pre-treated cells vs. non-treated cells in WT or 123.7 cells. 


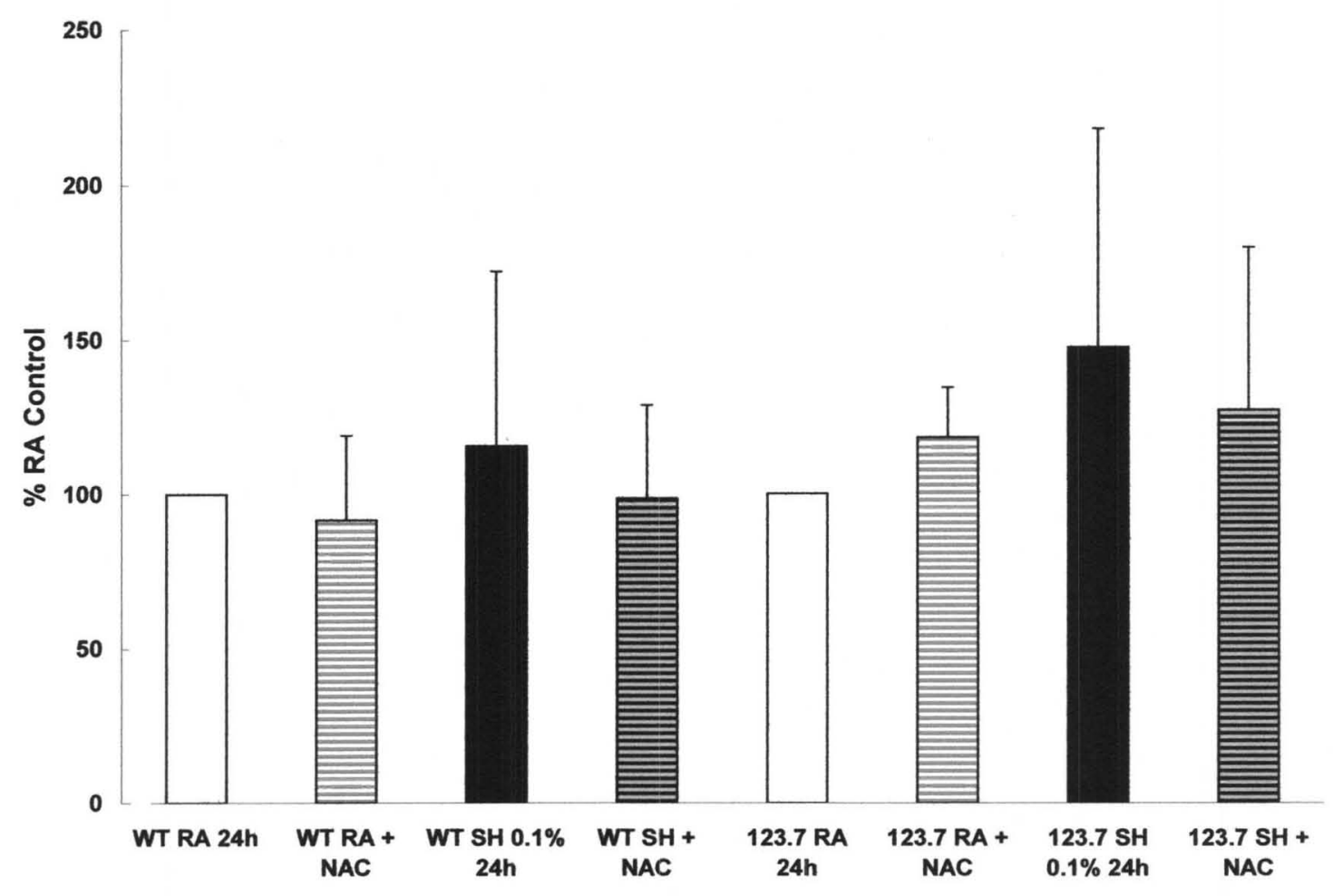

Figure 24. Effect of Antioxidant treatment on cAMP levels WT and 123.7 cells were exposed to either room air (RA) or sustained $0.1 \% \mathrm{O}_{2}$ hypoxia ( $\mathrm{SH}$ $0.1 \%$ ) for $24 \mathrm{~h}$. CAMP levels were analyzed in cells pre-treated with the antioxidant $\mathrm{N}$-acetyl cysteine relative to untreated controls. Antioxidant treatment had no effect on the levels of cAMP in any of the tested groups. Data expressed as the means of 5-6 individual experiments ( $n=5-6)$, with error bars indicating standard deviations. One-way ANOVA statistics did not detect a significant difference between the cAMP levels of $\mathrm{N}$-acetyl cysteine pre-treated cells vs. non-treated cells in WT or 123.7 cells 
Specific Aim 3: To determine whether PKA affects cellular energetic status through regulation of metabolic pathways

3 (A) Effect of PKA on mitochondrial potential and abundance: WT and PKA activity-deficient 123.7 cells had a small, insignificant decrease in JC-1 ratio upon hypoxic exposure (Figure 25). However, 123.7 cells exhibited higher JC-1 red/green ratios than WT cells overall (Figure 25). While treatment with the antioxidant $\mathrm{N}$-acetyl cysteine rescued WT cells from hypoxic cell death, it did not restore RA JC-1 ratios (Figure 25), suggesting that mitochondrial potential is not the primary cause of cell death at $24 \mathrm{~h}$ hypoxia. These data suggests that mitochondrial potential may be compromised at the onset of cellular death, and that PKA may have an inhibitory effect on mitochondrial metabolism.

COX IV expression decreased after 24h SH in both cell lines (Figure 26). However, 123.7 cells displayed significantly higher expression of COX IV than WT cells during RA and SH $0.1 \% 24$ h (Figure 26), suggesting an increase in mitochondrial enzyme or a mitochondrial enrichment when PKA was inactivated. Pretreatment with NAC did not prevent the SH-induced decrease in COX IV expression (Figure 26), suggesting again that increases in ROS may occur independently, or downstream of the hypoxia-induced metabolic changes. 


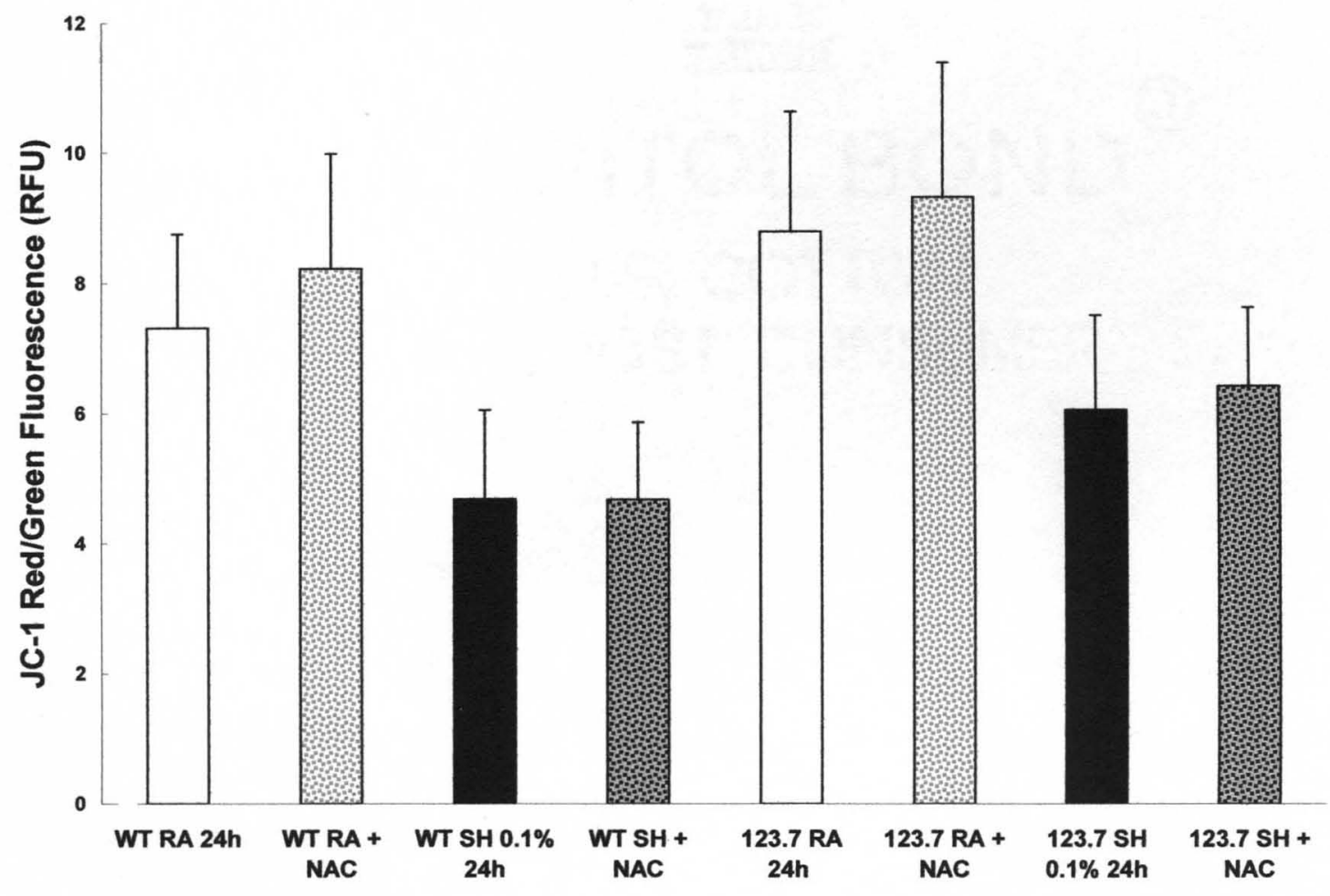

Figure 25. Mitochondrial Potential: JC-1 Assay WT and 123.7 cells were exposed to either room air (RA) or sustained $0.1 \% \mathrm{O}_{2}$ hypoxia $(\mathrm{SH} 0.1 \%$ ) for $24 \mathrm{~h}$.

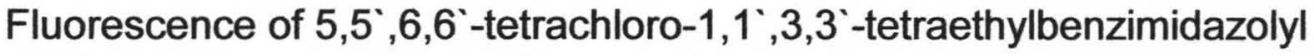
carbocyanine iodide (JC-1) was analyzed as an indicator of mitochondrial potential. Cells were pre-treated with the antioxidant $\mathrm{N}$-acetyl cysteine and compared to untreated controls. Exposure to hypoxia resulted in a small, insignificant decrease in $\mathrm{JC}-1$ fluorescence, but antioxidant treatment had no effect on JC-1 fluorescence ratios. The 123.7 cells, however, had higher overall JC-1 levels than WT cells. Data expressed as the means of relative fluorescence units (RFU) from 5 individual experiments $(n=5)$, with error bars indicating standard deviations. Two-way ANOVA, Tukey post hoc t-test, $\mathrm{p}<.05$ WT vs. 123.7 cells. 


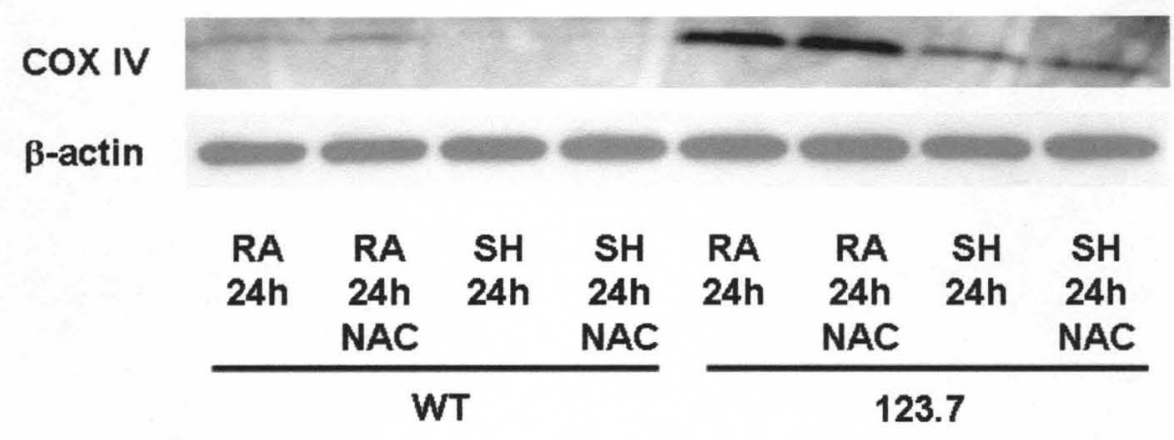

Figure 26. Effect of Antioxidant Treatment on COX IV Expression WT and 123.7 cells were exposed to either room air (RA) or sustained $0.1 \% \mathrm{O}_{2}$ hypoxia (SH $0.1 \%$ ) for $24 \mathrm{~h}$. Cells were pre-treated with the antioxidant $\mathrm{N}$-acetyl cysteine (NAC) and compared to untreated controls. The expression of cytochrome oxidase IV (COX IV) was analyzed and loading efficiency was confirmed through immunoblotting of $\beta$-actin. Both WT and 123.7 cells had a decrease in COX IV expression after $24 \mathrm{~h}$ of hypoxic exposure. However, 123.7 cells displayed higher COX IV expression than WT cells at both room air and sustained hypoxia. $\mathrm{N}$ acetyl cysteine treatment had no effect on COX IV protein levels. Results representative of 3 individual experiments $(n=3)$. 
3 (B) Effect of PKA activity on glycolytic flux: Media glucose levels were lower in normoxic WT cells $24 \mathrm{~h}$ after plating the cells, compared to 123.7 cells (Figure 27), indicating that WT cells have higher rate of glucose consumption and may have higher metabolic requirements for their basal metabolism. Hypoxia enhanced these differences between the cell types, with an increased uptake of glucose in 123.7 cells, but complete depletion of extracellular glucose in WT cells.

Extracellular $\mathrm{pH}$ decreased in both cell types upon hypoxic exposure (Figure 28), but WT cells displayed lower $\mathrm{pH}$ values under normoxic and hypoxic conditions. Hypoxia increased lactate production in both cell types (Figure 29), as expected from their increased glucose utilization, suggesting upregulation of anaerobic metabolism. However, WT cells displayed higher lactate values at normoxic and hypoxic states, indicating that PKA signaling may enhance glycolytic flux.

In addition, WT cells exhibited higher extracellular pyruvate levels under normoxic conditions (Figure 30), but were unaffected by hypoxic exposure. The PKA activity-deficient 123.7 cells displayed an increase in extracellular pyruvate upon hypoxic challenge (Figure 30). 


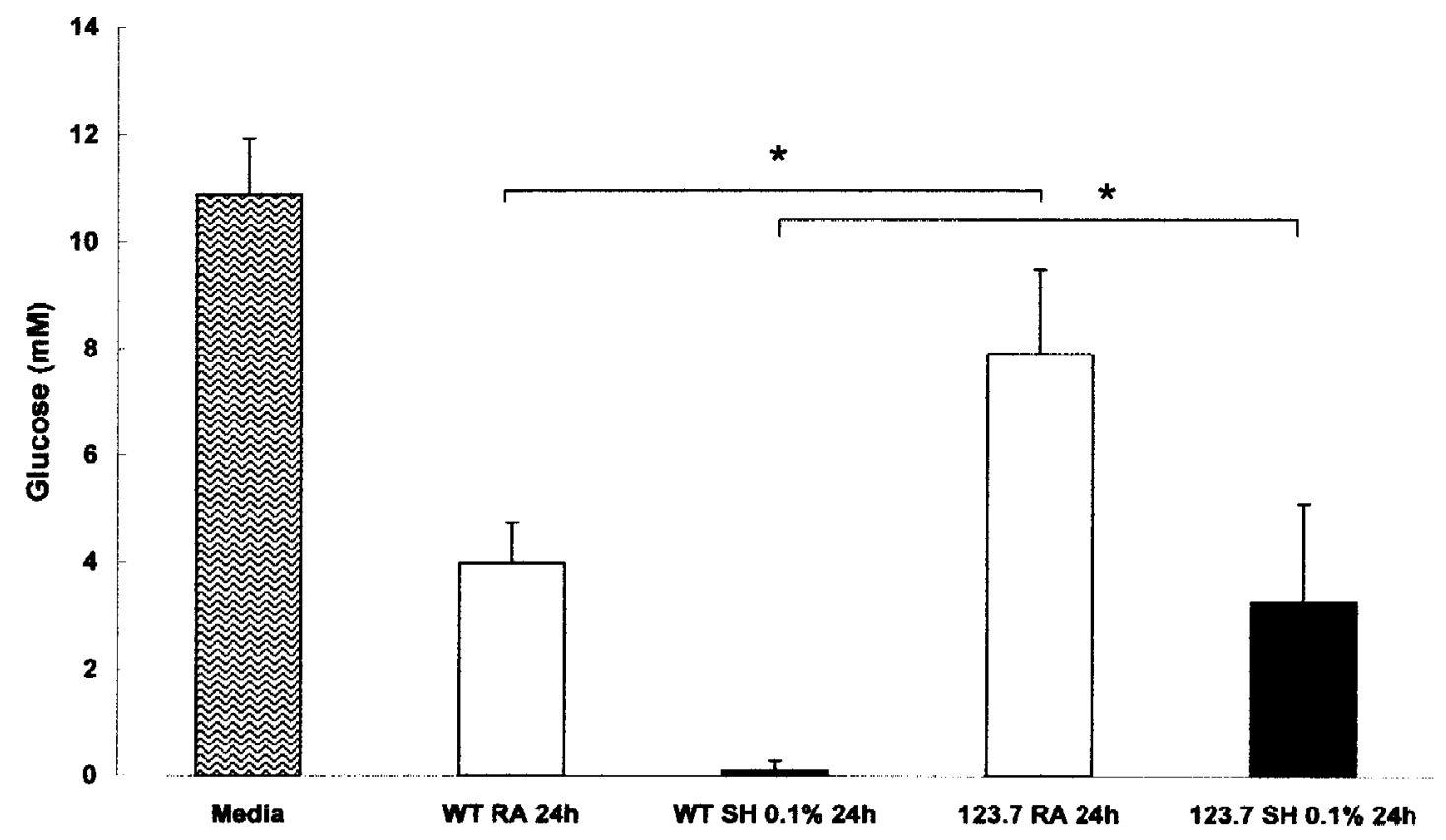

Figure 27. Glyolytic Flux: Extracellular Glucose WT and 123.7 cells were exposed to either room air (RA) or sustained $0.1 \% \mathrm{O}_{2}$ hypoxia ( $\mathrm{SH} 0.1 \%$ ) for $24 \mathrm{~h}$. Extracellular glucose levels were significantly lower in WT cells than in 123.7 cells following 24h of RA exposure. Hypoxic exposure enhanced these differences, with depletion of extracellular glucose stores in the WT cell line. Data expressed as the means of $8-10$ individual experiments $(n=8-10)$, with error bars indicating standard deviations. Two-way ANOVA, Tukey Post-hoc test, * $p<.001$ as indicated. 


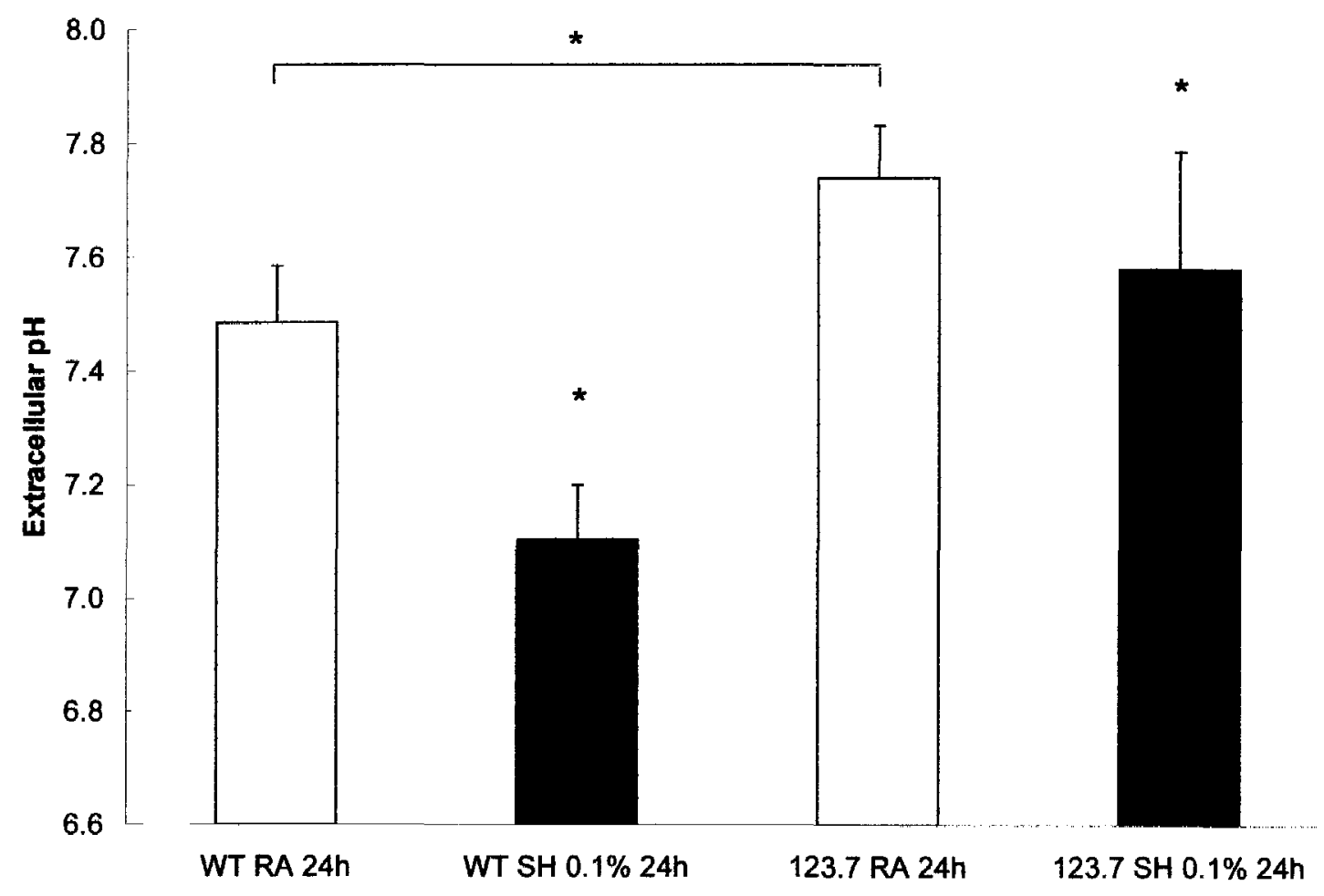

Figure 28: Glycolytic Flux: Extracellular pH WT and 123.7 cells were exposed to either room air (RA) or sustained $0.1 \% \mathrm{O}_{2}$ hypoxia ( $\mathrm{SH} 0.1 \%$ ) for $24 \mathrm{~h}$. Both WT and 123.7 cells had a drop in extracellular $\mathrm{pH}$ following $24 \mathrm{~h}$ of hypoxic exposure. However, extracellular pH was higher in 123.7 cells than in WT cells in both normoxic and hypoxic conditions. Data expressed as the means of 10 individual experiments $(n=10)$, with error bars indicating standard deviations. Tukey Post-hoc test, ${ }^{*} p<.05$ as indicated or RA $24 \mathrm{~h}$ vs. SH $0.1 \% 24 \mathrm{~h}$ in each cell line. 


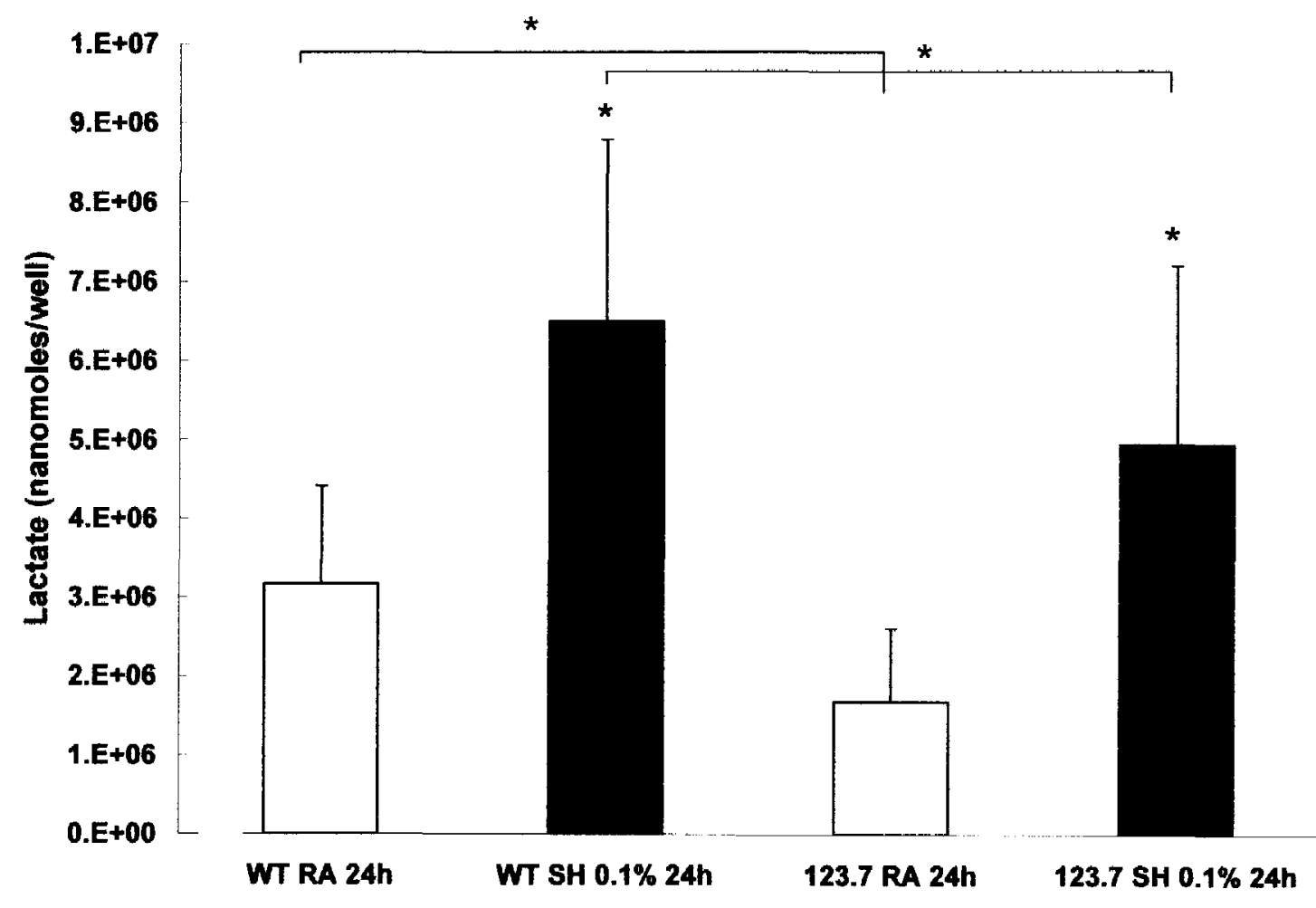

Figure 29. Glycolytic Flux: Extracellular Lactate WT and 123.7 cells were exposed to either room air (RA) or sustained $0.1 \% \mathrm{O}_{2}$ hypoxia ( $\mathrm{SH} 0.1 \%$ ) for $24 \mathrm{~h}$. Extracellular lactate was increased in both WT and 123.7 cells following hypoxic exposure. However, WT cells had higher extracellular lactate levels than 123.7 cells in both normoxic and hypoxic conditions. Data expressed as the means of 10 individual experiments $(n=10)$, with error bars indicating standard deviations. Two-way ANOVA, Tukey Post-hoc test, ${ }^{*} p \leq .001$ as indicated or RA $24 \mathrm{~h}$ vs. SH $0.1 \% 24 \mathrm{~h}$ in each cell type. 


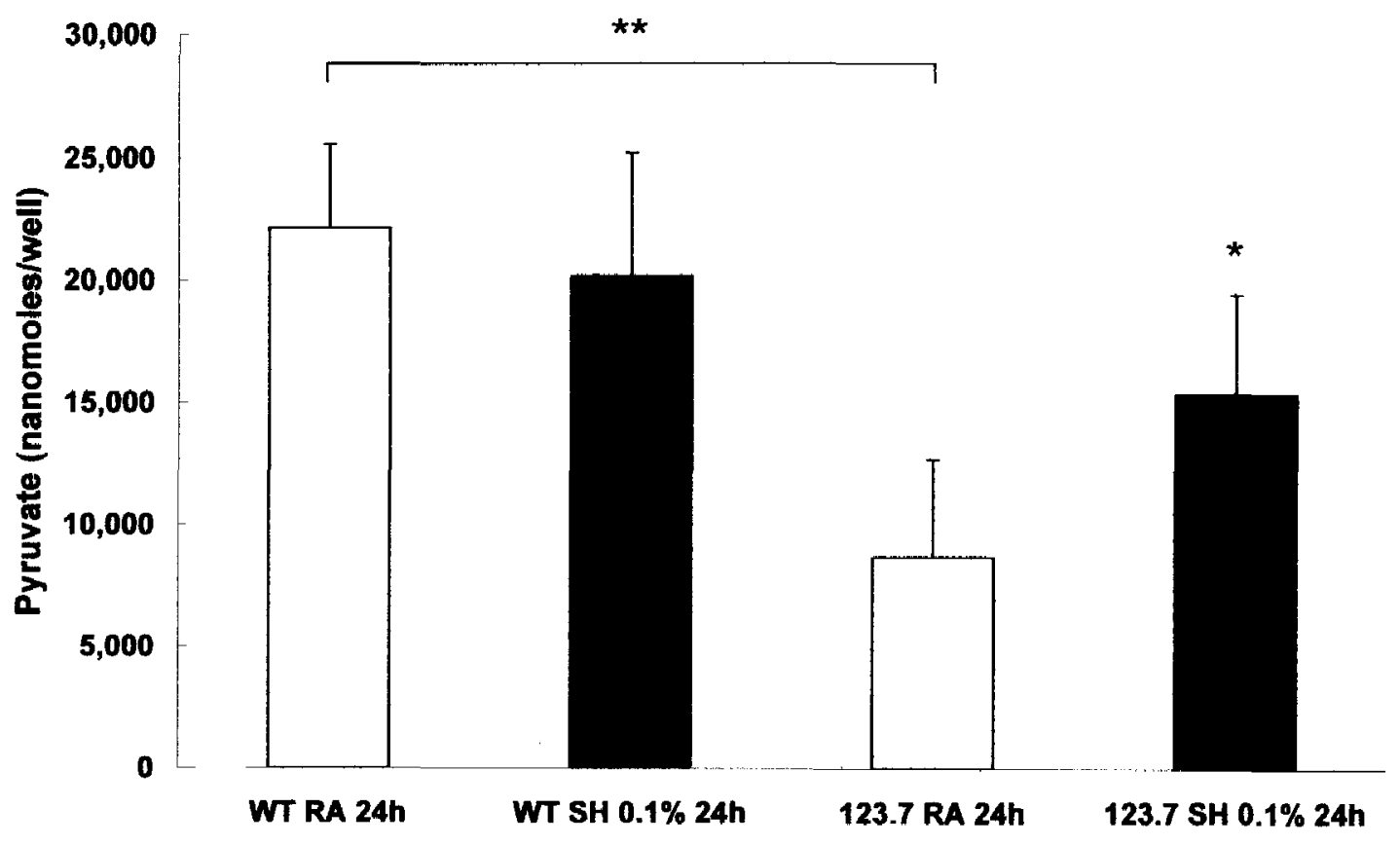

Figure 30. Glycolytic Flux: Extracellular Pyruvate WT and 123.7 cells were exposed to either room air (RA) or sustained $0.1 \% \mathrm{O}_{2}$ hypoxia (SH $0.1 \%$ ) for $24 \mathrm{~h}$. WT cells had a higher level of extracellular pyruvate than 123.7 cells under normoxic conditions, but experienced no change in extracellular pyruvate after 24h of sustained hypoxia. The 123.7 cells, however, had significantly higher levels of extracellular pyruvate following hypoxic exposure. Data expressed as the means of 10 individual experiments $(n=10)$, with error bars indicating standard deviations. Two-way ANOVA, Tukey Post-hoc text, ${ }^{* *} p<.001$ as indicated, ${ }^{*} p<.01 \mathrm{RA} 24 \mathrm{~h}$ vs. SH $0.1 \% 24 \mathrm{~h}$ in each cell type. 
3 (C) Effect of Hypoxia-Induced Oxidant Stress on Glycolytic Flux: Extracellular glucose levels were unaffected by antioxidant treatment with $\mathrm{N}$-acetyl cysteine (Figure 31), suggesting that PKA activity may contribute to the upregulation of glucose use under hypoxic states independently from oxidative stress. Hypoxiainduced decreases in pH were also unaffected by NAC treatment (Figure 32). Furthermore, treatment with $\mathrm{N}$-acetyl cysteine did not affect lactate or pyruvate values (Figures 33 and 34), indicating that oxidative stress does not alter glycolytic rate. 


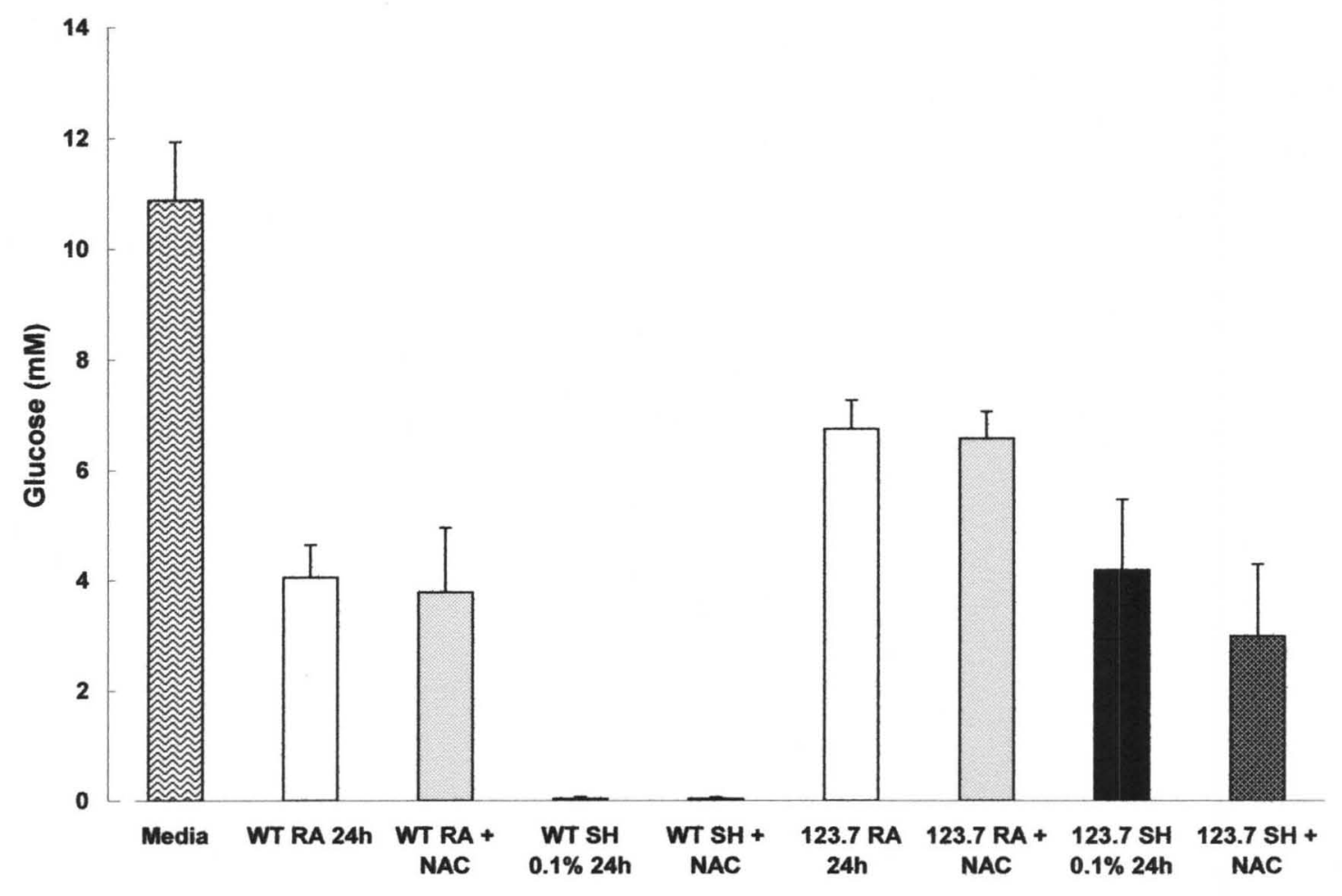

Figure 31. Effect of Antioxidant treatment on Extracellular Glucose WT and 123.7 cells were exposed to either room air (RA) or sustained $0.1 \% \mathrm{O}_{2}$ hypoxia (SH $0.1 \%$ ) for $24 \mathrm{~h}$. Cells were pre-treated with the antioxidant $\mathrm{N}$-acetyl cysteine and compared to untreated controls. One-way ANOVA statistics did not detect a significant difference between the extracellular glucose levels of $\mathrm{N}$-acetyl cysteine pre-treated cells vs. non-treated cells in WT or 123.7 cells. Data expressed as the means of 6-9 individual experiments $(n=6-9)$, with error bars indicating standard deviations. 


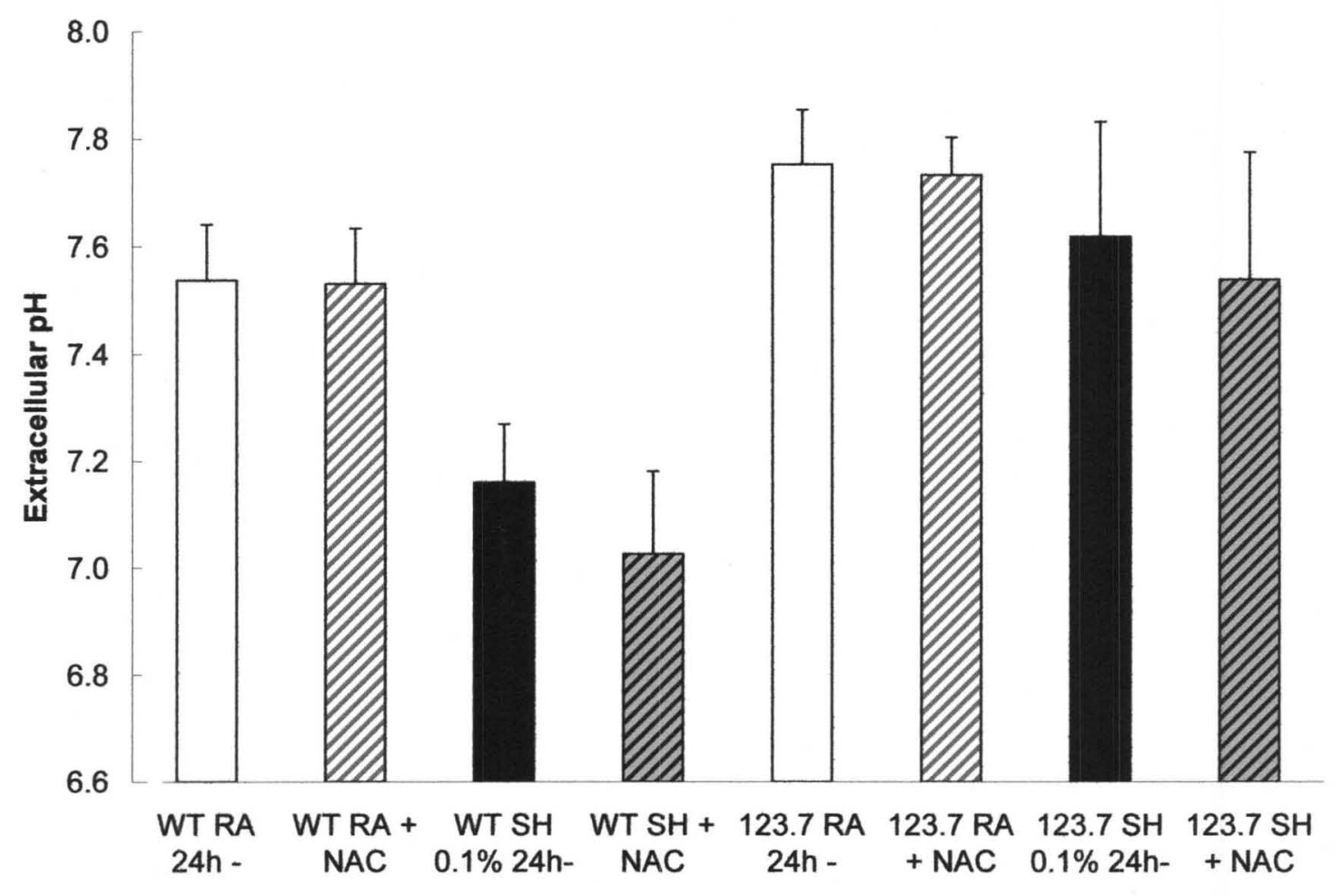

Figure 32. Effect of Antioxidant treatment on Extracellular pH WT and 123.7 cells were exposed to either room air (RA) or sustained $0.1 \% \mathrm{O}_{2}$ hypoxia ( $\mathrm{SH}$ $0.1 \%$ ) for $24 \mathrm{~h}$. Cells were pre-treated with the antioxidant $\mathrm{N}$-acetyl cysteine and compared to untreated controls. One-way ANOVA statistics did not detect a significant difference between the extracellular $\mathrm{pH}$ levels of $\mathrm{N}$-acetyl cysteine pretreated cells vs. non-treated cells in WT or 123.7 cells. Data expressed as the means of 7 individual experiments $(n=7)$, with error bars indicating standard deviations. 


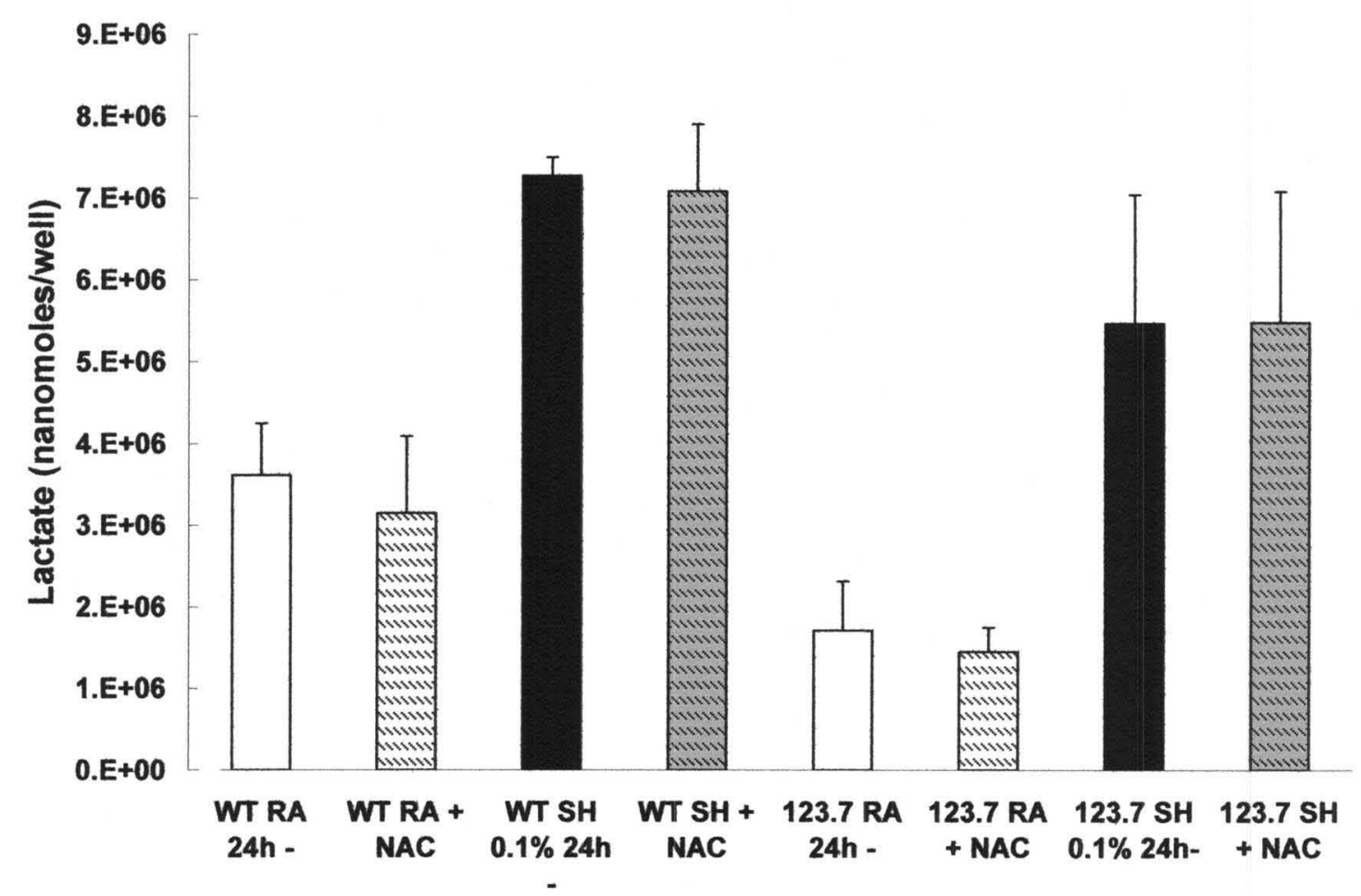

Figure 33. Effect of Antioxidant Treatment on Extracellular Lactate WT and 123.7 cells were exposed to either room air (RA) or sustained $0.1 \% \mathrm{O}_{2}$ hypoxia $(\mathrm{SH} 0.1 \%)$ for $24 \mathrm{~h}$. Cells were pre-treated with the antioxidant $\mathrm{N}$-acetyl cysteine and compared to untreated controls. One-way ANOVA statistics did not detect a significant difference between the extracellular lactate levels of $\mathrm{N}$-acetyl cysteine pre-treated cells vs. non-treated cells in WT or 123.7 cells. Data expressed as the means of 7 individual experiments $(n=7)$, with error bars indicating standard deviations. 


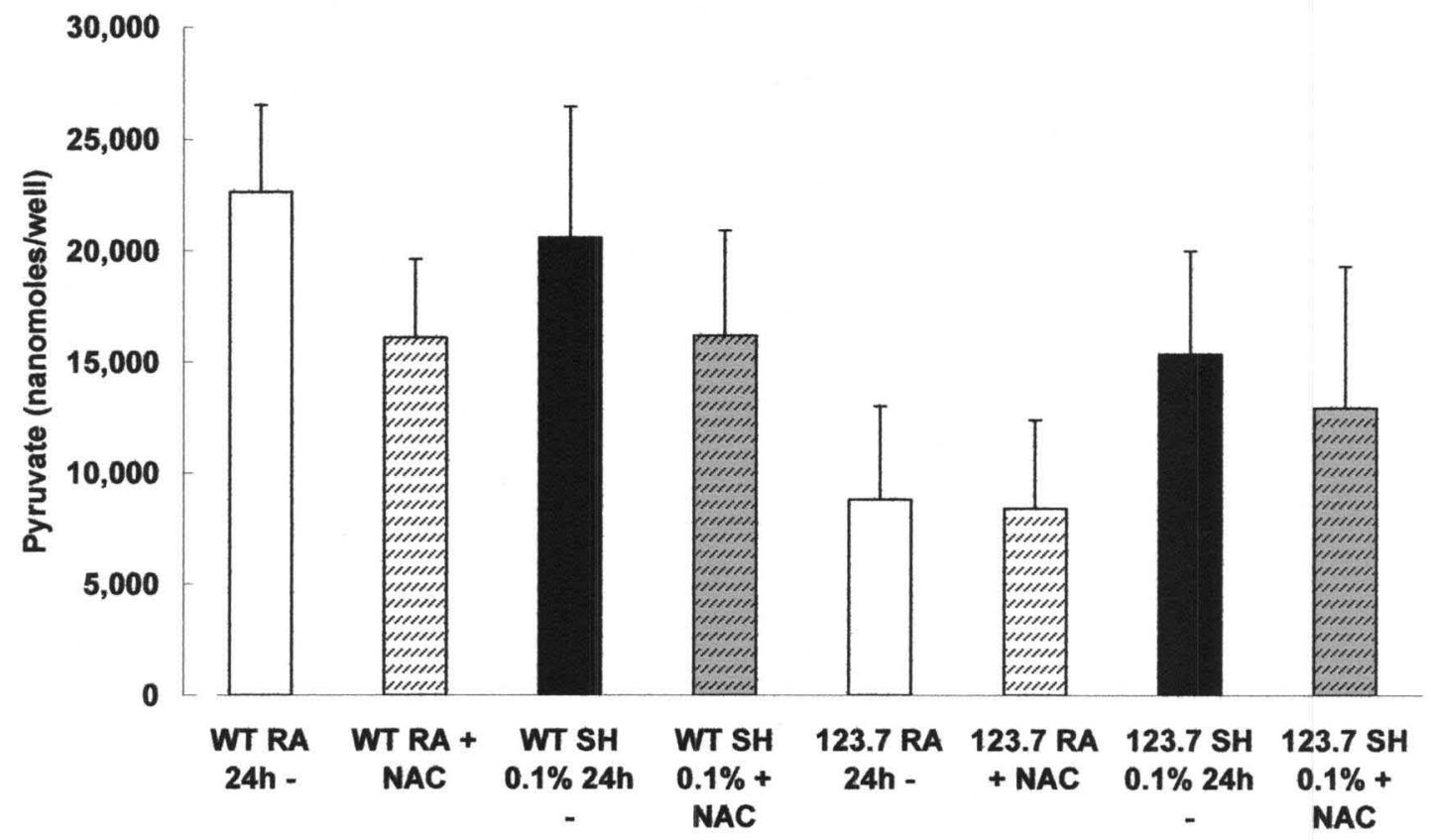

Figure 34. Effect of Antioxidant Treatment on Extracellular Pyruvate WT and 123.7 cells were exposed to either room air (RA) or sustained $0.1 \% \mathrm{O}_{2}$ hypoxia ( $\mathrm{SH} 0.1 \%$ ) for $24 \mathrm{~h}$. Cells were pre-treated with the antioxidant $\mathrm{N}$-acetyl cysteine and compared to untreated controls. One-way ANOVA statistics did not detect a significant difference between the extracellular pyruvate levels of $\mathrm{N}$ acetyl cysteine pre-treated cells vs. non-treated cells in WT or 123.7 cells. Data expressed as the means of 10 individual experiments $(n=10)$, with error bars indicating standard deviations. 
Specific Aim 4: To determine whether restoration of PKA activity in 123.7 cells will abrogate differences in hypoxic susceptibility and energy homeostasis between the two cell types.

Transfection of 123.7 cells with active PKA catalytic $\alpha$ subunit: 123.7 cells were transfected with plasmids encoding active PKA catalytic $\alpha$ subunit to restore PKA activity in these cells. Over-expression of PKA cat $\alpha$ was verified by Western blotting and PKA activity assays. Western blotting displayed an increase in PKA cat $\alpha$ expression in transfected cells at both RA and SH (Figure 35). Increased PKA enzymatic activity in transfected 123.7 cells after $24 \mathrm{~h}$ SH was detected by PKA activity assays, which also verified transfection efficiency (Figure 36). 
PKA cat $-\alpha$

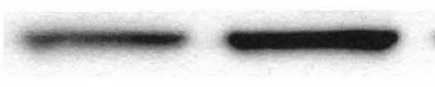

$\beta$-actin

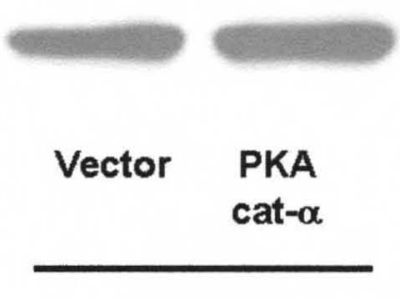

RA

$24 h$

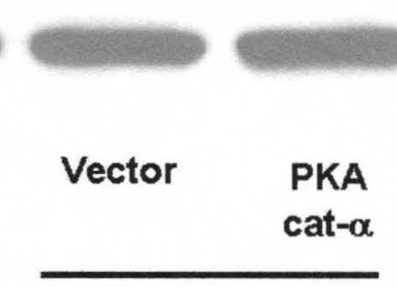

SH

$0.1 \%$

$24 \mathrm{~h}$

\subsection{Cells}

Figure 35. Effect of PKA cat $\alpha$ Transfection on PKA cat $\alpha$ expression PKA activity-deficient 123.7 cells were transfected with empty vectors or plasmids encoding the active catalytic subunit of Protein Kinase A (PKA cat- $\alpha$ ). Following transfection, cells were exposed to either room air (RA) or sustained $0.1 \% \mathrm{O}_{2}$ hypoxia (SH $0.1 \%$ ) for $24 \mathrm{~h}$. The expression of PKA cat- $\alpha$ was analyzed and loading efficiency was verified through immunoblotting of $\beta$-actin. The mutant 123.7 cells transfected with the active catalytic subunit of PKA had increased expression of PKA cat- $\alpha$ under room air and sustained hypoxia conditions. Results representative of 7 individual experiments $(n=7)$. 


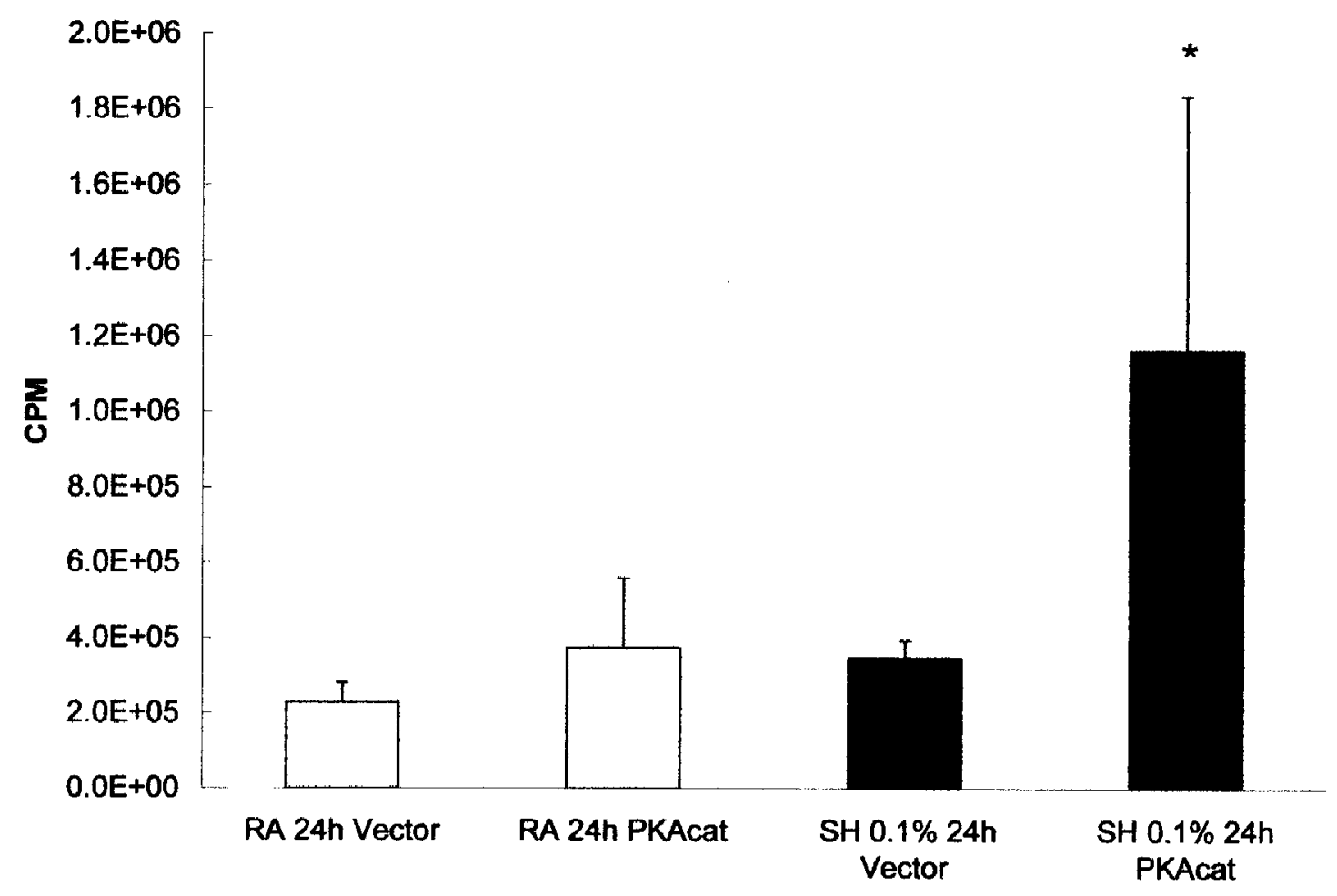

Figure 36. Effect of PKA cat $\alpha$ Transfection on PKA Activity levels PKA activity-deficient 123.7 cells were transfected with empty vectors or plasmids encoding the active catalytic subunit of Protein Kinase A (PKA cat- $\alpha$ ). Following transfection, cells were exposed to either room air (RA) or sustained $0.1 \% \mathrm{O}_{2}$ hypoxia (SH $0.1 \%$ ) for $24 \mathrm{~h}$. The mutant 123.7 cells transfected with PKA cat- $\alpha$ plasmids had higher levels of PKA activity than the vector controls under hypoxic conditions. Data expressed as the means of the counts per minute (CPM) of 5 individual experiments $(n=5)$, with error bars indicating standard deviations. Twoway ANOVA, Tukey post hoc t-test, " $p<.005$ PKA cat $\alpha$ transfected cells vs. vector controls of the same oxygen condition. 
Effect of PKA cat $\alpha$ transfection on hypoxia-induced ROS production and cell

death: Transfection of 123.7 cells with an active catalytic subunit of PKA led to a significant increase in hypoxia induced ROS production at $24 \mathrm{~h}$ relative to $R A$ controls (Figure 37). However, WT cells still exhibited a larger increase in DCF fluorescence upon hypoxic challenge. Furthermore, the increase in ROS formation upon transfection in 123.7 cells did not result in a concomitant increase in cellular death, even after hypoxic challenge, as shown by Trypan Blue exclusion assays (Figure 38). Thus, although partially restoring PKA cat $\alpha$ in the 123.7 cells increased ROS response to hypoxic challenge, the response was significantly below WT cell levels (Figure 37) and the resulting oxidative stress did not induce cell death. These data suggests that additional signaling events may contribute to ROS formation and cell death in WT cells. 


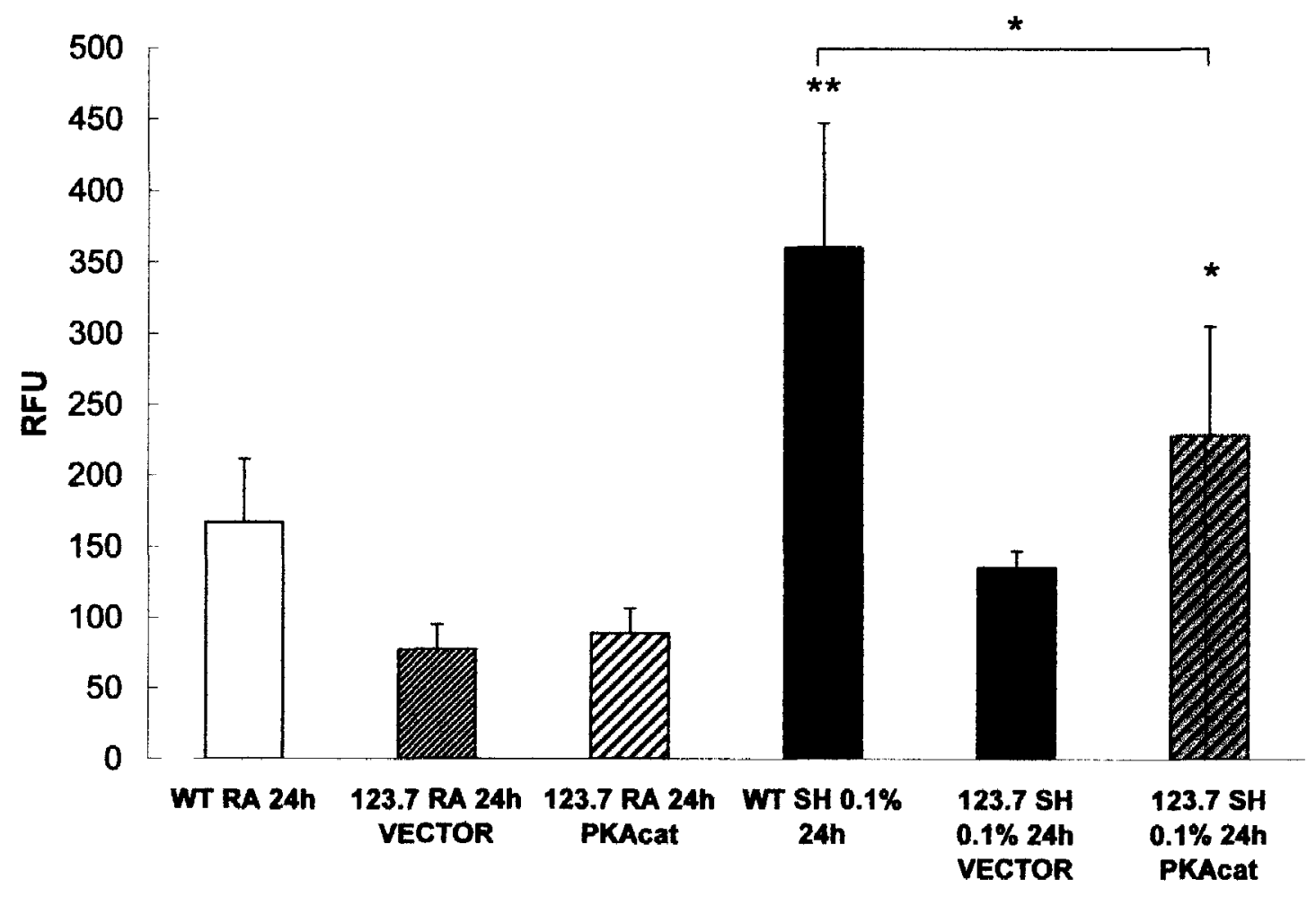

Figure 37. Effect of PKA cat $\alpha$ Transfection on Hypoxia-induced ROS Levels PKA activity-deficient 123.7 cells were transfected with empty vectors or plasmids encoding the active catalytic subunit of Protein Kinase A (PKA cat- $\alpha$ ). WT and 123.7 cells were exposed to either room air (RA) or sustained $0.1 \% \mathrm{O}_{2}$ hypoxia ( $\mathrm{SH} 0.1 \%$ ) for $24 \mathrm{~h}$. ROS levels, as detected by dichlorofluorescein (DCF) fluorescence, were significantly increased in WT cells following $24 \mathrm{~h}$ of severe hypoxia, while 123.7 cells transfected with empty vectors experienced no significant alterations in DCF fluorescence. The mutant 123.7 cells transfected with PKA cat- $\alpha$ had a significant increase in DCF fluorescence following hypoxic exposure, but these values were lower than WT cells. Data expressed as the means of relative fluorescence units (RFU) from 5 individual experiments $(n=5)$, with error bars indicating standard deviations. Two-way ANOVA, Tukey post hoc 
t-test, " $p<.005$ as indicated or PKA cat $\alpha$ transfected cells vs. vector controls of the same oxygen condition, ${ }^{* *} p<.001$ RA $24 \mathrm{~h}$ vs. SH $0.1 \% 24 \mathrm{~h}$. 


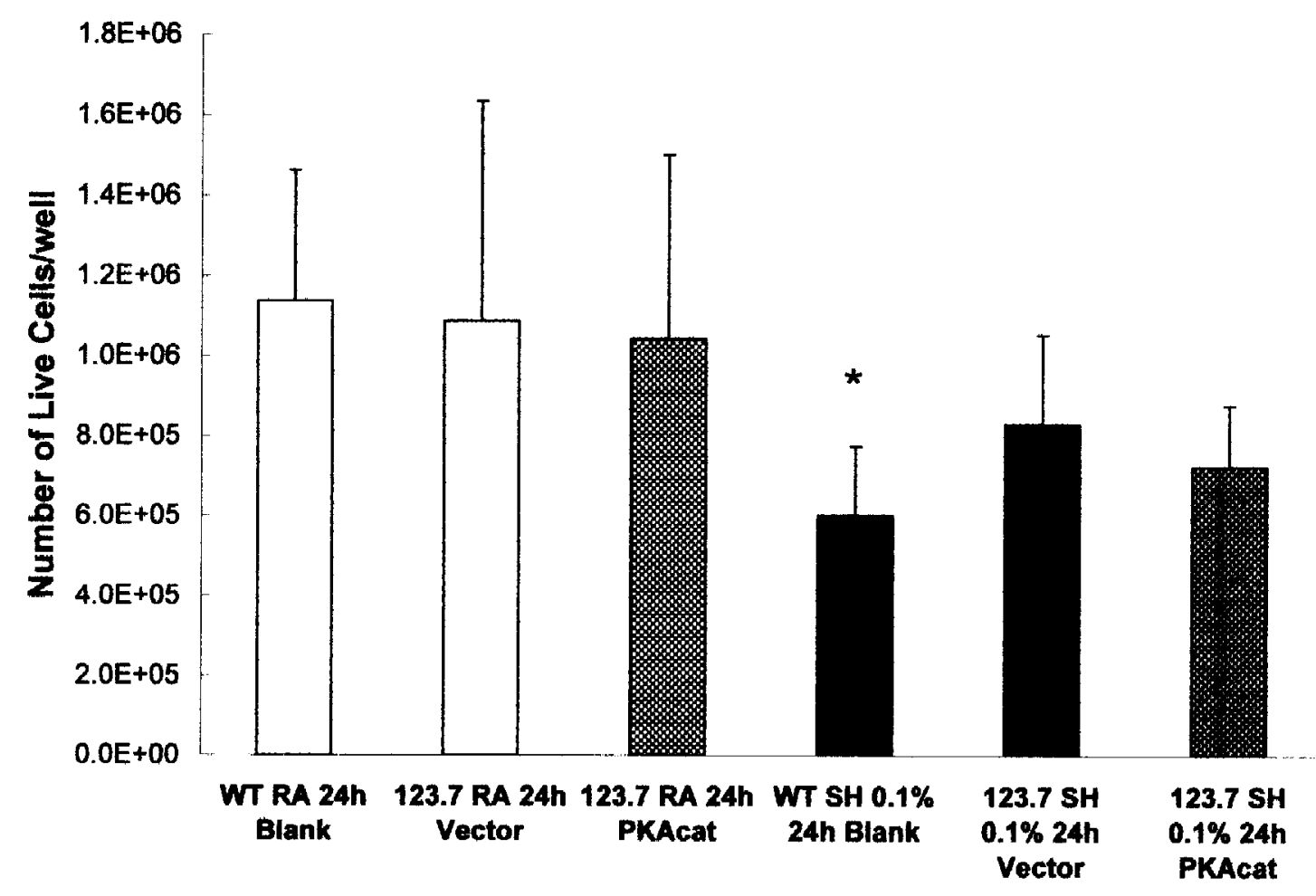

Figure 38. Effect of PKA cat $\alpha$ Transfection on Hypoxia-induced Cell Death PKA activity-deficient 123.7 cells were transfected with empty vectors or plasmids encoding the active catalytic subunit of Protein Kinase A (PKA cat- $\alpha$ ). WT and 123.7 cells were exposed to either room air (RA) or sustained $0.1 \% \mathrm{O}_{2}$ hypoxia ( $\mathrm{SH} 0.1 \%$ ) for $24 \mathrm{~h}$. Cell viability was assessed using the Trypan Blue exclusion assay. The number of live cells per well was significantly decreased in WT cells following $24 \mathrm{~h}$ of severe hypoxia, while transfected 123.7 cells had no change in the number of live cells. Data expressed as the means of 10 individual experiments $(n=10)$, with error bars indicating standard deviations. Two-way ANOVA, Tukey post hoc t-test, " $p<.05$ RA $24 \mathrm{~h}$ vs. SH $0.1 \% 24 \mathrm{~h}$ for one cell line. 
Effect of PKA cat a transfection on hypoxia-induced metabolic response:

Transfection of 123.7 cells with PKA cat $\alpha$ did not significantly change extracellular pH (Figure 39), glucose consumption (Figure 40), lactate release (Figure 41), pyruvate release (Figure 42), or COX IV expression (Figure 43) relative to empty vector controls or untransfected cells. These findings suggest that increased PKA activity affects ROS levels, without altering cell metabolism. However, it can not be ruled out that prolonged PKA activation may be necessary for upregulation of metabolism to the levels seen in WT cells. Alternatively, a more sustained increase in ROS levels triggers metabolic responses which may be induced by $\mathrm{HIF}-1 \alpha$ or $\mathrm{NF}-\mathrm{kB}$ transcriptional activation. 


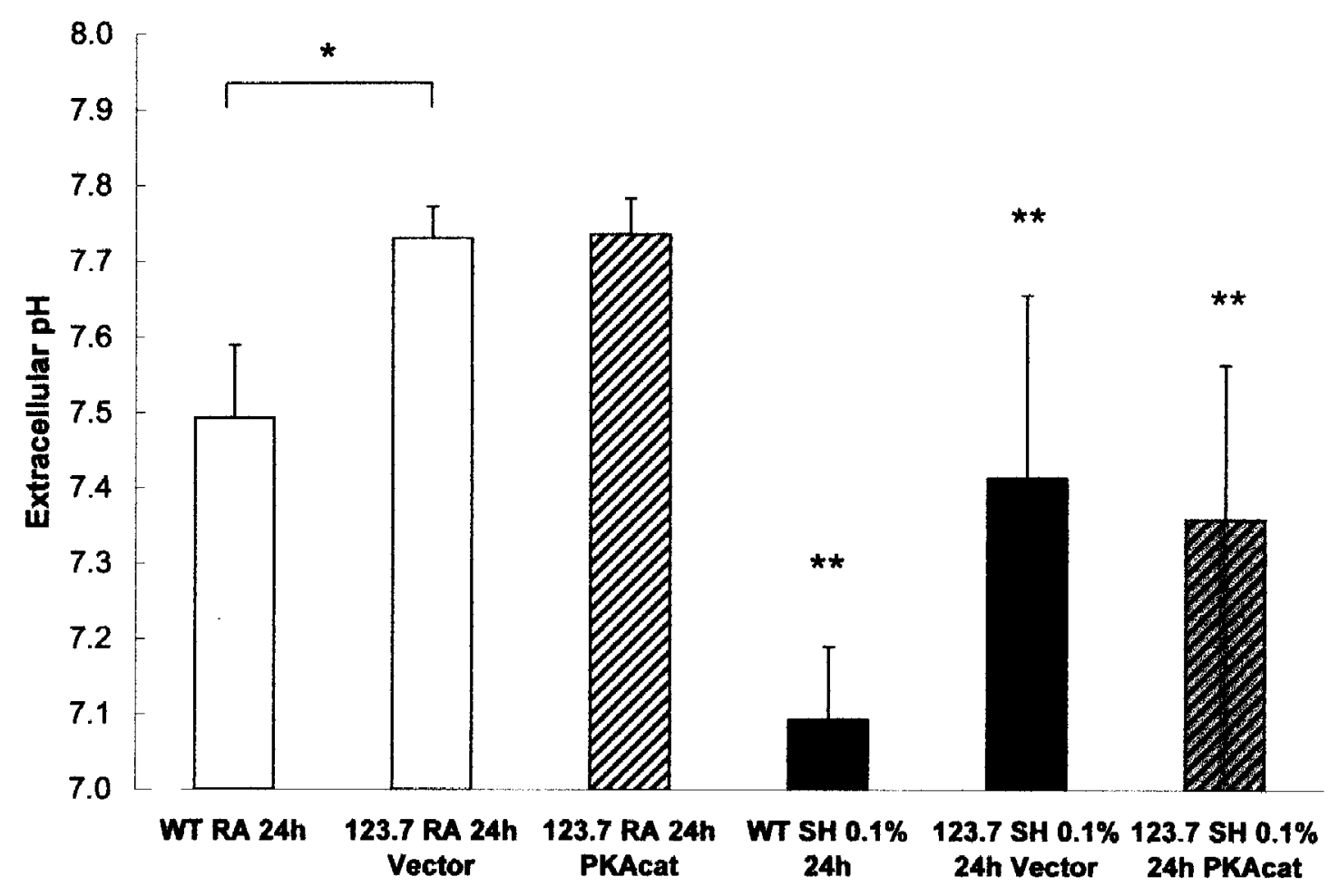

Figure 39. Effect of PKA cat $\alpha$ Transfection on Extracellular pH PKA activity-deficient 123.7 cells were transfected with empty vectors or plasmids encoding the active catalytic subunit of Protein Kinase A (PKA cat- $\alpha$ ). WT and 123.7 cells were exposed to either room air (RA) or sustained $0.1 \% \mathrm{O}_{2}$ hypoxia (SH $0.1 \%$ ) for $24 \mathrm{~h}$. Both WT and transfected 123.7 cells had a drop in extracellular $\mathrm{pH}$ following $24 \mathrm{~h}$ of hypoxic exposure. However, extracellular $\mathrm{pH}$ levels were higher in transfected 123.7 cells than in WT cells in both normoxic and hypoxic conditions. Transfection of the 123.7 cells with PKA cat- $\alpha$ had no effect on the extracellular $\mathrm{pH}$ levels relative to the vector-transfected 123.7 cells. Data expressed as the means of 10 individual experiments $(n=10)$, with error bars indicating standard deviations. Two-way ANOVA, Tukey post hoc t-test, * $p<.01$ as indicated, ${ }^{* \star} p<.001$ RA $24 \mathrm{~h}$ vs. SH $0.1 \% 24 \mathrm{~h}$ for each condition. 


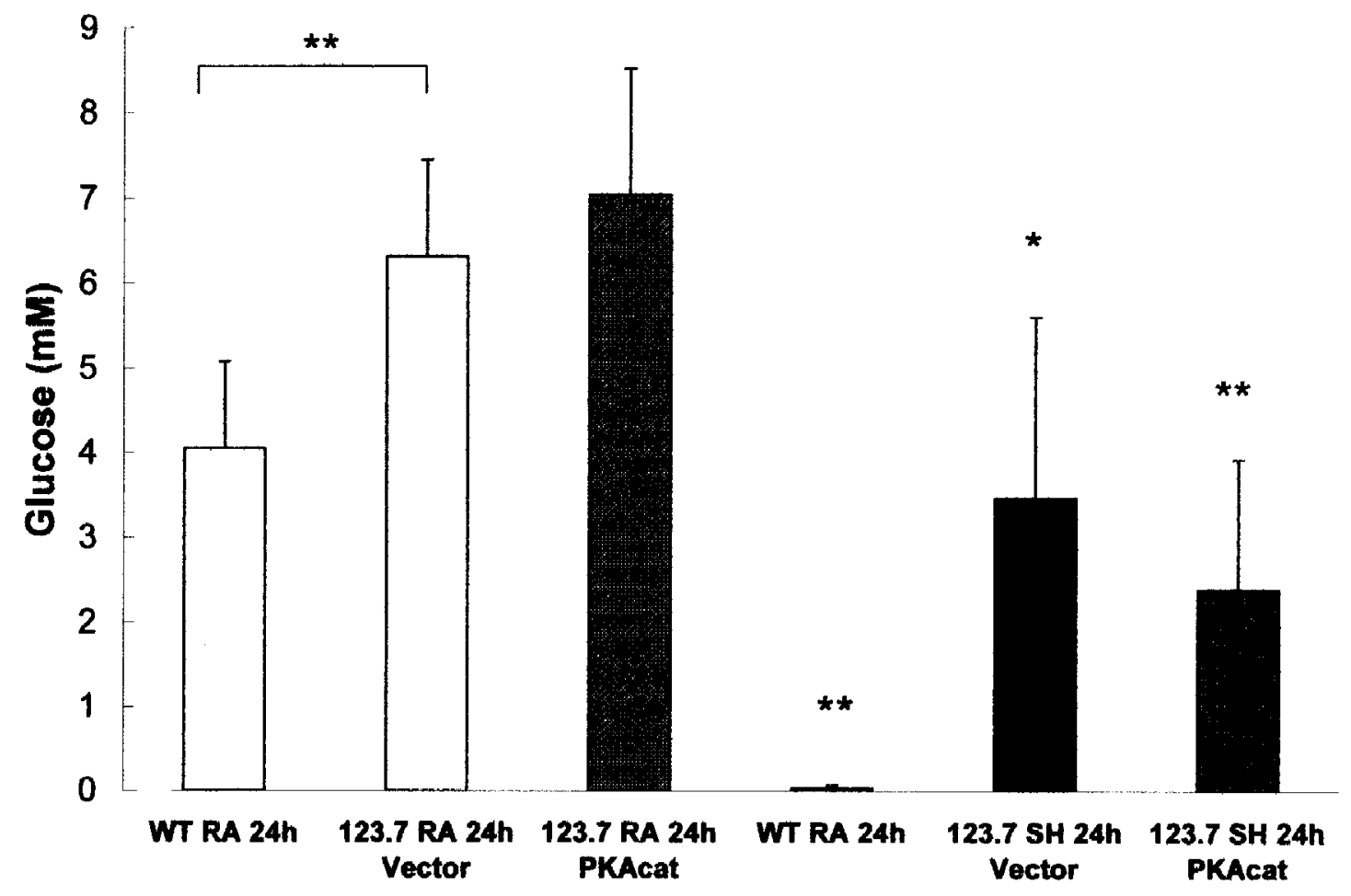

Figure 40. Effect of PKA cat $\alpha$ Transfection on Extracellular Glucose PKA activity-deficient 123.7 cells were transfected with empty vectors or plasmids encoding the active catalytic subunit of Protein Kinase A (PKA cat- $\alpha$ ). WT and 123.7 cells were exposed to either room air (RA) or sustained $0.1 \% \mathrm{O}_{2}$ hypoxia (SH $0.1 \%)$ for $24 \mathrm{~h}$. Extracellular glucose levels were significantly lower in WT cells than in transfected 123.7 cells following $24 \mathrm{~h}$ of RA exposure. Hypoxic exposure enhanced these differences, with depletion of extracellular glucose stores in the WT cell line. Transfection of the 123.7 cells with PKA cat- $\alpha$ had no effect on the extracellular glucose levels relative to the vector-transfected 123.7 cells. Data expressed as the means of 4-10 individual experiments $(n=4-10)$, with error bars indicating standard deviations. Two-way ANOVA, Tukey post hoc 
t-test, " $p<.05$ RA $24 \mathrm{~h}$ vs. SH $0.1 \% 24 \mathrm{~h}$ for each condition, ${ }^{\star *} p<.001$ as indicated, or RA $24 \mathrm{~h}$ vs. SH $0.1 \% 24 \mathrm{~h}$ for each condition. 


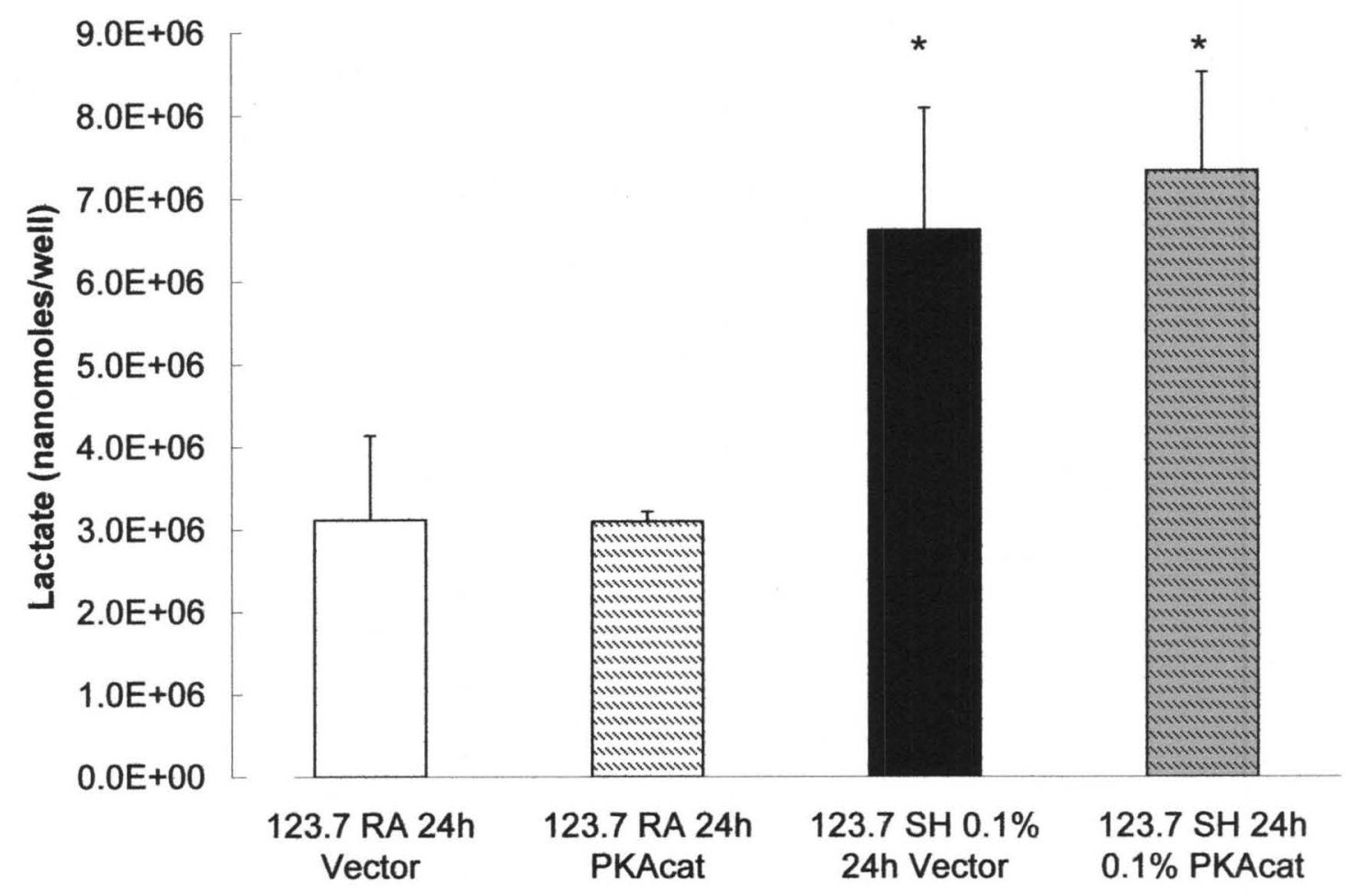

Figure 41. Effect of PKA cat $\alpha$ Transfection on Extracellular Lactate PKAactivity-deficient 123.7 cells were transfected with empty vectors or plasmids encoding the active catalytic subunit of Protein Kinase A (PKA cat- $\alpha$ ). 123.7 cells were exposed to either room air (RA) or sustained $0.1 \% \mathrm{O}_{2}$ hypoxia ( $\mathrm{SH} 0.1 \%$ ) for $24 \mathrm{~h}$. Extracellular lactate was increased in the 123.7 cells following hypoxic exposure, but transfection of the 123.7 cells with PKA cat- $\alpha$ had no effect on the extracellular lactate levels relative to the vector-transfected 123.7 cells. Data expressed as the means of 5 individual experiments $(n=5)$, with error bars indicating standard deviations. Two-way ANOVA, Tukey post hoc t-test, $p \leq .001$ RA $24 \mathrm{~h}$ vs. SH $0.1 \% 24 \mathrm{~h}$ for each condition. 


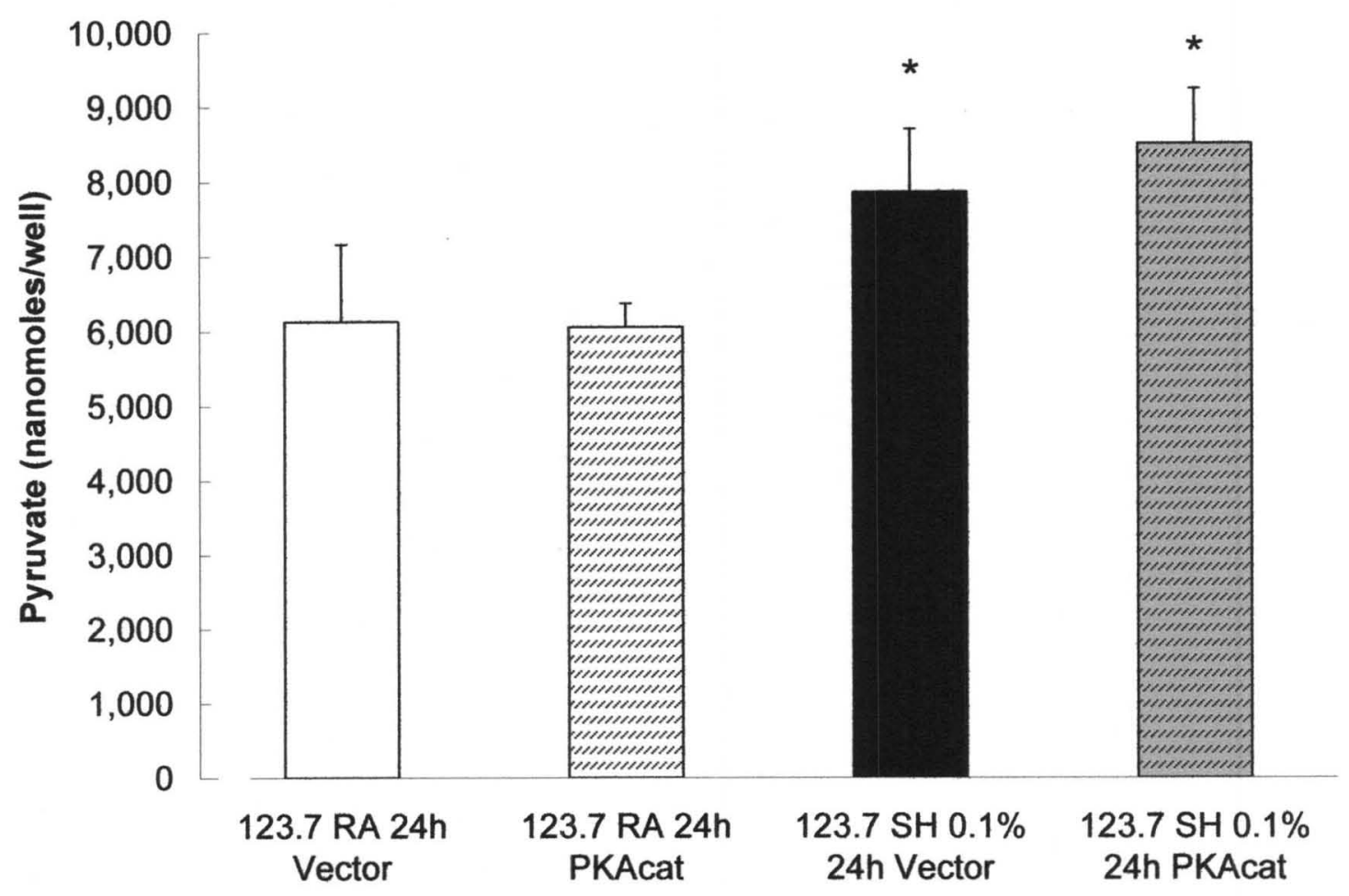

Figure 42. Effect of PKA cat $\alpha$ Transfection on Extracellular Pyruvate PKAactivity-deficient 123.7 cells were transfected with empty vectors or plasmids encoding the active catalytic subunit of Protein Kinase A (PKA cat- $\alpha$ ). 123.7 cells were exposed to either room air (RA) or sustained $0.1 \% \mathrm{O}_{2}$ hypoxia ( $\mathrm{SH} 0.1 \%$ ) for $24 \mathrm{~h}$. The 123.7 cells had significantly higher levels of extracellular pyruvate following hypoxic exposure, but transfection of the 123.7 cells with PKA cat- $\alpha$ had no effect on the extracellular pyruvate levels relative to the vector transfected 123.7 cells. Data expressed as the means of 5 individual experiments $(n=5)$, with error bars indicating standard deviations. Two-way ANOVA, Tukey post hoc ttest, * $p<.05$ RA $24 \mathrm{~h}$ vs. SH $0.1 \% 24 \mathrm{~h}$ for each condition. 


\section{CoX IV}

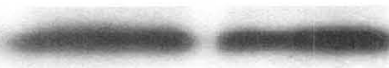

$\beta$-actin

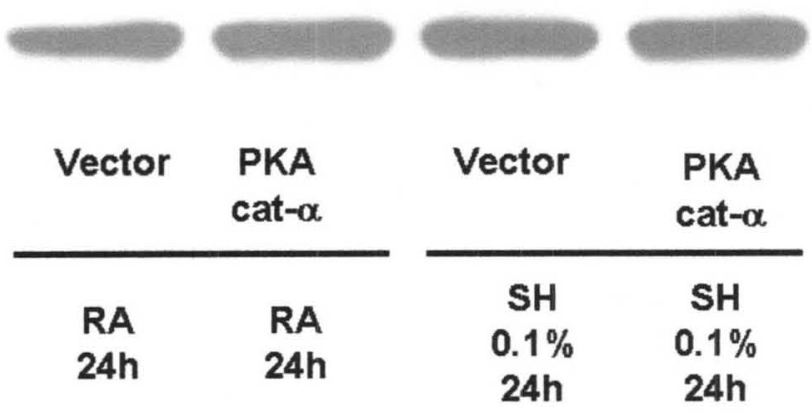

123.7 Cells

Figure 43. Effect of PKA cat $\alpha$ transfection on COX IV expression PKAactivity-deficient 123.7 cells were transfected with empty vectors or plasmids encoding the active catalytic subunit of Protein Kinase A (PKA cat- $\alpha$ ). Cells were exposed to either room air (RA) or sustained $0.1 \% \mathrm{O}_{2}$ hypoxia ( $\mathrm{SH} 0.1 \%$ ) for $24 \mathrm{~h}$. The expression of cytochrome oxidase IV (COX IV) was analyzed and loading efficiency was confirmed through immunoblotting of $\beta$-actin. The 123.7 cells had a decrease in COX IV expression after $24 \mathrm{~h}$ of hypoxic exposure. Transfection of the 123.7 cells with PKA cat- $\alpha$ had no effect on the COX IV expression levels relative to the vector transfected 123.7 cells. Results representative of 5 individual experiments $(n=5)$. 
Effect of PKA cat a transfection on energetic status: Transfection of 123.7 cells resulted in a small, but not statistically significant decrease in ATP levels (Figure 44), likely due to the short serum deprivation called for by the transfection protocol. However, there was no significant difference in ATP levels between 123.7 cells transfected with PKA cat $\alpha$ relative to empty vector controls (Figure 44). Again, it can not be excluded that a longer PKA activation could trigger the upregulation and maintenance of a higher metabolic rate similar to that seen in WT cells. 


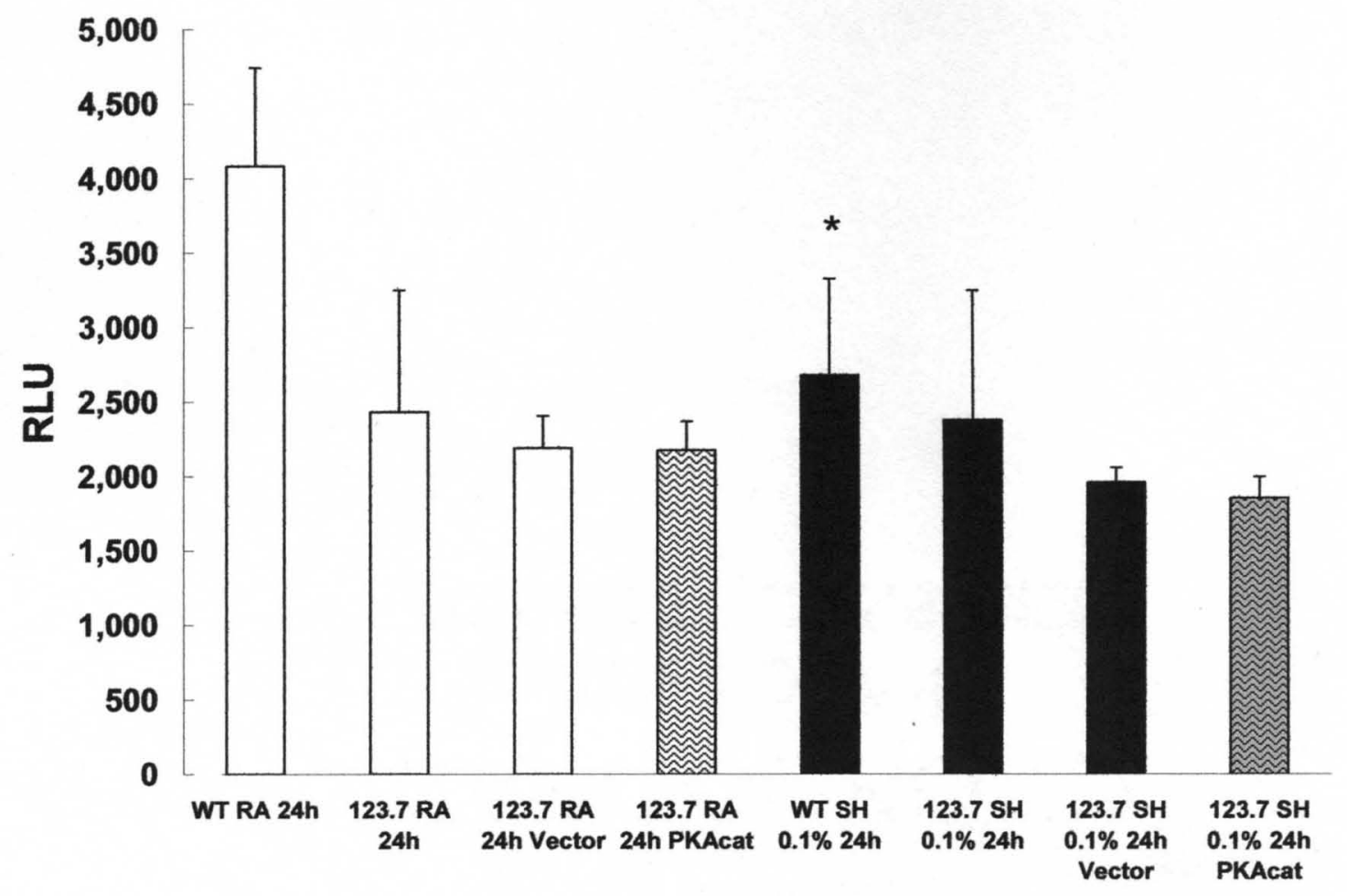

Figure 44. Effect of PKA cat $\alpha$ Transfection on ATP Levels PKA-activitydeficient 123.7 cells were transfected with empty vectors or plasmids encoding the active catalytic subunit of Protein Kinase A (PKA cat- $\alpha$ ). WT and 123.7 cells were exposed to either room air (RA) or sustained $0.1 \% \mathrm{O}_{2}$ hypoxia ( $\mathrm{SH} 0.1 \%$ ) for $24 \mathrm{~h}$. ATP levels were significantly decreased in WT cells following $24 \mathrm{~h}$ of hypoxic exposure, while 123.7 cells had no change in ATP levels. The 123.7 cells also had a lower basal level of ATP than WT cells. Transfection of 123.7 cells with PKA cat- $\alpha$ had no effect on the ATP levels relative to the vectortransfected 123.7 cells or non-transfected 123.7 cells. Data expressed as the means of relative luminescence units $(R L U)$ from 5-7 individual experiments $(n=5-7)$, with error bars indicating standard deviations. Two-way ANOVA, Tukey post hoc t-test, * $\mathrm{p}<.005$ RA $24 \mathrm{~h}$ vs. SH $0.1 \% 24 \mathrm{~h}$ for each condition. 


\section{DISCUSSION}

Hypoxia is characterized by an inadequate oxygen supply to the tissues in proportion to their metabolic needs, and leads to an imbalance in energy production and cell death. While many hypoxic signaling events have been elucidated, the role of the Protein Kinase A (PKA) has yet to be clarified. PKA has been attributed a function as both an anti-apoptotic kinase as well as a proapoptotic signal. Thus the contribution of PKA to hypoxia-induced cell survival is currently unclear.

In order to examine the role of the PKA pathway in hypoxia-induced signaling, I used a genetically altered line of PC-12 cells, 123.7 cells, which have a mutated PKA I regulatory subunit. I hypothesized, based on the current literature, that PKA activity regulates PC-12 hypoxic cell death via oxidative stress and cellular energy depletion. Specific Aim 1 was to determine whether PKA activity affects cellular tolerance to hypoxia and production of oxidant species. WT and 123.7 cells were exposed to either room air or sustained $0.1 \%$ oxygen hypoxia for up to $24 \mathrm{~h}$. WT cells had significant cell death at $24 \mathrm{~h}$ of sustained hypoxia, while the PKA-activity deficient 123.7 cells had no cell death at this time. This indicates that PKA activity contributes to hypoxia-induced cell

death, supporting our hypothesis that PKA regulates PC-12 hypoxic cell death. 
This supports earlier work, in which inhibitors of PKA were shown to have protective effects against ischemia-reperfusion injury in the rabbit heart (17). Activation of PKA has also been shown to be neuroprotective in a variety of neuronal models (31).

A potential mechanism for PKA's deleterious effect in WT cells may involve PKA regulation of the mitochondrial chain enzymes. PKA has been shown to directly phosphorylate complexes I and IV of the mitochondrial electron transport chain $(16,17)$. The phosphorylation of Complex I results in increased activity, while phosphorylation of Complex IV decreases its activity $(16,17)$. Complexes I and III have been identified as potential ROS leakage sites in the mitochondrial electron transport chain (10). Therefore, the PKA-dependent increase in activity of Complex I and decreased activity of Complex IV may result in disruption of the electron flow and increased ROS leakage $(16,17)$. This may shift the redox balance of the cell towards a state of oxidative stress.

Consequently, PKA activity may play a role in the modulation of hypoxia-induced oxidative stress and cellular death.

Indeed, the onset of cell death in WT cells following 24 hours of severe, sustained hypoxia correlates with an increase in oxidative stress as shown by dichlorofluorescein (DCF) assays. In contrast, no such increase was detected in 123.7 cells. These data support our hypothesis that PKA activity contributes to hypoxia-induced oxidative stress. Similar results have been found in rat macrophages and cardiomyocytes, in which PKA activity contributes to the formation of reactive oxygen species in the mitochondrial electron transport chain 
$(17,59)$. Interestingly, neither the GSH/GSSG ratio nor SOD-1 expression were altered in WT cells following hypoxia-induced oxidative stress. The absence of antioxidant response in these cells may indicate that the antioxidant systems in the PC-12 cell line are compromised at $24 \mathrm{~h}$.

The effects of PKA on the function of antioxidant systems have not been well-characterized in the literature. The low levels of detected oxidative stress in 123.7 cells could be due to upregulation of antioxidant systems, and thus enhanced detoxification of ROS. In the WT and 123.7 cells, there were no significant differences in the GSH/GSSG ratio, total glutathione levels, or SOD-1 expression. Consequently, PKA activity does not appear to play a role in the regulation of cellular antioxidant mechanisms in our experimental model. This suggests that 123.7 cells have lower levels of hypoxia-induced ROS production, rather than increased detoxification abilities.

Oxidative stress during hypoxia can directly lead to mitochondrial damage and interruption of energy production by the mitochondrial electron transport chain. Furthermore, during hypoxia, oxidative phosphorylation processes decline and cells must progressively rely on anaerobic metabolism. This can present an energy challenge for the cells, as glycolysis produces a net gain of only 2 ATP relative to the approximately $36-38$ ATP that can be produced by oxidative phosphorylation and glycolytic processes combined.

Specific Aim 2 was to determine whether PKA regulates hypoxia-induced cell death via oxidative stress and/or energy depletion. As expected, severe hypoxia decreased ATP levels by 24 hours in WT cells, indicating that hypoxic 
exposure disrupts energy production. In contrast, 123.7 cells had a lower basal level of ATP that did not further decrease following 24 hours of hypoxic exposure. These data support our hypothesis that PKA activity regulates PC-12 cell death via cellular energy depletion.

cAMP levels were also examined in these cells, as their mutated PKA regulatory subunit prevents binding of cAMP and could thus potentially alter cAMP levels within the cells and lead to changes in the energy pool. However, there was no alteration in cAMP levels between WT and 123.7 cells during normoxic or hypoxic incubation. This corroborates with earlier research showing that the mutation of PKA in 123.7 cells had no effect on cAMP levels (47).

PKA inactivation may allow 123.7 cells to operate at a lower energy cost under both normoxic and hypoxic states. This, in addition to their low ROS levels, could provide a potential mechanism for their higher tolerance to hypoxic injury. It has been well characterized that hypoxia-tolerant reptiles are able to enter into a hypometabolic state and conserve energy $(60,61)$. Although it has been speculated that protein kinases are responsible for the adaptive signaling pathways, the role of PKA has yet to be clarified (60). It is possible, however, that the ROS induced by PKA activity may contribute to hypoxia-induced energy failure.

In order to clarify the role of ROS in PC-12 cell death, WT and 123.7 cells were pre-treated with the antioxidant $\mathrm{N}$-acetyl cysteine (NAC) one hour prior to their hypoxic exposure. $\mathrm{N}$-acetyl cysteine treatment led to a drastic increase in the ratio of reduced/oxidized forms of glutathione under both normoxic and 
hypoxic conditions. However, NAC treatment did not affect the total glutathione levels in either cell line, suggesting that the antioxidant may be directly acting as a reducing agent for the existing pool of glutathione, rather increasing generation of new glutathione. Although the antioxidant function of NAC was previously thought to be due solely to its role in glutathione biosynthesis, more recent work suggests that NAC can also directly detoxify $\operatorname{ROS}(62,63,64)$.

Treatment of WT cells with NAC reduced ROS levels and improved cell survival, indicating that oxidative stress contributes to hypoxia-induced PC-12 cell death. While preventing WT cell death, $\mathrm{N}$-acetyl cysteine pre-treatment failed to restore ATP levels, suggesting that energy depletion during hypoxia may occur independently from oxidative stress. Alternatively, ROS production may be a consequence of metabolic change, occurring downstream of these changes and resulting in cell death. However, in chemical models of hypoxia, antioxidant treatment was found in PC-12 cells to restore ATP levels following administration of cyanide (65). Thus the effect of antioxidant treatment on energy depletion may depend on the type and severity of hypoxic insult, or the antioxidant used.

Specific Aim 3 was to determine whether PKA affects cellular energetic status through regulation of metabolic pathways. PKA has also been linked to the control of the glycolytic rate limiting enzyme, phosphofructokinase, implicating PKA in the regulation of glucose metabolism $(35,36)$. HIF-1 $\alpha$, a hypoxia-regulated transcription factor, recognizes and binds the hypoxia response element, activating transcription of a wide variety of genes. Among these genes are also several glucose transporters and multiple glycolytic 
enzymes. Increased HIF-1 $\alpha$ dependent transcription may provide energy resources allowing the cells to cope with the hypoxic stress. HIF-1 $\alpha$ protein stability and its ability to bind DNA are controlled by phosphorylation and by hydroxyprolination, and requires PKA-dependent transcription factors binding as co-activators for transcriptional activation $(6,37,38)$. Thus, in addition to its effects on oxidative stress, PKA may modulate cellular survival to hypoxia through regulation of metabolic pathways.

To determine whether mitochondrial function is differentially affected by hypoxia in these two cell types, changes in mitochondrial membrane potential were assessed using $\mathrm{JC}-1$, a fluorescent probe sensitive to changes in mitochondrial membrane potential. WT and 123.7 cells exhibited similar mitochondrial membrane potentials under normoxic states and both cell types showed a trend of decrease in JC-1 ratio upon hypoxic exposure. However, overall mean normoxic and hypoxic $\mathrm{JC}-1$ ratios were in higher in 123.7 cells than in WT cells. These data may indicate that PKA has an inhibitory effect on mitochondrial metabolism and contributes to the loss of mitochondrial membrane potential. In cardiomyocytes, the addition of exogenous PKA cat- $\alpha$ leads to a loss of the mitochondrial membrane potential (59).

However, in cardiomyocytes, the actions of PKA cat- $\alpha$ on mitochondrial membrane potential were blocked by administration of an antioxidant (Nagasaki, 2007). Antioxidant treatment was also found in PC-12 cells to restore mitochondrial membrane potential following cyanide treatment (65). In our experimental conditions, antioxidant treatment had no effect on the mitochondrial 
membrane potential. Thus it appears that the mechanism by which PKA controls mitochondrial function may differ according to the cell line and the extent and type of hypoxic insult.

To further examine the effect of PKA activity on mitochondrial function, the expression of cytochrome oxidase (COXIV) was examined. COXIV is the last enzymatic complex in the mitochondrial electron transport chain. Hypoxia decreases the $V_{\max }$ of cytochrome oxidase, resulting in production of ROS due to the improper flow of electrons and leakage of oxidant radically mainly at the levels of Complexes I and III $(14,15)$. COX IV expression was significantly higher in 123.7 cells relative to WT cells during both RA and SH, suggesting either an increase in mitochondrial enzyme or in mitochondrial number with PKA inactivation. As expected, COX IV expression was decreased upon hypoxic exposure in both cell types. Antioxidant treatment had no effect on COX IV expression in either cell type, indicating that ROS levels do not directly affect COX IV expression in our experimental model.

COX IV activity may still be sufficient in 123.7 cells, despite the lower oxygen levels, to allow the flow of electrons through the mitochondrial complexes. Additionally, in the absence of PKA activity, downregulation of COX IV activity by PKA phosphorylation may not occur. This could allow 123.7 cells to maintain mitochondrial energy production even under drastically reduced oxygen conditions, and increase their ability to maintain electron flow through the mitochondrial transport chain without electron leakage and ROS production. 
Maintenance of low levels of COX IV activity under hypoxic conditions has been observed in hypoxia-tolerant model systems (66).

HIF-1 $\alpha$, whose stabilization is influenced by PKA-dependent transcription factors, contributes to the shift from aerobic to anaerobic metabolism under hypoxic states. Additionally, hypoxia-induced ROS production has been shown to be necessary for stabilization of HIF-1 $\alpha$ (67). In the PKA activity deficient 123.7 cell line, HIF-1 signaling may be depressed, leading to disruption of this metabolic shift. This could explain the ability of 123.7 cells to maintain a low level of aerobic metabolism under hypoxic conditions.

In normally functioning cells, as COX IV expression and/or activity decreases under hypoxic conditions, cells must progressively rely on anaerobic metabolism for energy production. Glucose is quickly used within the cell to produce ATP via enhanced glycolytic activity. I have shown here that glucose levels in the media do significantly drop upon hypoxic exposure in both cell types. However, this decrease was much larger in the WT cells, which had negligible levels of extracellular glucose following $24 \mathrm{~h}$ of hypoxic exposure. The 123.7 cells had higher levels of extracellular glucose at both $\mathrm{RA}$ and $\mathrm{SH}$, indicating a lower glycolytic flux. This further indicates that PKA activity facilitates the hypoxiainduced metabolic shift from aerobic to anaerobic metabolism. The 123.7 cells appear to continue aerobic metabolism for a longer period of time than WT cells under hypoxic stress, allowing for more efficient ATP production, and potentially protecting them from hypoxia-induced cell death. 
WT and 123.7 cells had a drop in extracellular $\mathrm{pH}$ following hypoxic exposure, which is likely due to the efflux of lactate from the cell and/or the release of acidic cellular contents. Intracellular acidification may upregulate activity of the $\mathrm{Na}^{+} / \mathrm{H}^{+}$exchanger, but this process is likely limited by the accumulation of extracellular lactate surrounding the membrane (58). It has been shown in sheep purkinje fibers that inhibition of the $\mathrm{Na}^{+} / \mathrm{H}^{+}$exchanger had no significant effect on extracellular acidification following hypoxic exposure (58). Hypoxia-induced decreases in $\mathrm{pH}$ were not affected by $\mathrm{N}$-acetyl cysteine treatment, despite the fact that antioxidant treatment rescues WT cells. This suggests that hypoxia-induced decreases in extracellular $\mathrm{pH}$ may be primarily due to the release of lactate rather than from the release of acidic content from dying cells.

Indeed, extracellular lactate levels did increase in both WT and 123.7 cells after hypoxic exposure. WT cells, however, exhibited higher levels of lactate release under both normoxic and hypoxic conditions, in accordance with their increased glucose utilization, indicating that PKA activity enhances the production and/or release of lactate from cells. Additionally, WT cells exhibited higher extracellular pyruvate levels under normoxic conditions, but were unaffected by hypoxic exposure. The 123.7 cells displayed an increase in extracellular pyruvate upon hypoxic challenge. PKA has been shown to be necessary for the stabilization of lactate dehydrogenase mRNA (68). This complete inactivation of PKA activity in 123.7 cells may prevent the efficient conversion of lactate to pyruvate. 
PKA could upregulate glycolytic flux during hypoxia directly through enzymatic control, or indirectly due to the production of oxidant species. However, antioxidant treatment with $\mathrm{N}$-acetyl cysteine had no effect on extracellular glucose values, suggesting that ROS do not contribute to upregulation of glycolytic flux under hypoxic conditions. Furthermore, treatment with $\mathrm{N}$-acetyl cysteine did not affect lactate or pyruvate values, once again indicating that oxidative stress does not alter glycolytic rate. Thus, the effect of PKA on glycolytic flux appears to occur directly through regulation of enzymatic activity, rather than ROS production.

The PKA signaling pathway plays many vital roles in the cell. The majority of knockout mice containing a null mutation in the PKA catalytic $\alpha$ subunit experience early postnatal lethality (69). Those mice that do survive have upregulation of the PKA catalytic $\beta$ subunit (69). Since PKA activity is minimal in the $123.7 \mathrm{PC}-12$ cell line, compensations may have occurred in order for them to remain viable. For Specific Aim 4, I wanted to determine whether restoration of PKA activity in the 123.7 cells would abrogate differences in hypoxic susceptibility and energy homeostasis between WT and 123.7 cells. The 123.7 cells were transfected with plasmids encoding active PKA catalytic $\alpha$ subunits to restore PKA activity in these cells. Over-expression of PKA cat $\alpha$ was verified by Western blotting and PKA activity assays.

Transfection of 123.7 cells with an active catalytic $\alpha$ subunit of PKA increased ROS levels upon hypoxic exposure, albeit to a level less than that seen in WT cells. This finding confirms that PKA activity is necessary for the 
onset of oxidative stress under hypoxic conditions in our experimental model. However, the oxidative stress in transfected 123.7 cells did not appear to be significant enough to cause hypoxic cell death. This finding indicates that oxidative stress may lead to cell death in a dose-dependent manner, and that PKA transfection in 123.7 cells did not reach a threshold of oxidative stress necessary for induction of death.

Furthermore, transfection of 123.7 cells with an active catalytic subunit of PKA did not appear to affect metabolic variables such as extracellular $\mathrm{pH}$, glucose, lactate, or pyruvate levels. Similarly, intracellular ATP levels were not significantly altered relative to empty vector controls. This indicates that transient transfection of PKA cat $\alpha$ into 123.7 cells may not be sufficient to induce upregulation and maintenance of the high metabolic rate seen in WT cells. Conversely, metabolic adaptations may have occurred in 123.7 cells following prolonged PKA inactivation that may prevent efficient upregulation of metabolic processes following re-activation of the pathway.

In conclusion, the experiments which I have performed support my original hypothesis that PKA activity regulates PC-12 hypoxic cell death via oxidative stress (Figure 45). PKA activity appears to contribute to hypoxia-induced cell death via enhanced production of ROS, but does not appear to play a role in the regulation of cellular antioxidant mechanisms. The role of PKA in hypoxiainduced oxidative stress was confirmed through transfection studies in which restoration of PKA activity in the 123.7 cells increased their production of ROS. 
Hypoxia also leads to a decrease in mitochondrial potential, COXIV expression, and ATP levels, all of which appear to be PKA-activity dependent. On the other hand, PKA activity increases glycolytic flux in PC-12 cells, particularly under periods of hypoxia. PKA thus appears to affect cellular energetic status through regulation of metabolic pathways. However, I was unable to confirm the role of PKA in these processes through the transfection studies. Prolonged PKA activation may be necessary for upregulation of metabolism to the levels seen in WT cells. Alternatively, a more sustained increase in ROS levels may trigger metabolic responses which are induced by $\mathrm{HIF}-1 \alpha$ or NF-KB transcriptional activation (43).

This work dictates a need for further examination into the role of PKA in the hypoxic response, and identification of cellular targets that could be used to disrupt the deleterious effects of PKA under hypoxic states. Modulation of the PKA signaling pathway could thus be used as a novel therapeutic strategy to improve cellular adaptation and recovery in the many pathologies characterized by periods of hypoxia. 


\section{PKA}

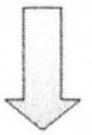

Hypoxia-induced

Signaling Events

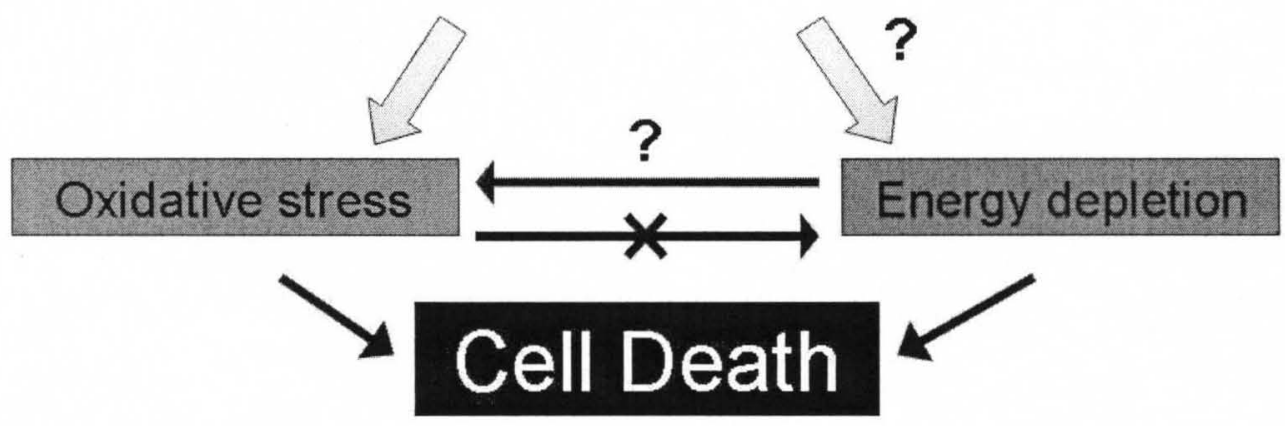

Figure 45: The Role of Protein Kinase A in Hypoxia-Induced PC-12 Cell Death I have confirmed that the PKA signaling pathway contributes to hypoxia-induced PC-12 cell death through the production of reactive oxygen species. It was also shown that oxidative stress contributes to cell death independently of energy depletion in PC-12 cells. I was unable to confirm, however, the role of PKA in hypoxiainduced energy depletion and the contribution of energy failure to cell death. 


\section{REFERENCES}

1. United States Department of Health and Human Services Centers for Disease Control and Prevention. The Burden of Chronic Diseases and their risk factors: National and State Perspectives, 2004.

2. Redline S, Strhol KP. Recognition and consequences of obstructive sleep apnea hypopnea syndrome. Otolarygol. Clin. North Am. 32:303-331, 1998.

3. Banasiak KJ, Haddad GG Hypoxia-induced apoptosis: effect of hypoxic severity and role of p53 in neuronal cell death. Brain Res. 797: 295-304, 1998

4. Gozal $E$, Simakajornboon N, Gozal D. NFKB induction during hypoxia in the dorsocaudal brainstem of the rat: Effect of MK-801 and L-NAME. J. Appl. Physiol. 85:372-376, 1998.

5. Gozal E, Simakajornboon N, Dausman JD, Xue Y-D, Corti M, El-Dahr S, Gozal D. Hypoxia induces selective SAPK/JNK-2-AP-1 pathway activation in the nucleus tractus solitarii of the conscious rat. J. Neurochem. 73: 665$674,1999$.

6. Semenza, GL. HIF-1: mediator of physiological and pathophysiological response to hypoxia. J. Appl. Physiol. 88: 1474-1480, 2000.

7. Laderoute KR, Calaoagan JM, Gustavson-Brown C, Knapp AM, Li GC, Mendonca HL, Ryan HE, Wang Z, Johnson RS. The response of cJun/AP-1 to chronic hypoxia is hypoxia-inducible factor $1 \alpha$ dependent. Mol. Cell. Biol. 22: 2515-2523, 2002.

8. Vijayasarathy C, Damle S, Prabu SK, Otto CM, Avandahi NG. Adaptive changes in the expression of nuclear and mitochondrial encoded subunits of cytochrome coxidase and the catalytic activity during hypoxia. Eur. J. Biochem. 270: 871-879, 2003. 
9. Cutrin JF, Donovan M, Cotter TG. Regulation and measurement of oxidative stress in apoptosis. J. Immunol. Methods. 265 (1-2): 49-72, 2002.

10. Beyer RE. An Analysis of the Role of Coenzyme Q in Free Radical Generation and as an Antioxidant. Biochem. Cell Biol. 70: 392, 1992.

11. Rocha M, Victor VM. Targeting Antioxidants to Mitochondria and Cardiovascular Diseases: The Effect of Mitoquinone. Med Sci Monit 13(7): RA132-145, 2007.

12. Droge W. Free Radicals in the Physiological Control of Cell Function. Physiol Rev 82:47-95, 2002.

13. Duranteau J, Chandel NS, Kiulisz A, Shao Z, Schumaker PT. Intracellular signaling by reactive oxygen species during hypoxia in cardiomyocites. J. Biol. Chem 273: 11619-11624, 1998.

14. Budinger GR, Chandel N, Shao ZH, Li CQ, Melmed A, Becker LB, Schumacker PT. Cellular energy utilization and supply during hypoxia in embryonic cardiac myocytes. A. J. Physiol. 270: L44-L53, 1996.

15. Chandel NS, Budinger SGR, Choe SH, Schumaker PT. Cellular respiration during hypoxia. J. Biol. Chem. 272: 18808-18816, 1997.

16. Scacco S, Vergari R, Scarpulla RC, Technikova-Dobrova Z, Sardanelli A, Lambo R, Lorusso V, Papa S. CAMP-dependent Phosphorylation of the Nuclear Encoded 18-kDA Subunit of Respiratory Complex I and Activation of the Complex in Serum-starved Mouse Fibroblast Cultures. J. Biol. Chem. 275: 17578-17582, 2000.

17. Prabu SK, Anandatheerthavarada HK, Raza H, Srinivasan S, Spear JF, Avadhani NG. Protein Kinase A-mediated Phosphorylation Modulates Cytochrome $\mathrm{c}$ Oxidase Function and Augments Hypoxia and Myocardial Ischemia-related Injury. J. Biol. Chem. 281: 2061-2070, 2006.

18. Yang WL, lacono L, Tang WM, Chin KV. Novel function of the regulatory subunit of Protein Kinase A: Regulation of cytochrome coxidase activity and cytochrome c release. Biochemistry 37: 14175-14180, 1998.

19. Taylor SS, Kim C, Vigil D, Haste NM, Yang J, Wu J, Anand GS. Dynamics of Signaling by PKA. Biochim Biophys Acta. 1754(1-2):25-37, 2005. 
20. Baillie GS, Scott JD, Houslay MD. Compartmentalization of Phosphodiesterases and Protein Kinase A: Opposites Attract. FEBS Lett. 579: 3264-327, 2005.

21. Brunton LL, Hayes JS, Mayer SE. Functional Compartmentalization of cyclic AMP and Protein Kinase in Heart. Adv. Cyclic Nucleotide Res. 14: 391-397, 1981.

22. Seta KA, Spicer Z, Yuan Y, Lu G, Milhorn DE. Responding to Hypoxia: Lessons from a Model Cell Line. Sci STKE. 2002 (146): RE11, 2002.

23. Anand GS, Hotchko M, Brown SHJ, Eyck LI, Komives EA, Taylor SS. Rsubunit Isoform Specificity in Protein in PKA Types I and II by Amide $\mathrm{H} /{ }^{2} \mathrm{H}$ Exchanges Mass Spectrometry. Journal of Molec. Biol. 374(2): 487-499, 2007.

24. Bruan RK, Vulliet PR, Carbonara-Hall DA, Hall FL. Phosphorylation of RII Subunit and Attenutation of cAMP Dependent Protein Kinase Activity by Proline-Directed Protein Kinase. Arch. Biochem. Biophys. 289(1): 187191, 1991.

25. Feliciello A, Gottesman ME, Avvedimento EV. cAMP-PKA signaling to the mitochondria: Protein Scaffolds, mRNA and phosphatases. Cell Signaling 17: 279-287, 2005.

26. Tasken K, Aandahl EM. Localized Effects of cAMP Mediated by Distinct Routes of Protein Kinase A. Physiol. Rev. 84: 123-167, 2004.

27. Dalton G, Dewey W. Protein Kinase Inhibitor Peptide (PKI): A Family of Endogenous Neuropeptides that Modulate Neuronal cAMP-dependent Protein Kinase Function. Neuropeptides 40 (1): 23-34, 2006.

28. Saito A, Hayashi T, Okuno S, Ferrand-Dranke M, Chan PH. Overexpression of copper/zinc superoxide dismutase in transgenic mice protects against neuronal cell death after transient focal ischemia by blocking activation of the bad cell death signaling pathway. J. Neurosci. 23: 1710-1718, 2003.

29. Zhang L, Insel PA. The pro-apototic protein Bim is a convergence point for cAMP/protein kinase A and glucocorticoid-promoted apoptosis of lymphoid cells. J. Biol. Chem. 279: 20858-20865, 2004.

30. Hanamoto T, Ozaki T, Furuya K, Hosoda M, Hayashi S, Nakanishi M, Yamamoto H, Kikuchi H, Toto S, Nakagawara A. Identification of Protein Kinase A catalytic subunit beta as a novel binding partner of p53 and regulation of p73 function. J. Biol. Chem. 280: 16665-16675, 2005. 
31. Tanaka K. Alteration of Second Messengers during Acute Cerebral Ischemia -Adenylate Cyclase, cAMP Dependent Protein Kinase, and cAMP Response Element Binding Protein. Progress in Neurobiology 65: 173-207, 2001.

32. Berridge MJ. Neuronal Calcium Signaling. Neuron. 21:13-26, 1998.

33. Supattapone S, Danoff SK, Theibert A, Joseph SK, Steiner J, Snyder SH. cAMP-Dependent Phosphorylation of a Brain Inositol Triphosphate Receptor Decreases Its Release of Calcium. Proc. Natl. Acad. Sci. USA. 85: 8747-8750, 1988.

34. Dinerman JL, Steiner JP, Dawson TM, Dawson V, Snyder SH. Cyclic Nucleotide Dependent Phosphorylation of Neuronal Nitric Oxide Synthase Inhibits Catalytic Activity. Neuropharmacology 33: 1245-1251, 1994.

35. Rosa JL, Perez JX, Ventura F, Tauler A, Gil J, Shimoyama M, Pilkis SJ, Bartrons R. Role of the N-terminal region in covalent modification of 6phosphofructo-2-kinase/ fructose-2,6-biphosphatase: comparison of phosphorylation and ADP-ribosylation. Biochem. J. 309: 119-125, 1995.

36. Rider MH, Bertrand L, Vertommen D, Michels PA, Rousseau GG, Hue L. 6-phosphofructo-2-kinase/ fructose-2,6-biphosphatase: head-to-head with a bifunctional enzyme that controls glycolysis. Biochem. J. 381: 561-579, 2004.

37. Semenza GL, Agani F, Booth G, Forsythe J, lyer N, Jiang BH, Wiener C, $\mathrm{Yu}$ A. Structural and functional analysis of hypoxia-inducible factor 1. Kidney Int. 51: 553-555, 1997.

38. Kvietikova I, Wenger RH, Marti HH, Gassmann M. The hypoxia-inducible factor-1 DNA recognition site is cAMP-responsive. Kidney Int. 51:564-6, 1997.

39. Zagorska A, Dulak J. HIF-1: the knowns and unknowns of hypoxia sensing. Acta Biochim Pol. 51(3):563-85, 2004.

40. Bruick RK. Expression of the gene encoding the proapoptotic Nip3 protein is induced by hypoxia. Proc. Natl. Acad. Sci. USA 97: 4734-4744, 2000.

41. Piret JP, Mottet $D$, Raes M, Michiels $C$. Is HIF-1 $\alpha$ a pro- or an antiapoptotic protein? Biochem Pharmacol. 64:889-892, 2002.

42. Schmid T, Zhou J, Brune B. HIF-1 and p53 communication of transcription factors under hypoxia. J. Cell. Mol. Med. 8: 423-431, 2004. 
43. Chandel NS, Maltepe E, Goldwasser E, Mathieu CE, Simon MC, Schumacker PT. Mitochondrial reactive oxygen species trigger hypoxiainduced transcription. Proc Natl/ Acad. Sci. USA. 95:11715-11720, 1998.

44. Greene LA and Tischler AS. Establishment of a noradrenergic clonal line of rat adrenal pheochromocytoma cells which respond to nerve growth factor. Proc. Natl. Acad. Sci. USA 73:2424-2428, 1976.

45. Greene LA and Tischler AS. PC-12 pheochromocytoma cultures in neurobiological research. Adv. Cell. Neurobiol. 3:373-414, 1982.

46. Seta K, Kim HW, Ferguson T, Kim R, Pathrose P, Yuan Y, Lu G, Spicer Z, Millhorn DR. Genomic and physiological analysis of oxygen sensitivity and hypoxia tolerance in PC12 cells. Ann N Y Acad Sci. 971:379-88, 2002.

47. Ginty DD, Glowacka D, DeFranco C, Wagner JA. Nerve growth factorinduced neuronal differentiation after dominant repression of both type I and type II cAMP-dependent protein kinase activities. J. Biol. Chem. 266:15325-15333, 1991.

48. Gozal E, Sachleben LR Jr, Rane MJ, Vega C, Gozal D. Mild Sustained and Intermittent Hypoxia Induce Apoptosis in PC-12 Cells via Different Mechanisms. Am. J. Physiol. Cell Physiol. 288:C535-C542, 2005.

49.Zhang S, Gozal D, Sachleben, Jr. L, Rane MJ, Klein J, Gozal E. Hypoxia induces an autocrine-paracrine survival pathway via platelet-derived growth factor (PDGF)-B/PDGF- $\beta$ receptor/phosphatidylinositol 3kinase/Akt signaling in RN46A neuronal cells. The FASEB Journal. Vol. 17, September 2003, pp. 1709-1711.

50. Mosmann T. Rapid colorimetric assay for cellular growth and survival. J. Immunol. Methods 65:55-63, 1983.

51. Rane M J,. Coxon PY, Powell DW, Webster R, Klein JB, Ping P, Pierce WM, McLeish KR. p38 kinase-dependent MAPK-2 activation functions as PDK2 for Akt in human neutrophils. J.Biol.Chem. 276(5): 3517-23, 2001.

52. Rane MJ, Pan Y, Singh S, Powell DW, Wu R, Cummins T, Chen Q, McLeish KR, Klein JB. Heat shock protein 27 controls apoptosis by regulating Akt activation. J. Biol Chem. 278:27828-27835. 2003.

53. MD Uhler, DF Carmichael, DC Lee, JC Chrivia, EG Krebs, GS McKnight. Isolation of cDNA clones coding for the catalytic subunit of mouse CAMPdependent protein kinase. Proc. Natl. Acad. Sci. USA. 83(5): 1300-1304, 1986. 
54. Hambleton J, Weinstein SL, Lem L, DeFranco AL. Activation of c-Jun Nterminal Kinase in Bacterial Lipopolysaccharide-stimulated macrophages. Proc. Natl. Acad. Sci. USA 93(7): 2774-2778, 1996.

55. Bruick RK. Expression of the gene encoding the proapoptotic Nip3 protein is induced by hypoxia. Proc. Natl. Acad. Sci. USA 97: 4734-4744, 2000.

56. Piret JP, Mottet D, Raes M, Michiels C. Is HIF-1 $\alpha$ a pro- or an antiapoptotic protein? Biochem Pharmacol. 64:889-892, 2002.

57. Schmid T, Zhou J, Brune B. HIF-1 and p53 communication of transcription factors under hypoxia. J. Cell. Mol. Med. 8: 423-431, 2004.

58. Bright CM, Ellis D. Intracellular pH Changes Induced by Hypoxia and Anoxia in Isolated Sheep Heart Purkinje Fibers. Exp. Physiology 77(1): 165-175, 1992.

59. Nagasaka S, Katoh H, Niu CF, Matsui S, Urushida T, Satoh H, Watanabe Y, Hayashi H. Protein Kinase A Catalytic Subunit Alters Cardiac Mitochondrial Redox State and Membrane Potential Via the Formation of Reactive Oxygen Species. Circ. J. 71: 429-436, 2007.

60. Storey KB. Metabolic Adaptations Supporting Anoxia Tolerance in Reptiles: Recent Advances. Comp. Biochem. Physiol. B. Biochem. Mole. Biol. 113 (1): 23-35, 1996.

61. Storey KB. Anoxia Tolerance in Turtles: Metabolic Regulation and Gene Expression. Comp. Biochem. Physiol. A. Molec. Integr. Physiol. 147 (2): 263-276, 2007.

62. DeVries N, DeFlora S. N-Acetyl-1-Cysteine. J. Cell Biochem. 17F: S270S277, 1993.

63. Issels RD, Nagele A, Eckert KG, Wilmanns W. Promotion of cystine uptake and its utilization for glutathione biosynthesis induced by cysteamine and $\mathrm{N}$-acetylcysteine. Biochem. Pharmacol. 37: 881-888, 1988.

64. Aruoma OI, Halliwell B, Hoey BM, Butler J. The antioxidant action of Nacetyl cysteine: its reaction with hydrogen peroxide, hydroxyl radical, superoxide, and hypochlorous acid. Free Radic. Biol. Med. 6: 593-597, 1989. 
65. Satpute RM, Hariharakrishnan J, Bhattacharya R. Alpha-ketoglutatarate and $\mathrm{N}$-acetyl Cysteine protect $\mathrm{PC}-12$ cells from cyanide-induced cytotoxicity and altered energy metabolism. Neurotoxicology 29 (1): 170$178,2008$.

66. Semenza GL. Oxygen-dependent Regulation of Mitochondrial Respiration by Hypoxia-inducible factor 1. Biochem. J. 405: 1-9, 2007.

67. Chandel NS, McClintock DS, Feliciano CE, Wood TM, Melendez JA, Rodriguez AM, Schumacker PT. Reactive Oxygen Species Generated at Mitochondrial Complex III Stabilize Hypoxia-Inducible Factor-1 alpha During Hypoxia: A Mechanism of O2 Sensing. J. Biol. Chem. 275 (33): 25130-25138, 2000.

68. Hong SS, Gibney GT, Esquilin M, Yu J, Xia X. Effect of Protein Kinases and Lactate Dehydrogenase Activity in Cortical Neurons during Hypoxia. Brain Research 1009: 195-202, 2005.

69. Skalhegg BS, Huang Y, Su T, Idzerda RL, McKnight GS, Burton KA. Mutation of the Ca subunit of PKA Leads to Growth Retardation and Sperm Dysfunction. Molecular Endocrinology 16 (3): 630-639, 2002. 


\title{
CURRICULUM VITAE
}

\author{
Cynthia Jayne Miller \\ 1901-A Manor House Dr. \\ Louisville, Ky. 40220 \\ Cell phone: (502) 762-8929 \\ cjmill04@gwise.louisville.edu
}

\section{Education:}

- 2006-Present University of Louisville Louisville, KY Integrated Programs in Biomedical Sciences Graduation Date:

Ph.D. in Physiology \& Biophysics July 2008

- 2004-2006 University of Louisville Louisville, KY Integrated Programs in Biomedical Sciences M.S. in Physiology \& Biophysics

- 2000-2004 Lindsey Wilson College Columbia, KY B.A. Biology, Minor in Chemistry

\section{Current Positions:}

- Ph.D. student mentored by Evelyne Gozal, Ph.D. Associate Professor, Department of Pediatrics, University of Louisville

\section{Work Experience:}

- 2008

- 2008

- 2007

- $2002-2004$
Physiology Instructor, 2008 Pre-matriculation Program School of Medicine, University of Louisville:

A course for entering medical students from under-represented or disadvantaged communities Group Tutor, Medical Physiology PHZB 801, School of Medicine, University of Louisville

Individual Tutor, Systemic Physiology PHZB 805, School of Dentistry, University of Louisville

Laboratory and Teacher Assistant for Biology Program, Lindsey Wilson College. Prepared solutions, organized laboratory exercises, maintained laboratory, assisted with classroom instruction, graded homework and tests, and proctored exams

Education Training:

- 2006-2007 Selected for the Future Faculty Program-University of Louisville 
Developed class syllabi, formulated laboratory exercises, and observed and assisted courses in the Department of Biology ELFH 683 College Teaching-University of Louisville

Awards \& Honors:

- 2006-Present

- 2004-2005

- 2004

- 2004

- 2000-2004

- 2000-2004

- 2000-2004
Society for Neuroscience Member

Integrated Programs in Biomedical Sciences Fellowship

Annual stipend and full waiver of tuition and fees

University of Louisville

B.A. Summa Cum Laude honors

Lindsey Wilson College

Senior Biology Award-Graduating Class of 2004

Lindsey Wilson College

Begley Scholarship

Full scholarship, tuition, and board for outstanding academic achievement

Lindsey Wilson College

President's List

Awarded to students who maintain a 4.0 GPA

Lindsey Wilson College

Student League of Sciences: President 2004, Secretary 2001-2003

Lindsey Wilson College

\section{Relevant Coursework:}

\section{Lindsey Wilson College}

All courses completed with an A or A+ score for a cumulative GPA of 4.0

General Biology with Laboratory

Anatomy \& Phys I and II with Laboratory

Medical Terminology

Genetics with Laboratory

Cell Biology with Laboratory

Zoology with Laboratory

Botany with Laboratory

Economic Botany with Laboratory
Biology Seminar I and II

General Chemistry I and II with Laboratory

Organic Chemistry I and II with Laboratory

Biochemistry with Laboratory

Introduction to Physical Science with

Laboratory

College Physics I and II with Laboratory

\section{University of Louisville}

All courses completed with an $A$ or $A+$ score for a cumulative GPA of 4.0

Systemic Physiology I and II

Advanced Human Physiology

Integrated Systemic Physiology

Advanced Biochemistry I and II

Experimental Physiology Lab
Cell Biology

Physiology Seminar

Selected Topics in Phys. (Statistics)

College Teaching 


\section{Peer-reviewed Presentations}

- 2007 Society for Neuroscience annual meeting-selected for individual poster presentation-"PKA Regulates ROS Production And Cellular Energy Metabolism In Hypoxic PC-12 Cells"

San Diego, CA

- 2007 Research Louisville-selected for poster presentation

"The Role of Protein Kinase A in Hypoxia-induced Oxidative Stress, Cellular Energy Depletion, and PC-12 Cell Death"

Louisville, KY

- 2006 Society for Neuroscience annual meeting-selected for individual oral presentation-"PKA Regulation of Hypoxia-Induced ROS Production and PC-12 Cell Death"

Atlanta, GA

- 2006 Research Louisville-selected for poster presentation

"Role of PKA in Hypoxia-Induced Reactive Oxygen Species Production and PC-12 Cell Death"

Louisville, KY

\section{Presentations}

- 2008 Oral Presentation-"The Role of Protein Kinase A in Hypoxia-induced PC-12 Cell Death"

- 2007 Oral Presentation-"The Role of Protein Kinase A in Hypoxia-induced Oxidative Stress, Cellular Energy Depletion, and PC-12 Cell Death" University of Louisville, Department of Physiology \& Biophysics

- 2007 Invited Lecturer-PHZB 617 Physiology Seminar

- 2006 Oral Presentation-"Role of Protein Kinase A in Hypoxia-Induced Reactive Oxygen Species Production and PC-12 Cell Death"

University of Louisville, Department of Physiology \& Biophysics

\section{Publications}

- In progress

PKA Regulates ROS Production and Cellular Energy Metabolism in Hypoxic PC-12 Cells

C.J. Miller ${ }^{1,2} *$, L.R. Sachleben ${ }^{2}$, Jr., M.J. Rane ${ }^{3}$, M. Dematteis ${ }^{6}$, A. Schurr ${ }^{4}$, E. Gozal ${ }^{5}$

Departments of Physiology \& Biophysics ${ }^{1}$, Pediatrics KCHRI ${ }^{2}$, Medicine/Nephrology ${ }^{3}$, Anesthesiology \& Perioperative Medicine ${ }^{4}$, Pharmacology \& Toxicology 5 , University of Louisville, School of Medicine, Louisville, KY, USA; HP2 Laboratory ${ }^{6}$, INSERM-UJF, Grenoble, France.

- Submitted

Aerobic Lactate Utilization Provides Neuroprotection Against Glutamatemediated, ROS-induced Damage in vitro.

Ralphiel S. Payne ${ }^{a}$, Cynthia J Miller ${ }^{b}$, Evelyne Gozal ${ }^{b, c}$ and Avital Schurr ${ }^{a}$, Departments of Anesthesiology \& Perioperative Medicine ${ }^{\mathrm{a}}$, Pharmacology \& 
Toxicology $^{\mathrm{b}}$ and Pediatrics ${ }^{\mathrm{c}}$, University of Louisville, School of Medicine, Louisville, KY 40202

Service:

- 2007-Present

- 2008

- 2007-2008
Graduate Student Representative

Student Academic Grievance Committee University of Louisville Judge, DuPont Manual High School Regional Science Fair: Math, Science, and Technology Magnet Program Louisville, Ky.

Judge, Our Lady of Perpetual Help Middle School Science Fair New Albany, In. 